\title{
Report of the Committee on Tabulating the Results of Steam-Engine and Boiler Trials, ${ }^{1}$ 1913.
}

\section{Members of the Committee :}

*Captain H. Riall Sankey, R.E. (rot.), Chairman.

*H. R. J. Bunstal.L.

Professor H. L. Callendar, F.R.S.

C. J. B. CoоKe.

F. S. Courtiney.

Engineer-Commander L. IR. Croisdale, R.N.

Professor W. E. Dalbi, M.A., F.R.S.

G. N. Huntly.

* Sir Alex. B. W. Kenneds, I.L.D., F.R.S.

* Michael Longitide, M.A.
* Sir Gullford L. Molesworth, K.C.I.E.

*A. F. Seaton.

Dr. 'T. E. Stanton.

C. E. Stromeyer.

*A. B. WILSON (the late).

Engineer-Commander W. M. Wisnou, R.N.

J. M. Woon.

Professor T. Hunson Beane, B.Se, F.R.S.E., Honorary Secretary.

C. H. Wingfield, Secretary.

To the Council of The Institution of Civil Engineers.

Gentlenen,

Your Committee have pleasure in submitting their Report embodying the results of the work done since their reappointment at the end of 1909 . This work consisted mainly in revising and

1 The Committee was originally appointed by the Council on the 29th June, 1897 , the members of the Committee being those marked above with an asterisk and the following: the late Sir William Anderson, K.C.B., Vice-President Inst. C.E., the late Sir Frederick J. Bramwell, Bart, Past-President Inst. C.E., the late Mr. Bryan Donkin, M. Inst. C.E., and Mr. C. J. Wilson.

The original Committee made an Interim Report on the 25th April, 1301 (Minutes of I'roceedings Inst. C.E., vol. cl, p. 221), and a Final lieport on the 14 th April, 1902 (ibid, vol. cl, p. 21s), the latter being accompanicd by draft forms suitable for use in connection with Steam-Engine and Boiler Trials and by Appendixes explanatory of the methods of conducting and recording such trials.

'The Committee was reappointed by the Council on the 19th October, 1909, to revise the Report of 1902 .

'The Report and sets of forms of foolscap size can be obtained from the Institution printers, Messrs. Wm. Clowes \& Sons, Ltd., 31 Haymarket, S.W. 
adding to the previous Report of your Committee on the same subject.

The principal jtems thus treated were:-

(1) The starting and conducting of boiler trials.

(2) The method of measuring the rate of boiler feed.

(3) The method of measuring the consumption of fuel, of taking samples, and of determining the calorific value.

(4) Sampling and analysing flue-gases, and determining the losses due to imperfect combustion, leakage, radiation, etc.

(5) The Furms for tabulating the results of trials.

As regards the last item, the original Forms intended for scientific purposes, in which it is necessary to measure losses, have been retained as far as boilers and reciprocating engines are concerned, but abridged Forms have also been drawn up for more general use, as described in note ( 1 ) on p. 285. These Forms are preceded by a general statement of the lines on which such tosts should be conducted, and they are accompanied by two Appendixes.

Appendix I describes the methods of carrying out the various ohservations, and the necessary appliances.

Appendix II explains the manner in which the Forms should be filled in, and the methods of working out the results of trials.

Yours faithfully,

II. Riali, Sankey, Chairmen.

C. H. Wincifieln, Secretary.

April, 1913. 


\section{INTRODUCTION.}

WhEs the ohject of a boiler or engine trial is to oblain data for scientific purposes the losses should always be measured, because they afford a valuable check on the accuracy of a trial. Such measurements consist in taking the temperature of the flue gases and analysing them, weighing the ash, measuring the loss of heat by radiation, etc. Though desirable, they are not essential in a large majority of trials, when those observations only are recorded which are necessary to ascertain whether the guarantee of performance given by the maker has been fulfilled. For such trials a shortened tabular statement has been provided under the headiug "Commercial Trials." 1

The makers of boilers and steam-engines often require to make experiments to elucidate some particular point; the methods of carrying out such trials must obviously be addressed specially to the point in question, and no attempt, therefore, has been made to deal with such matters in the following report.

Whether for scientific or commercial purposes, the principal measurements are those pertaining to the weighing of the fuel and the determination of its quality; to the weighing of the water evaporated, and to the measurement of the power produced. The data thus obtained suffice to determine the thermal efficiency of a boiler, or the British thermal units per indicated horse-power required by a steam-engine, or the more popular, but less accurate, measures of officiency-the pounds of water evaporated per pound of coal, or the pounds of steam (strictly the "equivalent feed" ${ }^{2}$ ) used by the engine per indicated horse-power per hour.

The various measurements required for a trial divide themselves, therefore, into two groups, which can be tabulated as follows:-

I. Measurements to Determinfe the Thermal Efficiency of a BoIler.

Relating to Water evaporated.

(1) Rate of water-evaporation.

(2) Measurement of steam-pressure.

(3) Determination of the "dryness fraction," i.e., the weight of dry steam per pound of moist steam.

1 See note $\left({ }^{1}\right)$ on p. 285.

2 See line 131 of Tables and explanation of this line on p. 362 . 
(4) If there is a superheater, the temperature of the steam issuing from it.

(5) Measurement of the feed temperature.

Relating to Fuel.

(6) Rate of fuel-consumption.

(7) Sampling of fuel and determination of its calorific value as fired.

Required to determine Losses.

(8) Measurement of temperatures of the atmosphere and of the flue gases.

(9) Collection and analysis of the flue gases.

(10) Sampling and weighing of the ashes from ash-pit.

(11) Chemical analysis of ashes, or determination of their calorific value.

(12) Ascertaining the weight of sparks and cinders passing into the smoke-box.

(13) Determination of the calorific value of cinders and sparks.

(14) Measurement of air-pressure.

(15) Radiation and leakage.

II. Measurements to Determine the Thermal Efficiency of

Relating to Steam.

a Steam-Engine.

(16) Measurement of rate of steam-supply by weight.

(17) Determination of the dryness fraction (dry steam per pound of moist steam) at the boiler side of the engine stop-valve, or

(17a) Temperature of the steam if superheated.

(18) Pressure of steam at the boiler side of the engrine stopvalve.

(19) Temperature (or pressure) of the exhaust steam, and the air-percentage, if any, contained therein.

Relating to Power.

(20) Measurement of the indicated horse-power.

(21) If possible, measurement of the brake or shaft horsepower.

A varioty of measurements are also required in connection with the accessories of a steam plant ; they are, however, similar to those tabulated above, and references will be found in the tabular forms to the methods of carrying them out explained in Appendix I. 


\section{TESTING STEAM-GENERATORS.}

Preparation for a Complete Bolletr Trial.

Before a trial is undertaken its object should be clearly defined and a programme settled. The chief observer or one of his assistants should visit the installation to be tested, in order to ascertain and explain what preparations the local conditions will require. A list of the necessary apparatus is given in Appendix I (pp. 297 to 299 ). On the occasion of this visit the positions for the following fittings should be selected, and orders given for holes to be drilled and tapped where necessary for their reception :-

Mercury cups to hold thermometers (to be screwed into the inlet and outlet of both the economizer and superheater). If it is desired to ascertain whether cold water is lodging in the bottom of Lancashire or other boilers of similar type, a horizontal tube should be screwed into the front part of the boiler, or preferably the front manhole door. 'The stopped end of the tube should be carried sufficiently far back to avoid the possible lodgment of cool water at the front end, which may arise from the bottom flue not extending right up to the front of the boiler.

A connection for a calorimeter for ascertaining the drynessfraction (to be screwed into the steam-pipe).

Holes should be drilled into the flue leaving the boiler, and into the flue leaving the economizer for the insertion of pyrometers and gas-collecting pipes; (it is desirable also to drill owe into the flue just before it reaches the superheater, if fitted). Other holes will be required for draught-gauge connections.

N.B.-Fire-clay must be provided for luting these holes in order to prevent leakage.

Instructions should be given to fit steam connections to the feed-pump, and water connections to and from feed-pump, feedtank, and measuring tank, and for all unnecessary pipe branches in either steam or water service to be blanked-flanged, or (if closed by valves) to have the joints broken so as to enable any leakage during the trial to be seen and measured.

It is particularly desirable that arrangements should be made for supplying the steam used by auxiliary apparatus, such as a steam 
blast, fans, pumps, etc., from a separate boiler entirely disconnected from that under trial, ${ }^{1}$ separate feed-measuring apparatus being provided if it is desired to ascertain the quantity of steam thus used. If such auxiliary boiler cannot be blanked off during the test, the pressure in it should, if possible, be maintained the same as that in the boilers under trial, in order to minimize leakage through the stop-valve.

\section{Precautionary Melsures.}

As short a time as possible before the day of the official trial the boilers should be thoroughly examined and scaled, the flues cleaned ont, any faulty brickwork carefully made good, and the shell-plates scraped and brushed; unless the object of the trial is to ascertain the evaporation of the boiler in its ordinary condition. On this occasion a search should be made for any possible underwater leakages, and when discovered they should be put right (pp. 312 and 330 ).

The valves and fittings of the boiler should be thoroughly overhauled. Special attention should be paid to the blow-off cock and to the economizer safety-valve, because water-leakages may occur here which entail a much greater loss than steam-leakages.

'The feed-pump glands should be re-packed if necessary, and a pipe should be arranged to return any leakage from them or from the escape-valve to the feed-tank.

\section{Conditions for and Duration of the Trial.}

As it is not possible to carry out a satisfactory trial unless steady conditions of working can be maintained for a long period, a trial shonld not be begun until a steady condition of temperature is established. The time required to do this will vary with the type of boiler; being longer in the case of boilers set in brickwork than with those which are lagrged and have little or no brickwork. In the former case as much as 2 days may be necessary in order to attain this condition; in the latter hour to 1 hour may be sufficient. (See p. 315.)

In order that the rate of firing ${ }^{2}$ and feeding may be steady

1 P. 383.

2 The accuracy of the results of the methods of coal and water measurement recommended in this Report depends on the constancy of the angle of inclination of the water and coal curves, especially the latter. If the coal line (Figs. 10, $11,12)$ varies greatly in inclination, the coal and water rates can be calculated at any time from its tangent, but a trial giving such a result is not so satisfuctory as it should be. 
throughout a trial, definite quantities of fuel should be weighed out periodically, and placed in front of each furnace, and at fixed intervals the stokehold observer should give the word for throwing this coal on the fires. The dampers may have to be altered, but the average combustion would be maintained. If the steam demand fluctuates, the exact times of firing the periodically weighed-out fuel should be noted.

The approximate duration of the trial should be fixed before commencing it, and should be a multiple of the period elapsing between the times of cleaning the fires ${ }^{1}$ it should never be less than 3 hours, and should be as long as possible in order to eliminate error in the measurement of the thickness of the fuel.

In most cases the principal observer will be able to measure the thickness of fuel to within 1 inch. As the error may be in opposite senses at the beginning and ending of a trial, it may amount to the weight of a layer of fuel 2 inches thick. If $\mathrm{C}$ is the weight of green coal, which will form 1 cubic foot of incandescent fuel, the total error should not exceed $\mathrm{C} \times \mathrm{A} \times \frac{2}{12}=\frac{\mathrm{CA}}{6} \mathrm{lbs}$. Therefore if $\mathrm{W}$ is the number of lbs. of fuel per hour, A the square feet of grate covered by fuel when its thickness is measured, and $n$ the percentage of error admissible, the trial must last $\frac{100 \mathrm{CA}}{6 n \mathrm{~W}}$ hours. $\mathrm{C}$ may be taken as $20 \mathrm{lbs}$. for large coal and $30 \mathrm{lbs}$. for small slack. In making use of this formula, however, it is necessary to have some regard to the quality as well as the size of the fuel. When it contains much dirt or makes a pasty clinker, the bars, if not self-cleaning, have to be cleaned at short intervals by the firemen, and at each cleaning there is loss of heat and combustible matter. 'The duration of the trial and the times of cleaning should therefore be so arranged as to give this loss the same average value that it would have if the trial were indefinitely prolonged. For instance, if the fuel were such as to make cleaning necessary every 4 hours, it would be unfair to make a 5 -hours' trial; 8 hours would be the proper time; or, if it were not possible to have the trial longer than 5 hours, a more accurate result would be obtained by working for 4 hours only and cleaning the fire-grates only once.

In connection with the duration of boiler trials, it should be remembered that if one boiler burns more coal per square foot

1 See Sect. 26, p. $22 \pm$ (Appcndix 1), as to average length of this period. 
of grate area than another per unit of time the trial may be of proportionally shorter duration without increase of error. The only object of prolonging the trial is to reduce the importance of an error in judgment as to the condition of the fire at the beginning and at the end of the test. This error may be taken to represent a constant weight of, say, $w$ lbs. of coal on a grate of given area for a trial of any length.

When burning IV lbs. of coal per hour the coal burnt in $\mathrm{N}$ hours will be $\mathrm{N} \times \mathrm{W}$, and the fractional error will be $\frac{w}{\mathrm{~W}} \times \frac{1}{\mathrm{~N}}$. The second term of this fraction is the only one usually considered, hence long trials, which are necessary with slow rates

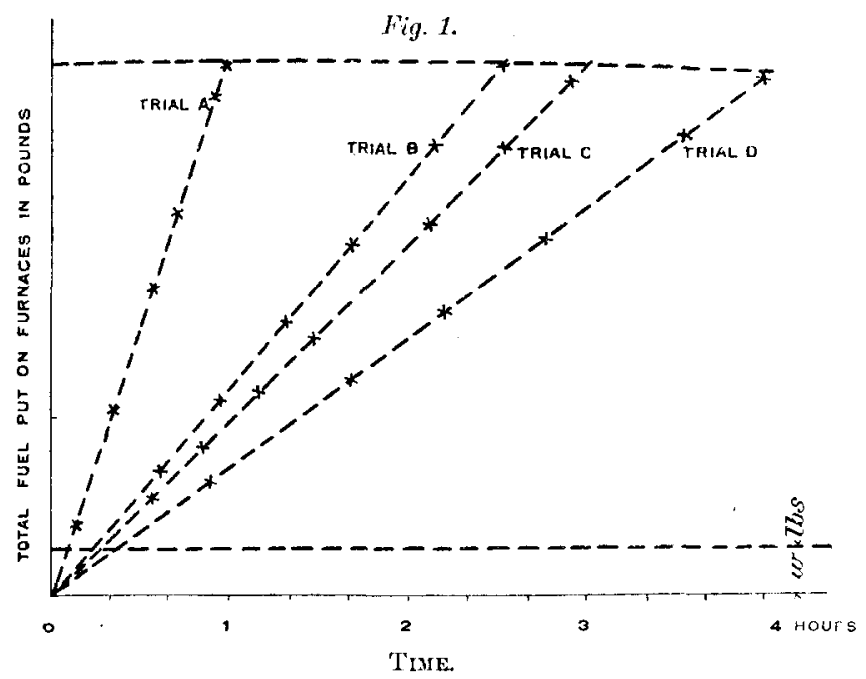

of combustion, are sometimes specified withont reason in the case of trials under forced draught.

If $\mathrm{W}$ is greatly increased the percentage error is not increased by reducing the duration of the trial. This is shown graphically in Fig. 1. In each of the four trials shown on this diagram at different rates of combustion the same weight of coal is burnt. Since in 1 hour in the one trial as much coal is burnt as in 4 hours in another, the percentage error is only the same in both cases, although the duration of the trial in the one case is 1 hour and in that of the other 4 bours.

See also p. 282 as to the influence of gange-glass errors on the duration of a boiler trial. 


\section{Maintenance of Water-Level.}

The water-level in the boiler should be kept as nearly as possible constant throughout the trial, either by adjusting the feed-valve and maintaining a constant rate of coal-consumption, or by keeping the rate of water-consumption constant and regulating the rate at which the coal is burnt.

The first method is used when the object of the trial is to ascertain the evaporation per pound of fuel at different rates of combustion; the second when it is desired to find out whether the boiler will evaporate a certain rate of water per hour; either method may be used if the object is to ascertain whether the boiler will evaporate a certain weight of water per hour with a given weight of fuel.

\section{Observers.}

Observers should call at the works on the evening before the official trial in order to receive instructions as to their stations, and to see that everything is in order. If convenient it will be advantageous to run a short preliminary trial on this occasion.

On the day of the official trial the observers should be at their respective posts at least $\frac{1}{2}$ hour before the trial starts, and they should at once carefully notice the position of the dampers, the heights of the water-levels and the steam- and air-pressures, so that, when the time arrives for the official start, they will be in a position to form some estimate as to whether the rate of firing and foeding is that which it is intended to maintain.

As the accuracy of the results of a boiler trial depends not only upon that of the observations made during its progress, but also upon the rate of evaporation, ${ }^{1}$ the state of the boiler, the brickwork surrounding it, the steam and water in it and in the economizer (if fitted), and the fuel upon the grate being as nearly as possible identical at the beginning and the end of the trial, the management of the boiler during the time preceding these two epochs should receive the most careful attention of the chief observer. He should do his best to ensure that any fluctuations in steampressure, water-consumption, or thickness of fire, etc., unavoidably occurring at the beginning and end of the trial should not be in

1 The rate of evaporation per unit of time should be the same at each reading of the water-level, since the height of the water in the gauge-glass is thereby materially affected, being always higher-often by 1 inch-when the boiler is giving off its full supply of steam than when evaporation has nearly ceased.

[THE INST. C.E. VOL. CXCV.] 
opposite diructions, in order that they may tend to cancel each other. For this reason he ought to be on the spot some time before the commencement of the trial.

\section{Mierhod of Conducting a Conplete Boiler Trial.}

\section{Preliminary Work.}

The boiler having been at work at full pressure long enough to heat the brickwork (if any) to the normal working temperature, ${ }^{1}$ the chief observer should personally see the stokehold floor cleared, leaving on it only sufficient unweighed fuel for immediate needs; instruct the stoker to bring the water in the glass to, or slightly above, the level at which it is intended to keep it throughout the trial, and arrange with him at what time the fircs are to be burnt down for cleaning. ${ }^{2}$ Next, he should visit each of the observing stations at least $\frac{1}{2}$ hour before the official start to see that his assistants are getting their apparatus ready, and should compare his watch with theirs. In particular, he should satisfy himself that all joints ordered to be broken or fitted with blank flanges are broken or blanked, and that one of the two tanks for measuring the feed (assuming two tanks to be used), is full and ready for connecting to the feed-puinp.

When the fires are nearly ready for clenning, any fuel left on the stokehold floor should be cleared away, and a quantity sufficient for making up the fires after cleaning (usually about 8 or $12 \mathrm{Ibs}$. per square foot of grate, or a thickness of 3 or 4 inches) should be weighed out and roughly divided into as many heaps as there are furnaces, so that each furnace may get its fair share. The fires can then be cleaned in some definite order, say from right to left, and should be at once made up with the weighed fuel on the stokehold floor. ${ }^{3}$ The time of beginning and finishing the cleaning should be recorded; also it is well to make a note of the steam-pressure and water-level in order that these conditions may be reproduced at the end of the trial. If the pressure tends to fall during the cleaning of the fires the feed may be checked or shut off entirely. As soon as the fires are cleaned and made up, the ash-pits and, where there are moving bars, the flues behind the bridges, should be cleared and the ashes and clinkers wheeled away, but not weighed.

When all the fuel weighed out has been thrown on to the grates and the fires are thoroughly incandescent, levelled, and nearly ready for more fuel, the chief observer, after seeing that the first

1 See p. 314 .

- See Fig. 13, p. 32.;.

s The coul thrown on after clcaning the grates and before commoncing the trial should be recorded, but not logged as consumed during the trial. 
sealed parcel of coal to be used for the trial is ready, or that the first boxful has been weighed, and is standing on the scales ready to be tipped on to the stokehold floor, should tell the assistant in charge of the feed measurement at what time he proposes to commence the trial, and instruct him to keep the water in the feedtank very slightly above the datum level, and to be prepared to shut off the measuring tank in use (and which is partly emptied) when the whistle is blown to start the trial, and to begin using the water from the full tank as soon as the level in the feed-tank drops to datum. ${ }^{1}$ After hearing the whistle, this assistant should be instructed to record the instant when the water-level in the feed-tank falls to datum as that at which the trial begins, so far as feed-water is concerned, and to immediately adjust the thimble or other mark on the water-gauge glass of the boiler to the height of the water-level shown after thoroughly blowing out the gaugeglass fittings, and this mark must not be touched again throughout the trial.

\section{Starting the Trial.}

On the return of the chief observer to the stokehold, if he has judged the fires well, he will find them thoroughly burnt through, clear, and free from holes. If necessary they should be levelled and, as nearly as possible at the time agreed upon with the observer in charge of the feed-measurements and at the moment when the steam-pressure has dropped perceptibly-say, by 5 lbs. per square inch-he should commence the trial by blowing a whistle, at the same time noting the time and the steam-pressure. (The water-level, as already mentioned, is noted at the moment the water-measurement commences, which may be a minute or so after firing has begun.) The principal observer himself should then take a rake or a specially made tool, ${ }^{2}$ level and gauge each fire in several places, and note the average thickness on each grate. If the fires are not more than 3 or 4 inches thick, the duration of the trial necessary to attain any required degree of accuracy may be halved by pushing the whole of the fire on to the back half of the grate before gauging the thickness; afterwards spreading it again before recharging. ${ }^{3}$

1 For fuller particulars see Sections 1 to 5, pp. 300-307.

2 For sketch of such a tool see p. 299, Fig. 2.

3 ' 'This procedure must not be adopted in the case of boilers with small expanded smoke-tubes, as the cold air entering the furnace between the uncovered bars would cause leakage. 
The first parcel of weighed fuel, which should be ready on the scales or in a sack, should then be tipped on the stokehold floor, roughly divided into as many heaps as there are furnaces, and fired as required. This, as well as all fuel subsequently fired, must be reckoned as fuel used during the trial.

Assuming that the preliminary work commenced at 8.3 a.m., the chief observer's record would be similar to the following:-

$8.3 \mathrm{a}: \mathrm{m}$. Steam-pressure, $120 \mathrm{lbs}$; water in glass, $5 \frac{\mathrm{I}}{4}$ inches; began cleaning fires from right to left.

8.4 "Weighed out 200 lbs. of coal.

8.13 "Finished cleaning fires; checked feed.

8.15 " Finished first parcel of $200 \mathrm{lbs}$. of coal; weighed out 100 lbs. more.

8.20 , Finished second parcel of $100 \mathrm{lbs}$.

8.24 "Visited feed-tanks; told assistant trial would begin about 8.27 , and instructed him to have the level in feed-tank just above datum at 8.26.

8.25 "Thickness of left fire $2 \frac{1}{8}$ inches, right fire 3 inches.

8.27 "Commenced trial. Steam-pressure, 115 lbs., opened feed check-valves wider.

8.28 "Water-measurement begun; water in glass, 5 inches.

Having thus himself taken the first observations, the chief observer should personally tell each of his assistants to begin their work within any short time after the commencement of the trial.

When possible the rate of firing should be fixed upon before the start, and adhered to throughout the trial. A careful record should be made of the time on each occasion when the fires are burnt out, when they are cleaned, and when re-fired. If the coal is very dirty, and the grates have to be cleaned two or three times during a trial, it is advisable to make the intervals as nearly equal as possible, and to treat them as being independent trials (Fig. 12, p. 319). All the ashes and clinker which have been drawn out of the furnaces and flues during the trial should be slaked as quickly as possible, ${ }^{1}$ weighed after the trial, and crushed for sampling.

\section{Ending the Trial.}

At the end of the trial exactly the same procedure is to be followed as at the commencement, except that the water in the

2 This procedure must not be adopted in the case of boilers with small expanded smoke-tubes, as the cold air entering the furnace between tho uncovered bars would cause leakage. 
feed-tank is kept a little. below the datum level until the whistle blows to stop, and that the coal used for making up the fires after cleaning is counted as fuel burnt during the trial.

Assuming a duration of 9 hours, a trial commencing at 8.27 a.m. would end at about $5.27 \mathrm{p} . \mathrm{m}$. In this case the chief observer should direct his attention to the furnace and boiler water-gauge about 4.45 p.m. to see that the fires are being burnt down sufficiently to be cleaned at about 5.3 p.m., and that the water-level is somewhere about $5 \frac{1}{4}$ inches from the bottom of the glass as before. [See Appendix I, Sect. 2 (p. 301), and note on p. 298.]

As near 5.3 p.m. as possible the chief observer should note the time, the steam-pressure and the water-level as at 8.3 in the morning, order the fires to be cleaned, weigh back any coal there may be on the stokehold floor, weigh out $200 \mathrm{lbs}$. of coal; in fact, go through the same performance as he went through in the morning, and as nearly as possible at the same intervals of time; except that the ashes drawn from the ash-pits and flues must now be slaked as soon as possible, ${ }^{1}$ and weighed, instead of being thrown away, and the 200-1b. and 100-1b. parcels of fuel weighed out must be counted as fuel burnt during the trial. No ashes, clinker or fuel that may accumulate on the bars, or in the ash-pits and flues after the cleaning, must be withdrawn or taken account of.

During this time the principal observer should carefully watch the fires to see that they are burning evenly through, and not becoming so thin as to form holes, through which air can pass, and so reduce the steam-pressure. It is not essential that they should be of exactly the same thickness as at the commencement of the trial, but they ought to be of the same quality, i.e., as well burnt and without green coal.

Just before the end of the allotted time, the boiler watergauge should be read and the stearn-pressure recorded, and, if firing by hand, the stoking stopped just as a fresh charge is about to be thrown. (See Sect. 2, p. 280.) As soon as the steampressure drops to the same extent as at the commencement, ${ }^{2}$ the principal observer should again blow his whistle, so that the

I To prevent change of their calorific value by further combustion.

2 It may be assumed that at this instant the furnace again ceases to supply sufficient heat to maintain the working pressure at the rate of evaporation which has been nsed during the trial, and that therefore the condition of the fire and of the boiler generally is the same as it was at the beginning of the trial. 
water-feed, and if there be mechanical stokers, the coal-feed, may be stopped, and the final readings taken by the other observers. He himself should again gauge the thickness of the fires, as at the commencement of the trial, so that the weight of fuel on the grates may be calculated. If this exceed or fall short of the weight on the grates at starting, the excess or deficiency must be deducted from or added to the weight of fuel used during the run. For this purpose the weight of unburnt fuel in pounds corresponding to a given thickness of well-burnt fuel on each grate may be taken as $A \times T \times 2 \cdot 5$ for slack or for fires consolidated by being pushed on to the back halves of the grate, and as $\mathbf{A} \times \mathbf{T} \times 1 \cdot 7$ for large coal, where $A$ is the area in square feet of the part of the grate covered by the fuel, and $T$ the average thickness of the fuel in inches.

By acting in this way the chief observer will get a record very similar to that of the preliminary measurement taken before the commencement of the trial, thus :-

5.3 p.m. Steam-pressure, 119 lbs. ; water in glass, $5 \frac{1}{2}$ inches ; began cleaning fires from right to left.

5.4 " Weighed out 200 lbs. of coal.

5.13 " Finished cleaning fires; checked feed.

5.15 "Finished first parcel of $200 \mathrm{lbs}$. coal ; weighed $100 \mathrm{lbs}$. more; opened feed check-valve wider.

5.20 " Finished second parcel of $100 \mathrm{lbs}$; then visited feed-tanks and told observer to read water-gauge at about 5.26 p.m. and to stop feed-pump on hearing the whistle. Steam-pressure, $119 \mathrm{lbs}$.

5.27 " Steam-pressure, 115 lbs. Finished trial and blew whistle; left fire $2 \frac{1}{2}$ inches thick, right fire 3 inches thick.

5.29 " Feed-tank filled to datum level; measuring tank in use shut off and contents noted.

5.30 " Pump restarted; measuring tanks used as required.

After this those in charge of thermometers, etc., may be told that no more readings are required.

The grates must not be loaded with green coal to bring up the thickness of the fire at the end of the trial, nor must the waterlevel be raised quickly in order to bring it to the original height. ${ }^{1}$ Any divergence from the original thickness of coal or height of water must be allowed for by calculation, as already explained.

1 See p. 300 and footnote on p. 298. 
Throughout the trial the boiler steam-pressure should be noted at regular intervals, say every $\frac{1}{4}$ hour, in order that the mean boiler pressure during the trial may be calculated. ${ }^{1}$ It is also desirable to record the water-levels in the gauge-glasses at about the same intervals. With regard to intermediate readings of water-consumption, see Sect. 8 , p. 310 .

It will be found a great convenience to plot the various observations of coal and water consumption, on section paper, throughout the trial.

\section{Logging the Coal-Consumption.}

In general one weighing-machine and one observer will suffice to $\log$ the coal-consumption, but if the estimated consumption exceeds 1 ton per hour, or if more than two boilers are under trial, it may be necessary to duplicate the weighing plant or to have the tally kept by several observers booking the deliveries on the stokehold floor, instead of by only one at the weighingmachine. If weighing is carried out during the trial, the boxes described on p. 298, Appendix I, should be used alternately and the tally kept as in the following example:-

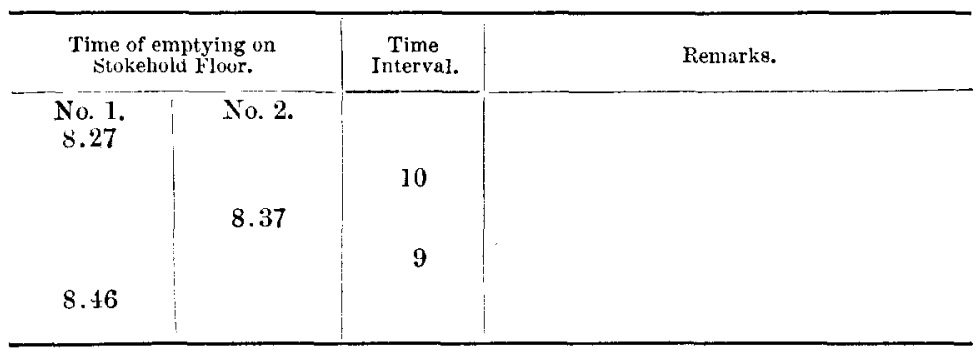

Irregularities in the time intervals when filling up the furnaces after cleaning the grates, or from other causes, should be noted in the "Remarks" column.

When sacks are used they should be emptied in the order of the consecutive numbers upon the labels, and as each sack is emptied upon the floor the label should be detached, endorsed with the

1 The effect of frcquent observations in minimizing errors is to reduce their cumnlative result inversely as the square root of the number of observations. 
time, and kept by the observer as a check upon the tally, which should be kept as in the following example:-

\begin{tabular}{c|c|c|c|c}
\hline $\begin{array}{c}\text { Number of } \\
\text { Sack. }\end{array}$ & $\begin{array}{c}\text { Time wben } \\
\text { Emptied. }\end{array}$ & $\begin{array}{c}\text { Time of Throwing } \\
\text { First Shovelful. }\end{array}$ & $\begin{array}{c}\text { Time } \\
\text { Interval. }\end{array}$ & Remarks. \\
\hline 1 & 8.23 & 8.29 & 6 & \\
2 & 8.33 & 8.35 & 6 & \\
3 & 8.39 & 8.41 & & \\
\hline
\end{tabular}

The time of throwing on the first shovelful of each of the weighed charges should be carefully noted, ${ }^{1}$ and it will probably be a check to stop the stoking at an instant when the stokers are just about to begin throwing coal on to the fire from a new charge, as this is the time at which, in the judgment of the stoker, the last charge was as completely burnt as its predecessors.

If the rate of combustion is required more accurately than is given by the tally sheet, an observer should stay in the stokehold and keep count of the shovelfuls thrown on to each furnace and the time of throwing on. The total weight of fuel used, divided by the total number of shovelfuls fired, will give the average weight of one shovelful.

\section{Sampling.}

A half shovelful of coal should be collected from each weighing during the trial, after breaking the coal and taking both small and large, and should be dealt with according to the instructions in Appendix I (p. 322).

All the ashes and clinker which have been drawn out of the furnace and flues during the trial, except those after the first time of cleaning the fires, should be slaked as quickly as possible, so as to stop any further combustion; and should be weighed after the trial and crushed for sampling (Sect. 25, p. 323).

\section{Recording Temperatures.}

If economizers and superheaters are attached to the boiler the temperatures of their contents should be taken at intervals, say every $\frac{1}{4}$ hour, because in estimating their duties and the boiler duty separately, it is necessary to know the average temperatures throughont the trial.

1 As to plotting these charges see Sect. 20, p. 318. 
If gas analyses and flue temperatures be taken their records should be as nearly continuous as possible, for the same reason.

\section{Mechanical Stokers. ${ }^{1}$}

When mechanical stokers with fixed bars are used the same programme should be adhered to with the following additions :-

(a) The stokers should be stopped while the grates are being cleaned.

(b) The increased rate of feeding the fuel required to make up the fires after cleaning previous to the commencement of the trial should be noted; also for how long it continues, and the same rate of feed should be used for the same interval of time after cleaning the grates previous to the end of the trial.

(c) The hoppers should be fer by hand, their trunks being disconnected, and should be filled with unweighed coal at the beginning of the trial, and with weighed coal at the end.

When the stokers are fitted with chain grates or other moving bars, which carry the fuel forward and drop the ash over the ends, the starting and ending of a trial is a simple matter. These stokers need not be stopped while the clinkers and ashes are being drawn; the furnace should be fired at the predetermined rate before the commencement of the trial for a period long enough to enable the moving bars to discharge all the fuel lying upon them at the beginning of this period, and towards the end of the period the ash-pit into which the bars discharge should be cleared and the hoppers filled up with unweighed fuel, the interval between the clearing of the ash-pits and the commencement of the trial being noted.

At the beginning of a similar interval before the intended finish of the trial the ash-pits should be again cleared and the hoppers filled with weighed coal. The ashes now taken from the ash-pits, as well as any taken out during the trial, must, of course, be slaked and weighed.

When the fuel is gas or oil, there are neither grates to clean nor fires to gauge, and the procedure in starting and finishing a boiler trial is simplified by the omission of these operations; otherwise it should be as already described.

I See p. 332 (Appendix I) for steam used by steam jets and fans. 


\section{TESTING STEAM-ENGINES.}

\section{Stanting an Exalne 'Tlital.}

To start an engine trial correctly is a very simple matter. It is only necessary to note the time, read the counter, and place the collecting vessels under the discharge pipes from the steam traps and open or leaky drains, if any. Similarly, to finish the trial, the clock and counter must be read, and the collecting vessels withdrawn.

\section{Duration of an Evgine Trial.}

(1) If measurement is by boiler feed.

When the steam-consumption is deemed to be the boiler feed the duration of the trial will depend on the steadiness of the waterlevel in the water-gauge glass on the boiler. If the level can be read with certainty to within $n$ tenths of an inch at the beginning, and if the weight of water corresponding with the displacement of the water-level by $n$ tenths of an inch is $w$ lbs., the error in estimating the contents of the boiler at the beginning and enil of the trial cannot exceed $2 w$ lbs. That this error may not exceed II per cent. of the total consumption, the trial must evidently be continued until $\frac{200 w}{m}$ lbs. of water have been pumped into the boiler.

(2) If measurement is by condensation.

When the steam-consumption is deemed to be the discharge from a surface condenser, the duration of the trial, so far as the measurement of the steam is concerned, may bear to the time required in the previous case about the same ratio that the area of the vessel in which the discharge from the condenser is collected bears to the area of the water surface of the boiler. That is to say, if the water-level in a collecting vessel can bo reacl to $n$ tenths of an inch, and if $w$ is the weight of water corresponding with a displacement of the water surface by $n$ tenths of an inch, then, to limit the error to $m$ per cent., the trial must be continued till $\frac{200 w}{i t}$ lbs. of water have been discharged from the condenser. 
Of course, trials of a few minutes' duration, which in many cases would satisfy this condition, may yet $b_{0}$ altogether unreliable through errors in measurement of time, through momentary variations of load and speed, and through irregularity in the rate of the air-pump discharge. If very short trials are absolutely necessary, it is essential that all observations should be taken simuitaneously, and that many trials should be made and averaged.

As the discharge from a water-tight surface condenser always weighs less than the steam supplied to an engine, by the weight of the leakage visible and invisible from glands and drains, account should always be taken of the method of measurement adopted when comparing the results of engine trials; and the method to be adopted when giving or demanding guarantees of steam-consumption should be specified.

\section{Steali Turbines.}

The main difficulty in testing a steam turbine arises in ascertaining the brake horse-power. This is usually done by readings from a dynamo driven by the turbine, the current of which is passed through a liquid or other resistance, or by measuring the torque of the driven shaft. In other cases a Froude's hydraulic brake gives reliable results, but requires special construction owing to the high speed at which these motors usually run.

Where the power is taken direct to an electric generator, and the brake horse-power computed from the output in watts, the calibration of the generator forms the essential element in the measurement. As such generators, especially when running at high speed, have a varying efficiency, this calibration is difficult and to some extent uncertain. It would appear, therefore, that an absolutely reliable brake horse-power test of a turbine can only be obtained from either a torsion or friction brake, and any results derived from and dependent on the electrical measurements should only be accepted as approximate, unless both generator and instruments are calibrated apart from the system, immediately before and after the trial.

For both direct and exhaust turbines the observer should note in his remarks on the trial the time taken between the start of the apparatus and the attainment of full load. 


\section{RECORDING THE RESULTS OF A BOILER OR ENGINE TRIAL.}

The following tabular forms are recommended for this purpose, and the methods of calculating the various items will be found in Appendix II. 


\title{
$(285)$ \\ The Enstitution of Civil Engineers.
}

\author{
Standard Forms for Tabulating the Results of \\ Steam-Engtate and Boiler Trials.
}

\section{$=$ \\ COMPLETE STEAM-PLANT TRIAL. \\ REPORT}

on the trial of a Complete Steam Plant

working at

made on the

at the request of

under the divection of

and in the presence of

NOTES.-(1) The lines printed in italics relate to data which may be omitted where a shorter form of Report for general purposes is desired (see Committee's Report, p. 266).

(2) The Numbers in the first column of each Form have reference to Appendix II, p. 335 et seq.

The standard forms for a Boller Trial consist of Reference numbers 1 to 87 inclusive, and those for an Exgine Trial, of reference numbers 88 to 131 inclusive. 
I.

\section{BOller, Sheet I. General Description and Dimensions.}

'Type of Boiler. Made by

Maker's rating of the output of the Boiler lbs. of steam per hour.

Test made at an output of Ibs. steam per hour.

Object of the Trial

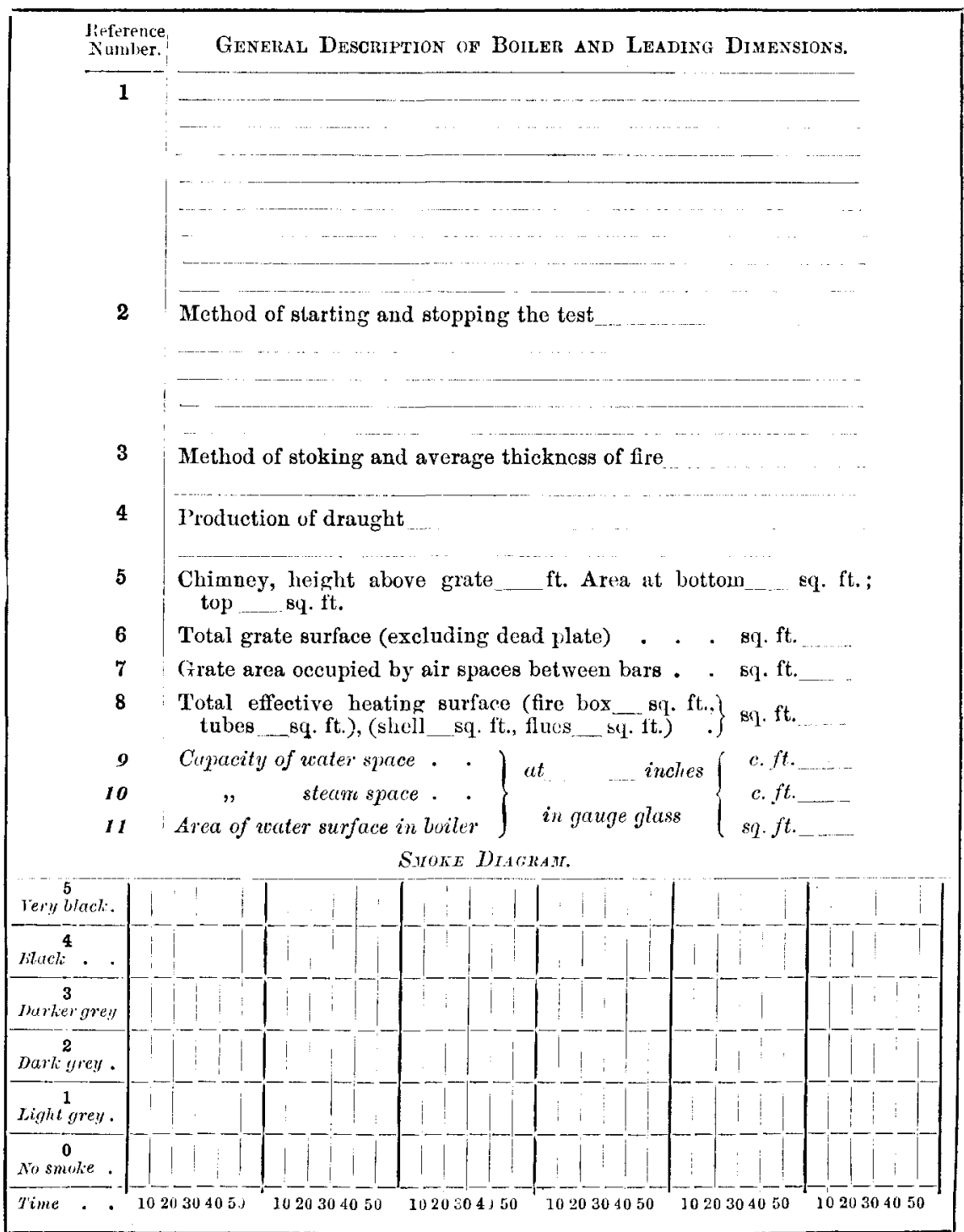


II.

BOILER.

Sheet II.

Data Deduced From Observations.

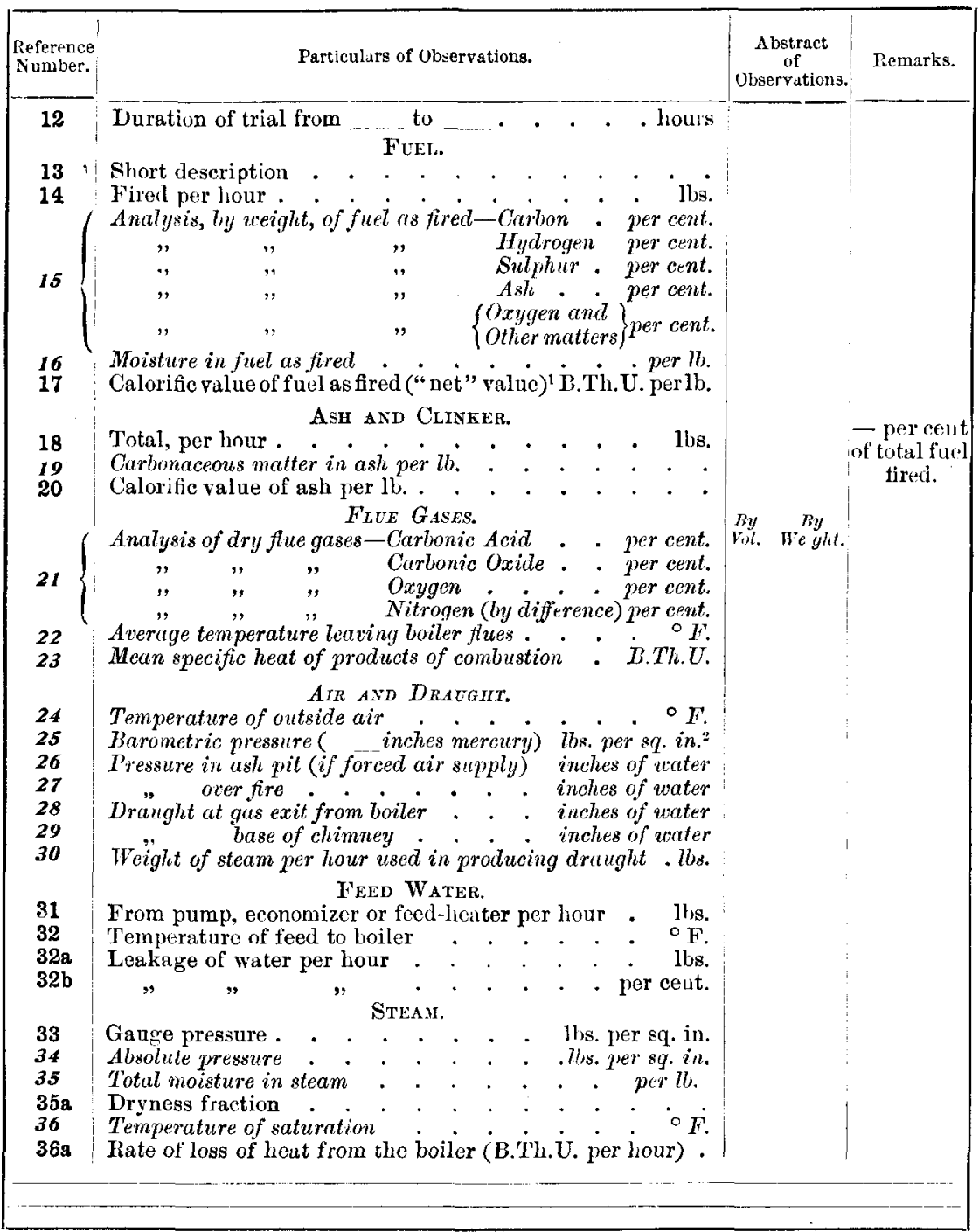

NoTe.-When jacket condensed steam and relieater condensed steam are returned direct to the boiler, the weight of each, returned per hour, should, if possible, be determined, and also the temperatures at which they enter the boiler. The blank lines are intended for use in such cases, and for any other observations which it may be desired to record.

1 For definition of "net" caloritic value see p. :338.

2 See explanation of line 101 (p. 355). 
III.

Botleh. Sheet 1II. Heat Account and Deductions.

\begin{tabular}{|c|c|c|c|}
\hline $\begin{array}{l}\text { Reference } \\
\text { Number. }\end{array}$ & Heat Account (per lb, of fuel as fired). & B.Th.U. & Per Cent. \\
\hline 37 & Total heat value of $1 \mathrm{lb}$. of fuel as fired. & & $100 \cdot 0$ \\
\hline 38 & $\begin{array}{l}\text { Heat transferred to the water (and thermal } \\
\text { efficiency).. } . . \\
.\end{array}$ & & \\
\hline 39 & Heat earried away by products of combustion. . & & \\
\hline 40 & Heat carried away by excess air . . . . . & & \\
\hline $4 I$ & Heat lost by incomplete combustion. . . . . & & \\
\hline 42 & Heat lost by unburnt carbon in ash . . . . & & \\
\hline $42 a$ & Heat in red-hot clinker and ash . . . . . & & \\
\hline 43 & Loss per hour by radiation. . . . . . . . . & & \\
\hline \multirow[t]{3}{*}{44} & 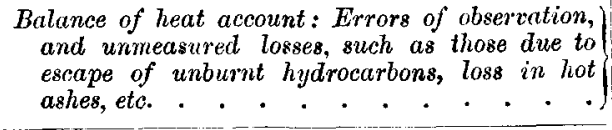 & & \\
\hline & Total of lines 38 to 44 , equal to line 37 & & $100 \cdot 0$ \\
\hline & Deductions. & & \\
\hline 45 & 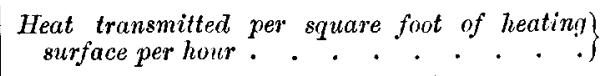 & B.Th.U. & \\
\hline 46 & $\begin{array}{l}\text { Weight of fuel fired per square foot of grate per } \\
\text { hour } . \cdot \cdot \cdot \cdot \cdot \cdot \cdot \cdot \cdot\end{array}$ & $7 b 8$. & \\
\hline 47 & Water evaporated per $1 b$. of fuel as fired. & lbs. & \\
\hline 48 & $\begin{array}{l}\text { Equivalent evaporation from and at } 212^{\circ} \mathrm{F} \text {. per } \\
\text { lb. of fuel as fired } \cdot \cdot \cdot \cdot \cdot \cdot \cdot \cdot{ }^{*}\end{array}$ & Ibs. & \\
\hline 49 & $\begin{array}{l}\text { Weight of feed, from and at } 212^{\circ} \mathrm{F} . \text {, per square } \\
\text { foot of heating surface per hour } \cdot{ }^{\cdot} \cdot{ }^{\cdot}\end{array}$ & lbe. & \\
\hline 50 & Velocity of steam across water surface $\cdot \cdot \cdot \cdot\{$ & $\begin{array}{l}\text { feet per } \\
\text { second. }\end{array}$ & \\
\hline $5 \boldsymbol{I}$ & Air used per lb. of fuel as fired . . & $l l s$. & \\
\hline $\boldsymbol{5 2}$ & $\left.\begin{array}{l}\text { Weight of air theoretically required per } l b . \text { of } \\
\text { fuel as fired } . \cdot \cdot \cdot \cdot \cdot \cdot \cdot \cdot \cdot\end{array}\right\}$ & $l b 8$. & \\
\hline 53 & Ratio of air used to air theoretically needed. . & & \\
\hline 54 & $\begin{array}{l}\text { Weight of products of combustion per ll. of coal } \\
\text { as fired } \cdot \cdot \cdot \cdot \cdot \cdot \cdot \cdot \cdot \cdot,\end{array}$ & $l b s$. & \\
\hline $\boldsymbol{5 5}$ & Weight of gases per lb. of coal as fired . . . & lbs. & \\
\hline 56 & Heat-capacity of gases per $l b$. of coal as fired. & B.Th.D. & \\
\hline
\end{tabular}


ECONOMIZER AND SUPERHEATER. Sheet I.

General Description and Dimensions.

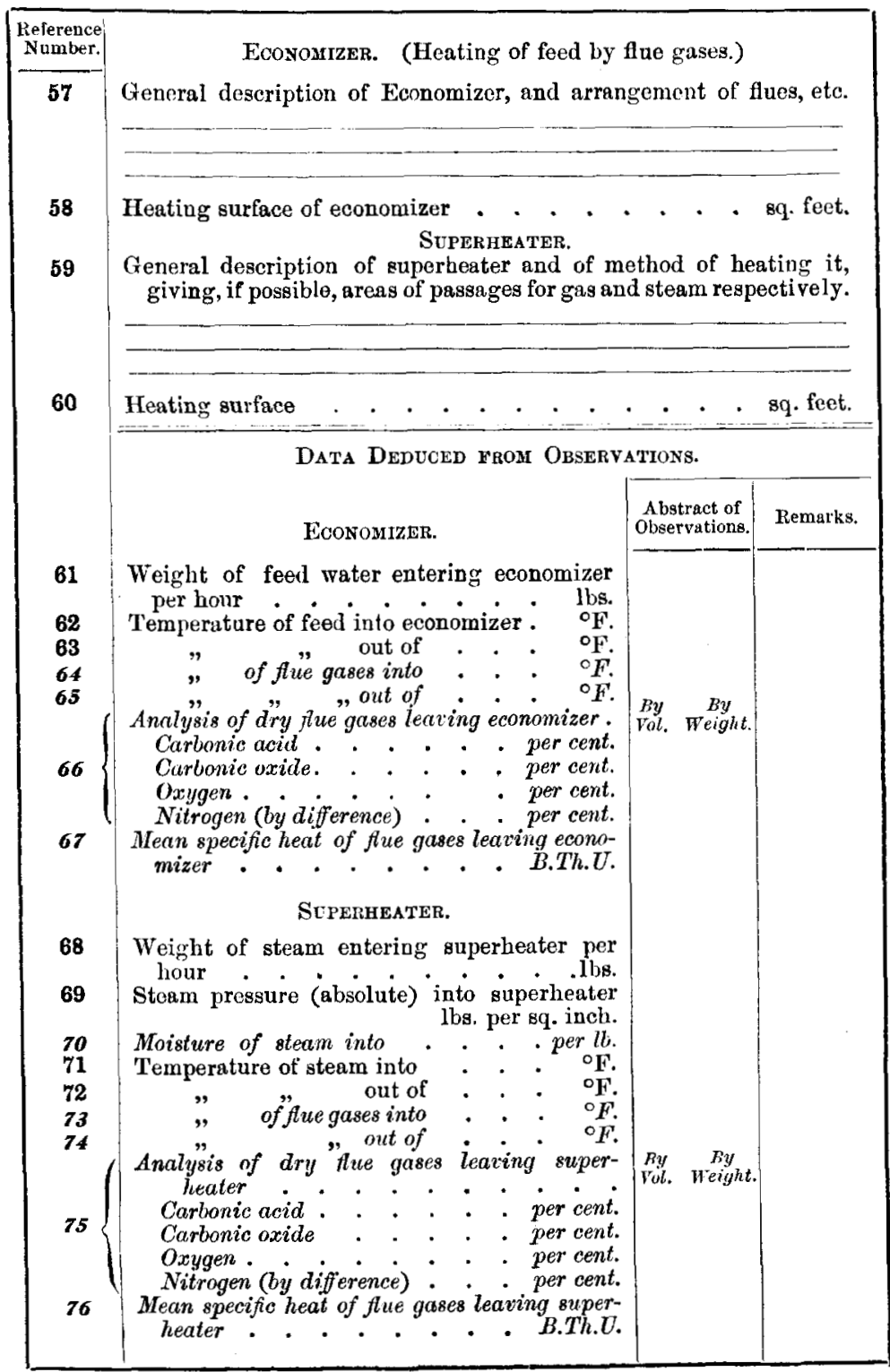

[THL INST. C.E. VOL. CXCV.] 
V.

ECONOMIZER AND SUPERHEATER. Shect II.

Heat accolnt and Deductions.

\begin{tabular}{|c|c|c|c|}
\hline $\begin{array}{l}\text { Reference } \\
\text { Number. }\end{array}$ & Heat account (per lb. of fuel as fired). & B.Th.U. & Per cent. \\
\hline & ECONOMLZR. & & \\
\hline 77 & 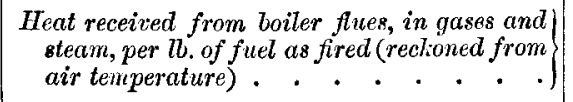 & & $100 \cdot 0$ \\
\hline 78 & $\begin{array}{l}\text { Heat transferred to the water (and efficiency) } \\
\text { of economizer). } . .\end{array}$ & & \\
\hline 79 & Iteat carried off in the chimney gases. . . . & & \\
\hline \multirow[t]{3}{*}{80} & 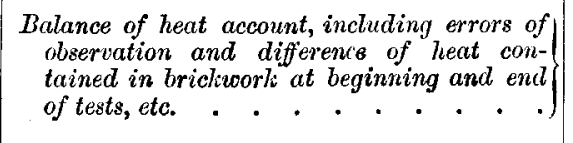 & & \\
\hline & Total of lines 78 to 80, equal to line 77 & & $100 \cdot 0$ \\
\hline & 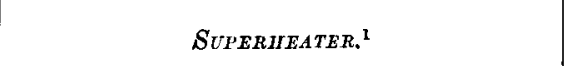 & & \\
\hline 81 & 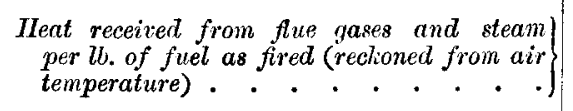 & & $100 \cdot 0$ \\
\hline 82 & $\begin{array}{l}\text { Heat transferred to steam (and efficiency of } \\
\text { superheater) }\end{array}$ & & \\
\hline 83 & Heat carried off in the climney gases. . . & & \\
\hline \multirow[t]{3}{*}{84} & $\begin{array}{c}\text { Balance of heat account, including errors of } \\
\text { observation, etc. } \cdot \cdot \cdot \cdot \cdot \begin{array}{ccc}\cdot & \cdot & \cdot\end{array} \mid\end{array}$ & & \\
\hline & Total of lines 82 to 84 , equal to line 81 & & $100 \cdot 0$ \\
\hline & DEDICTIONS. & & \\
\hline 85 & $\begin{array}{l}\text { Heat transmitted per square foot of heating } \\
\text { surface of economizer per hour }\end{array}$ & B.Th.U. & \\
\hline 86 & $\begin{array}{l}\text { Heat transmitted per square foot of henting } \\
\text { surface of superheater per hour } .\end{array}$ & B.Th.U. & \\
\hline 87 & $\begin{array}{l}\text { Thermal efficiency of boiler superheater and } \\
\text { economizer combined } . .\end{array}$ & per cent. & \\
\hline
\end{tabular}

${ }^{1}$ If separately fired, enter results on a boiler Furm. 
ENGINE. Sheet I. General Description and Dimensions.

Type of Engine

Maker's rating of the power.
Made by \{

I.HP. at revs, per min. and

1bs. per sq. inch, stop ralve gange-pressure.

Test made at I.HP.

Character of load

Object of trial

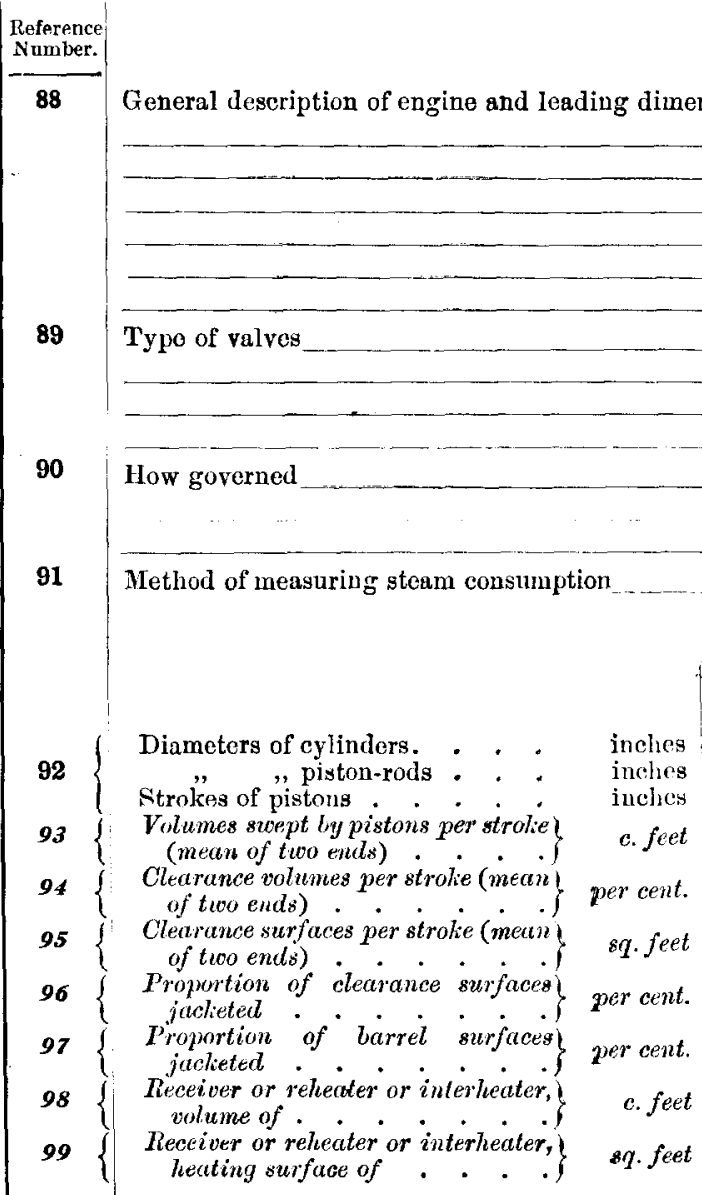

Farticulars of cylinders. H.P. I.P. - L.P. 
VIT.

eNGine. Sheet II. Data Devuced from Observations.

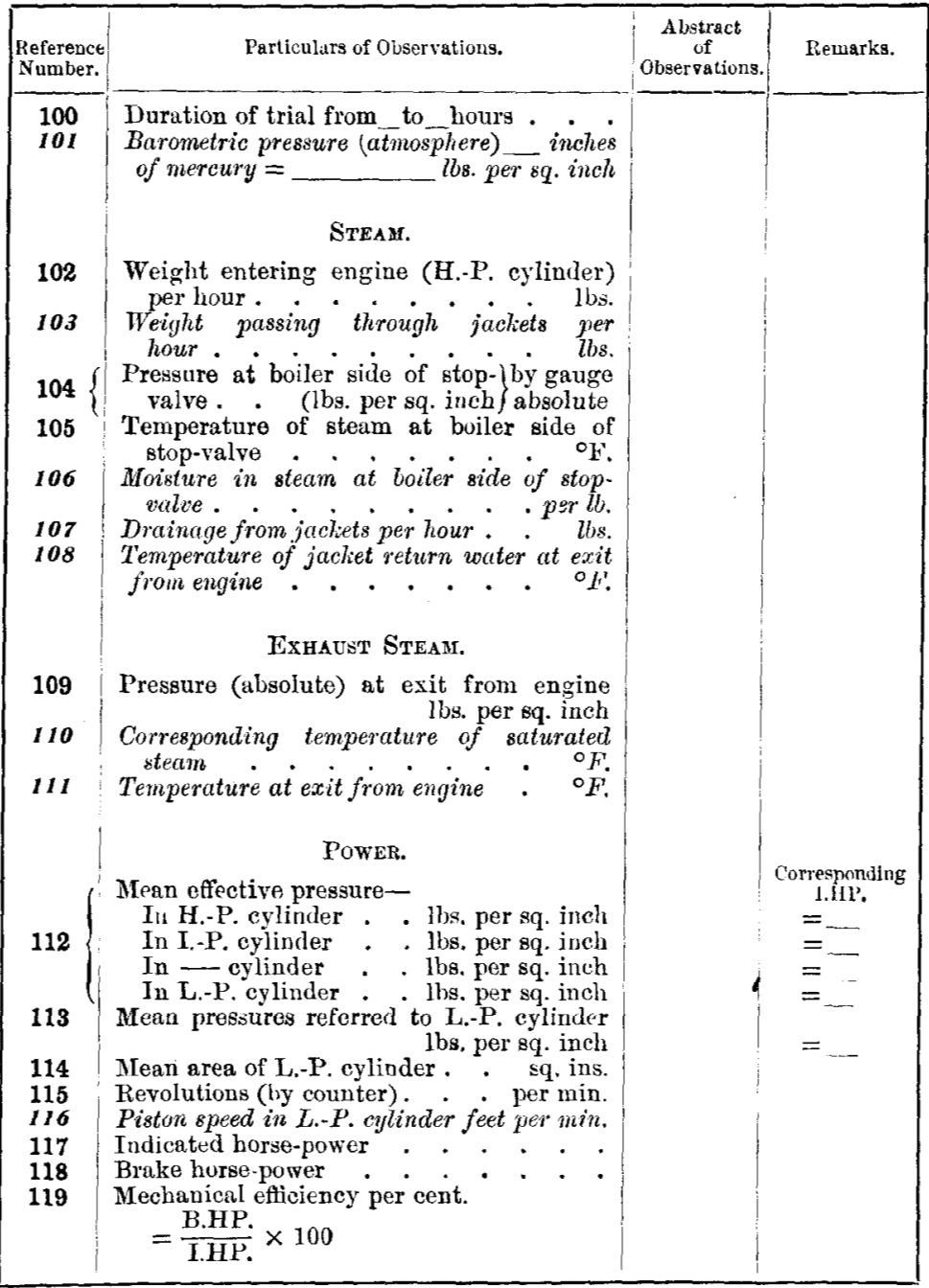

Noтe.-Blank lines are left in this Form for filling in observations which may be taken in engiues using reheaters or interheaters, and for recording such observations as the temperature range in the cylinders, pressures in the jackets, and any other observations which it may be specially desired to record. 
ENGINE. Shect III. Heat Account and Deductions.

\begin{tabular}{|c|c|c|c|}
\hline $\begin{array}{l}\text { Reference } \\
\text { Number. }\end{array}$ & Heat Account (from $32^{\circ}$ F.). & B.Th.U. & Per Cent. \\
\hline 120 & Gross heat supply entering engine per minute. & & $100 \cdot 0$ \\
\hline 121 & $\begin{array}{l}\text { Hent equivalent of indicated horse- } \\
\text { power } .+\cdot \cdot \cdot, \cdot \text { per min. }\end{array}$ & & \\
\hline 122 & 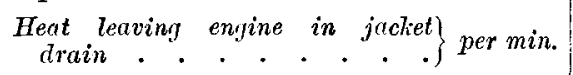 & & \\
\hline 123 & 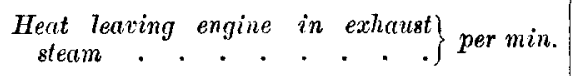 & & \\
\hline \multirow[t]{3}{*}{124} & $\begin{array}{l}\text { Balance of Heat Account (errors of observa- } \\
\text { tion, losses by radiation, etc.). } .+. \cdot\end{array}$ & & \\
\hline & Total of lines 121 to 124 , equal to line 120. & & $100 \cdot 0$ \\
\hline & Deductions (reckoned from exhaust temper & ture). & \\
\hline 125 & Heat supplied per minute per I.HP. . . . & B.Th.U. & \\
\hline 126 & Thermal efficieney • • • • • • • • • • • • & per cent. & \\
\hline 127 & $\begin{array}{l}\text { Heat theoretically required per minute by the } \\
\text { "Institution of Civil Engineers' standard of } \\
\text { comparison" per I.IIP. (Ranline's cycle) }\end{array}$ & B.Th.U. & \\
\hline 128 & Efficiency ratio . & $\cdot \quad \cdot$ & \\
\hline 129 & Heat supplied per minute per B.HP. . . & B.Th.U. & \\
\hline 130 & Pounds of steam nsed per I.HP.-hour . . & - lbs. & \\
\hline \multirow[t]{4}{*}{131} & $\begin{array}{l}\text { Equivalent pounds of steam used per I.HP. } \\
\text { hour at } 1,100 \text { B.Th.U. per lb. * * • • }\end{array}$ & - $\quad$ lbs. & \\
\hline & - & - & \\
\hline & & & \\
\hline & & & \\
\hline
\end{tabular}

Remarks :

Note.-In engines using reheaters, interheaters, etc., the lieat returned from them to the boiler should be entered in the heat bqlance on the "out"-side. 
$I X$.

ENGINE ACCESSORIES. Sheet I. GENERAL DESCRTITION AND DIMENSIONS.

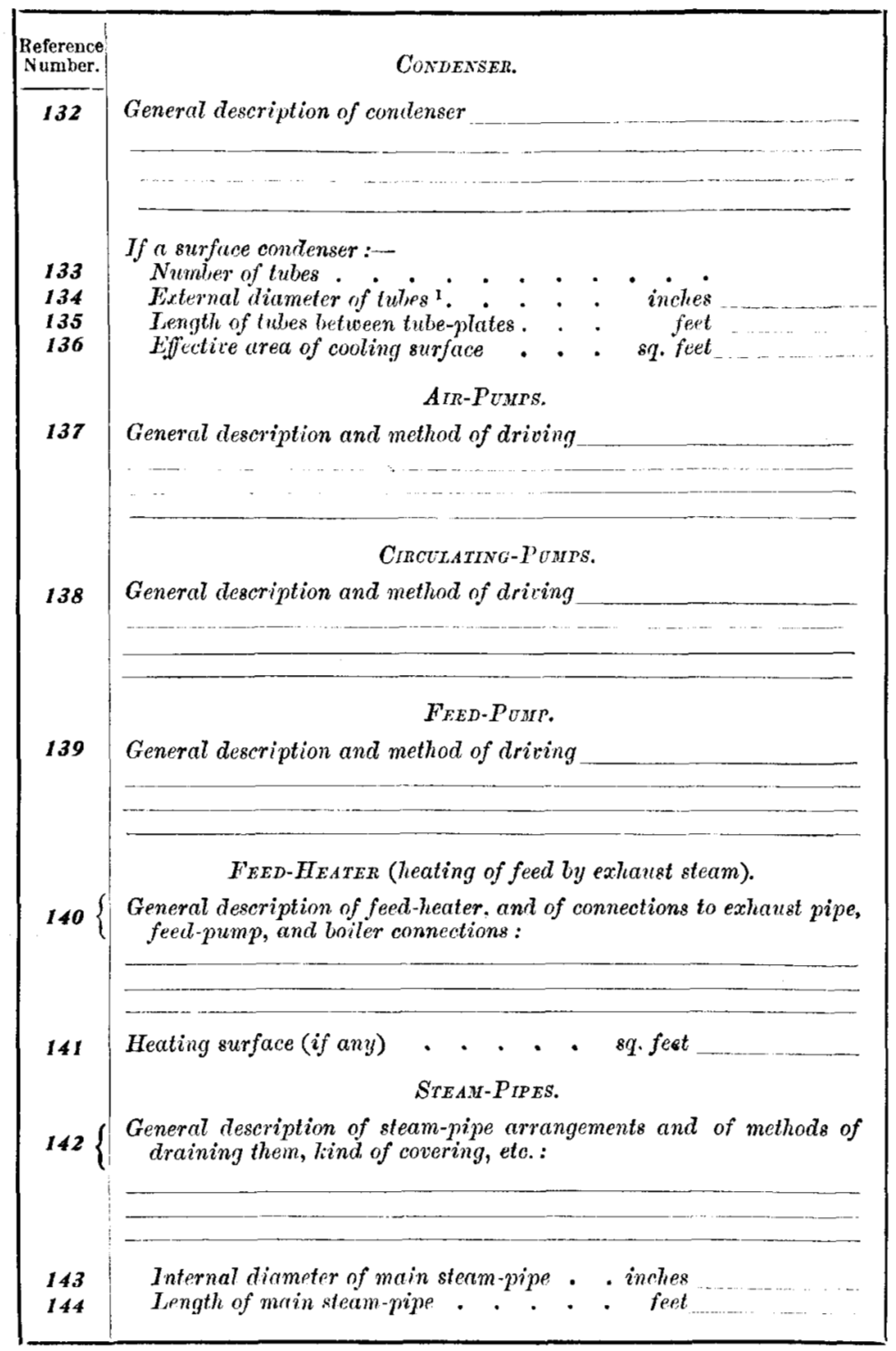

1 If the condensor is of a type in which the steam is inside the tubes, their internal diameter should be given. 
ENGINE ACCESSORIES. Sheet II. DATA DEDUCED FROM OESERVATIONS.

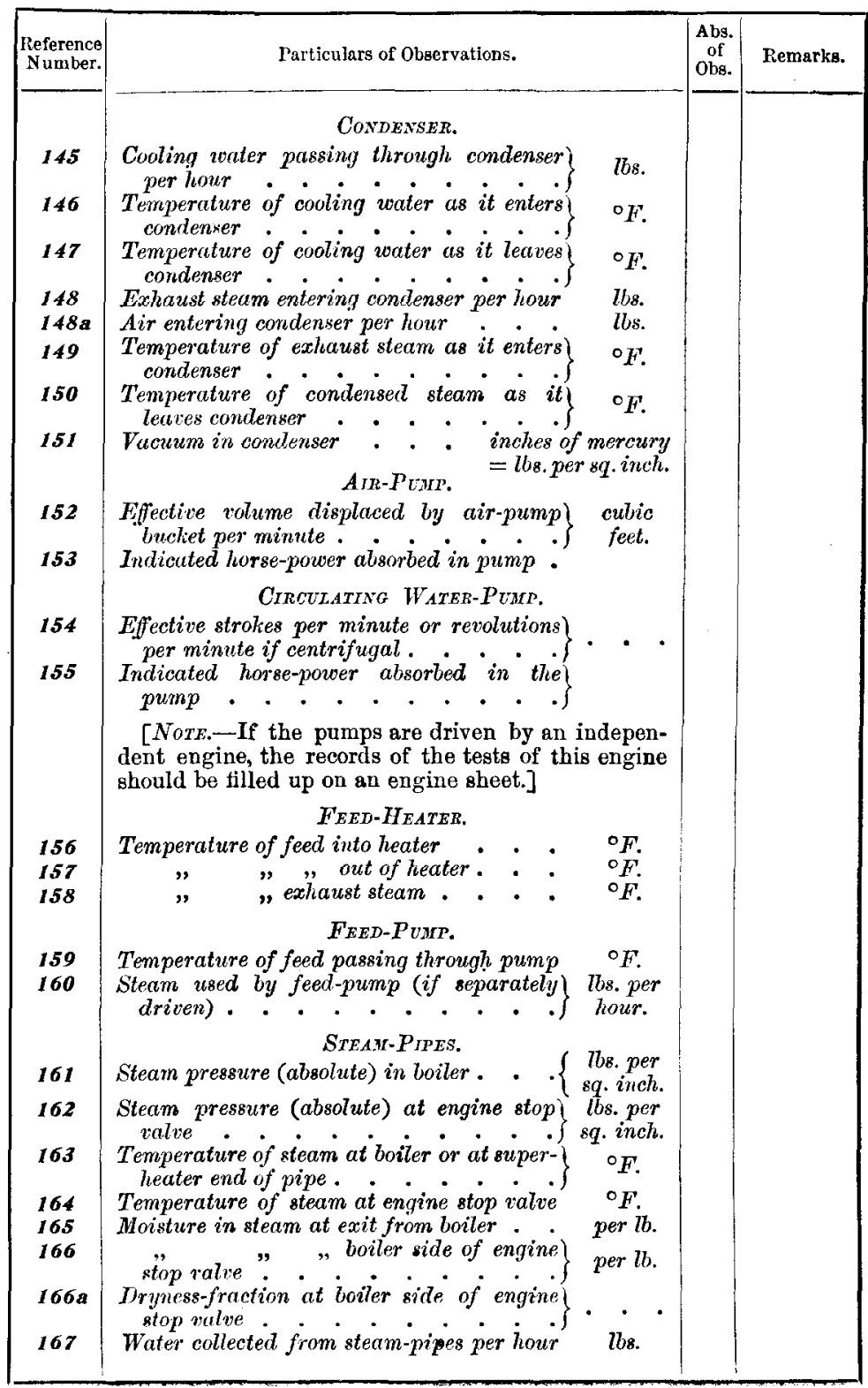


$\mathrm{XI},-$

\section{SUMMARY.}

Rated Power of the Plant I.HP.

Test made at of the rated pouer.

Economy of the Complete Steam Plant.

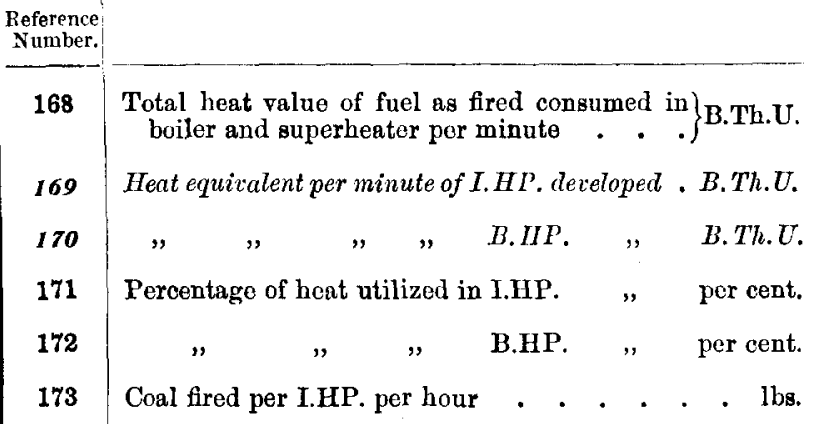

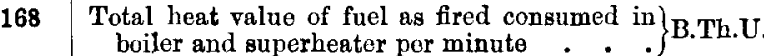

169

Heat equivalent per minute of I.HP. developed . B.Th.U.

$170 \quad, \quad, \quad$, $\quad$ B.IIP. , $\quad$ B.Th.U.

171 Percentage of heat utilized in I.HP. " per cent.

172 " " " B.HP. , per cent.

173 Coal fired per I.HP. per hour . . . . . . lbs.

REMARKS: 


\section{APPENDIX I.}

\section{Methods Suggested for Making the Measurements Required in Boller and Steam-Engine Trials.}

\section{INTRODUCTION.}

Some of the more reliable and accurate methods of measurement employed when carrying out boiler and engine trials, together with notes on the apparatus required, have been collected together in this Appendix.

In some steam-engines a reheater is used, warmed by steam taken direct from the boiler, and the resulting hot water is taken straight back to the water-space of the boiler, thus forming a closed loop. Heat is thus supplied to the engine, the amount of which cannot be obtained by measurement of the feed, and if no account is taken of this heat a serious error, to the advantage of the engine, will be made. A similar case occurs if the jacket-steam is returned direct to the boiler. Attempts have been made to measure this supply of heat to the engine, but with only moderate success, and it is regretted, therefore, that it has not been found possible to give a description of a suitable method. ${ }^{1}$ Approximate methods of determining losses from radiation and leakage are given (pp. 312,315 ), but they occupy so much time that they can seldom be put in operation.

\section{List of Apparatus Required for a Boller Test.}

With the exception of Nos. 11, 12,13,14, 15, 16 and 17 , the following apparatus should be supplied in all cases, in accordance with instructions to be given by the chief observer:-

(1) Tanks to be erected for weighing or measuring the feed. (See p. 300, etc.)

(In the latter case they must be calibrated. See p. 306.)

(2) A feed-tank fitted with a point-gauge or a float. (See pp. 300 and 306.)

I See, however, line 103, 1. 355. 
(3) If convenient, brass clips or thimbles can be fitted to slide on each water-gauge glass to mark the position of the water-level.

Strips of white wood marked in inches and $y^{1} \overline{0}$ inch ${ }^{1}$ should be fixed between the glands of the water-gauge cocks of the boiler alongside the glasses.

(4) A sensitive weighing machine, accurate to one-thousandth of the load on the scale, for weighing the fuel and ashes. At sea a calibrated spring balance can be used for this purpose.

(5) If the fuel is to be weighed during the trial, two portable receptacles with two handles, each containing not more than 2 cwt., or preferably about 16 per cent. of the estimated hourly consumption.

(6) If weighing is carried out before the commencement of the trial, a sufficient number of sealed and consecutively numbered sacks, each containing not more than $1 \mathrm{cwt}$. of coal, and preferably about 8 per cent. of the estimated hourly consumption. The weighing should be super-

1 A Table or curve may be prepared, giving the volumes of water corresponding to each $\frac{1}{10}$ inch on the gauge-glass scale with corrections for expansion due to temperature, and will be found convenient for making allowances for variations in the gauge readings. (Sce p. 310.)

It should be remembered that when the final level is higher than the initial level the weight of water to be deducted from the measured feed is not the weight of the layer of water contained between the two levels, but the difference between this and an equivalent weight $w$ which, if converted from water at feed temperature into steam at boiler pressure, would have absorbed the same quantity of heat as was required to hent the layer of water between the gauge levels from the temperature of the feed to the temperature of the steam, but not to evaporate it.

'Thus if $\mathrm{W}$ is the weight of water between the two gange levels, $t$ and $\mathrm{T}$ the temperatures of the feed and of the steam respectively, $l$ the heat of evaporation, commonly called the latent beat of $1 \mathrm{lb}$. of steam at temperature ' $\mathrm{T}$, and $w$ the equivalent weight referred to, then

$$
w=\frac{\mathrm{W}(\mathrm{T}-t)}{\mathrm{T}-t+l},
$$

and $(W-w)$ is to be deducted from the measured feed;

i.e.,

$$
\left\{1-\frac{\mathrm{T}-t}{\mathrm{~T}-t+\mathrm{L}}\right\} \times 10
$$

is the percentage of the layer of excess water by which its actual volume is to be diminished.

When the final level is lower than the initial the weight to be added to the measured feed is of course the actual weight $W$ of the layer of water contained between the two gauge levels at temperature $\mathrm{T}$. 
intended by the chief observer or his assistant, and the numbers should be on labels which can be detached from the sacks and kept for checking purposes.

(7) A galvanized-iron dust-bin, with a capacity of from 4 to 6 cubic feet, for storage of the coal samples taken in 1 day, provided with a cover.

(8) Buckets for collecting leakages.

(9) A tool (Fig. 2), for gauging the thickness of fuel on the grate.

(10) Mercurial "bath thermometers" for measuring the temperature of feed-water.

(11) A wet- and dry-bulb thermometer for measuring the temperature and moisture of the atmosphere.

Fig. 2.

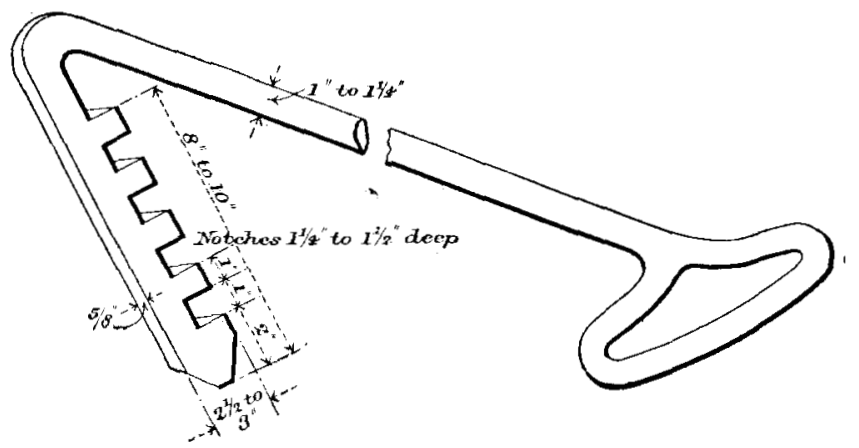

(12) Nitrogen thermometers, and mercury for the thermometer cups.

(13) A Barrus or other calorimeter.

(14) Pyrometers as required.

(15) An aspirator for sampling the gas (p. 331).

(16) Gas-sampling tubes filled with mercury (footnote p. 331).

(17) An apparatus for analysing gases on the spot.

(18) A table or its equivalent for carrying the apparatus, and fitted as a temporary laboratory.

(19) Arrangements should be made for supplying artificial illumination to this table, and to all dark places where readings have to be taken; also to all observers' stations. 
No. 1.-Princirles of Exact Fred-Water Measurementr.

The following principles are regarded as essential to measurement of the feed-water with precision. They are not, however, always possible of attainment in their entirety, and in that case a less direct method has to be adopted.

(1a) A feed-tank should be provided from which the feed-pump draws; containing a fixed point-gange (Fig. 4, p. 303) or a float, by which to recover a given datum level at any instant; and

(1b) In combination with this, an adjustable mark with which to register the position of the water-level in the boiler at the commencement of a trial. This may conveniently take the form of a thin metal thimble sliding on the boiler gauge-glass when this is of circular section.

(2) Matters must be so arranged that at the beginning of a trial the water in the feed-tank stands at the datum level, i.e., that of the fixed point-gauge, and that the thimble or other mark registers the level in the boiler gange-glass.

(3) At the termination of the trial these two levels should be exactly recovered before the final readings of water-consumption are taken.

(As will be noted later, there is sometimes a difficulty in getting the water in the boiler to the exact level required, and the volume which would be contained in the space between the actual and the intended levels has then to be calculated. $)^{1}$

(4) During the course of the trial known quantities of water are weighed or measured and fed into the boiler. (It is convenient, but not essential, to do this at such a rate as to keep the water-level in the feed-tank approximately constant.)

The water-level in the boiler must not be raised to the thimble by pumping faster for a comparatively short time, or large errors will be introduced. ${ }^{2}$

(5) In addition to readings at the beginning and end of a trial, intermediate readings of water-consumption should be taken not less than ten times during its progress, and preferably at intervals of from 15 to 30 minutes according to the duration of the trial, in

See note on p. 298 as to curve for correction.

2 See note on p. 273 and sect. 9 , p. 310 , as to the importance of steady ronditions of feel supply and evaporation. 
order to ensure that the rate of evaporation remains approximately constant throughout. ${ }^{1}$

So long as the foregoing conditions are observed the exact methods of measurement may be varied, but the following are recommended :-

\section{No. 2.-Measurement by Weight.}

(1) When testing small boilers a weighing machine and a bucket form a very handy arrangement for supplying the feedtank. The water in the feed-tank should be slightly above the datum level before the trial begins, and when the time to start approaches no water should be adied till the point of the fixed gauge appears on the surface. The time should then be noted as that when water-measurement commences, after which each bucketful is weighed before tilting it into the feed-tank, and logged immediately afterwards. When an intermediate reading is desired several bucketfuls are poured in at such a rate as to raise the water slightly above the datum level. The surface is then watched ${ }^{2}$ as the pump gradually lowers it, and the instant at which it reaches the datum level is noted as that at which the previously weighed water had entered the boiler.

The water-level in the boiler should be constant throughout; but if this condition cannot be maintained a correction must be made to the quantities so measured, and the distance between the water-level then in the boiler and that at the outset must be noted at each reading, in order to enable this correction to be made. (See note, p. 298.)

When the end of the trial approaches, the water in the boiler should be as nearly as possible at the level of the thimble or other

1 The probable cumulative error in making obscrvations will vary inversely as the square root of their number.

2 When an electric bell is fitted in connection with a float, this watching is unnecessary : but care must be taken that the motion of the float is not affected by friction. The error due to friction can be minimized by making the horizontal section of the float of ample area. 'Taking the temperature of the water as $100^{\circ}$ and the allowable error as $\frac{1}{16}$ inch, the following Table shows the force available. If double this error is allowed the force is doubled-

\begin{tabular}{|c|c|c|c|c|c|c|}
\hline Diameter of float & - & - & 6 inches & 8 inches & 10 inches & 12 inches \\
\hline Area of float. & . & - & $28 \cdot 27$ & $50 \cdot 27$ & $78 \cdot 54$ & $113 \cdot 1$ \\
\hline $\begin{array}{l}\text { Force in ounces } \\
\text { error }\end{array}$ & per $\frac{1}{16}$ & $\left.\begin{array}{cc}\text { inch } \\
\cdot & .\end{array}\right\}$ & $1 \cdot 02$ & $1 \cdot 81$ & $2 \cdot 82$ & $4 \cdot 06$ \\
\hline
\end{tabular}


mark on the gauge-glass, and that in the feed-tank should be kept a little below the datum level. When the word is given to stop the trial, the final reading of the water-level in the boiler is taken, and the feed-pump is shut off, the time of doing this being logged as that of finishing water-measurements. (If the water-level in the boiler is not at its original height, a correction must be made as described in the footnote on p. 298.) The weight of water needed just to raise the water in the feed-tank to the datum level

Fig. 3.
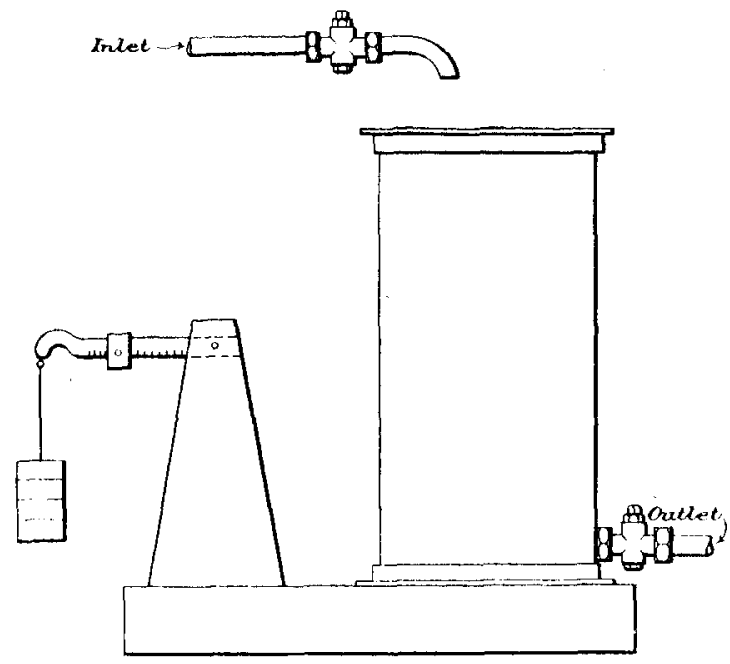

is then ascertained, and the pump is again started The water weighed, including that added while the pump was shut off, is to be logged as having been completely evaporated at the time the pump was shut off.

(2) A more elaborate plant for weighing the water is shown in Fig. 3. It is used in the same way as the bucket already described in connection with a feed-tank. The outlet pipe must be flexible.

\section{No. 3.-Measurement by Volume.}

Except with small boilers the actual weighing of feed-water presents so many difficulties and inconveniences that volumetrio measurement has to be substituted. 
(1) Fig. 4 shows the feed-measuring arrangement which is considered best. It consists of two calibrated tanks, each holding considerably more than 10 minutes' supply. These are of circular section, having conical ends, the upper parts of which terminate

Fig. 4.

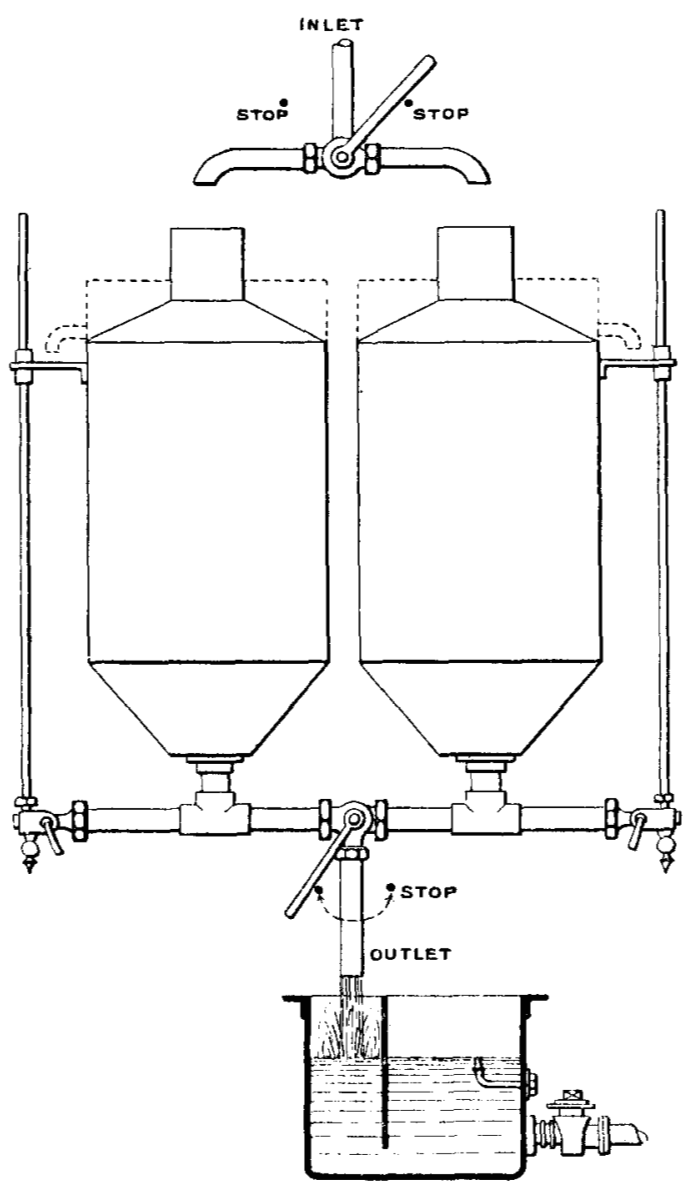

in short cylinders. (Owing to the small sectional area of these cylinders, errors in volume due to slight inaccuracies of filling or of reading the water-level in them are insignificant.)

The cylinders may either be filled to a fixed height of the water- 
gauge or be filled to overflowing. In the latter case a trough round the edge of the upper cone, as shown by dotted lines, will be found a convenient means of catching the overflow, which is then drained

Fig. 5.

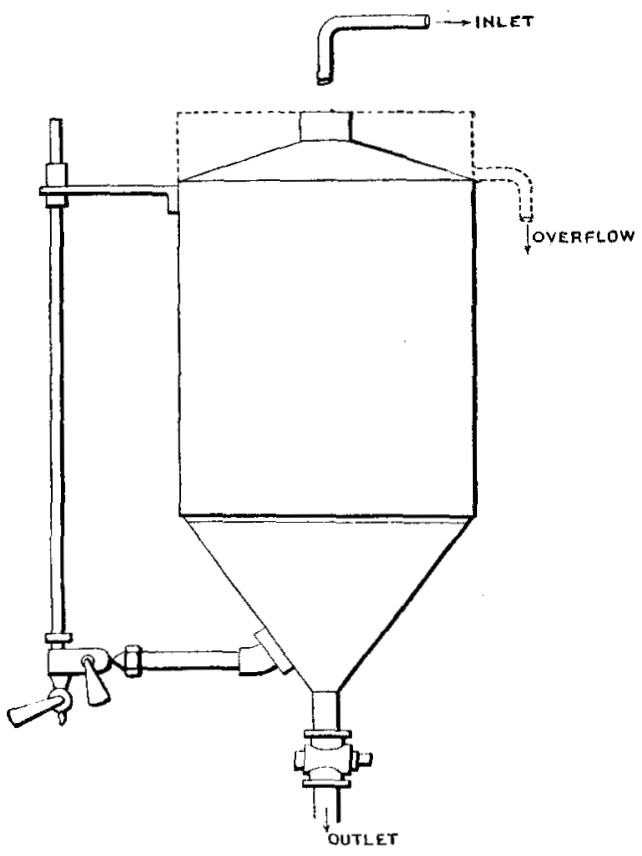
away by a suitable pipe.

When in use these tanks are filled and completely emptied into the feed-tank alternately, according to the detailed instructions on p. 308. Separate cocks may be fitted for this purpose to each tank, but the three-way cocks ${ }^{1}$ shown will be found most convenient. Valves should not be used with this or any other arrangement when leakages cannot be detected, for a small piece of wood or other obstruction can easily prevent a valve being closed.

(2) When conical-ended tanks cannot be obtained, cylindrical ones, fitted with long gauge-glasses, can be used in-

1 The three-way supply-cocks must be so designed that when the handles are vertical both pipes are closed, and they should be of such a size that either tank cau be filled in 3 minutes less time than is occupied in feeding the boiler with the other tankful. The rate of outflow of the lower cock diminishes with the falling water-level in the measuring tank. Where the sides are parallel, as in Fig. 6, the time in seconds in which the water falls from a level $\mathbf{H}$ inches above the lower end of the discharge pipe to a level $h$ inches above the same point will be $\mathrm{T}=\frac{\mathrm{A}}{3} \bar{a}(\sqrt{\mathrm{H}}-\sqrt{\bar{h}})$, where $A$ and $a$ are the sectional areas of the tank and of the discharge pipe respectively.

Where the ends are conical, as in Figs. 4 and 5 , the time occupied will be less thau this. 
stead. ${ }^{1}$ In such tanks it is best to fill them to a predetermined height, as indicated by the gange-glass or by a float carrying a light rod, which actuates a pointer sliding freely on a scale. Where this is used care must be taken to prevent the watersupply striking the float, and to see that the pointer does not stick. (See note on p. 301.)

(3) At sea it is difficult to be sure that a flat-bottomed tank is emptied to the same degree each time. A water gaugeglass should be therefore fitted either forward or aft of such a tank exactly on its vertical centre line, so that the rolling of the ship affects its readings as little as possible, and the emptying cock should be shut as soon as a mark near the lower end of this gaugeglass is reached by the water-level. ${ }^{1}$ All calibrations are made from this mark as zero.

Fig. 6.

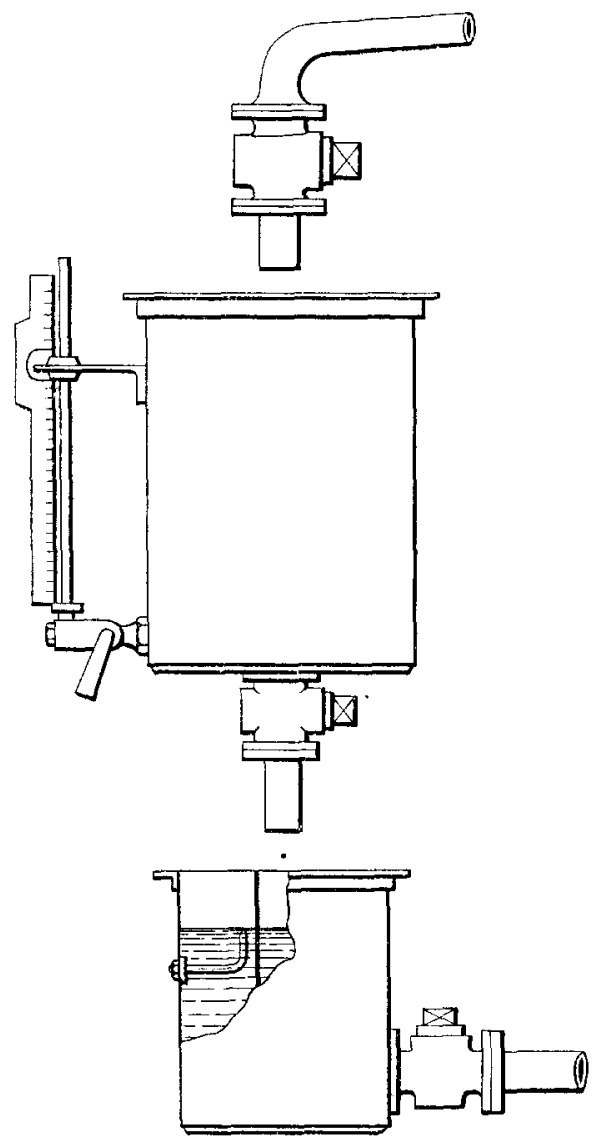

(4) Where cost is a consideration a single tank like those in Figs. 5 or 6 can be used. In this case there must be

1 As it is not easy to read the level within less than $\frac{1}{8}$ inch in the time available, and as the error may oceur in opposite senses when reading the upper and lower levels, the tanks should be deep enongh to allow the surface of the water to fall at least $100 \times \frac{1}{4}$ inch $=25$ inches, in order to limit the error in measurement to 1 per cent. The deeper the tank and the smaller the area of the water surface the more accurate the measurement.

[THE INST. C.E. VOL. CXCV.] 
sufficient room above the datum level in the feed-tank to contain more than half the volume in the measuring tank, and the filling and emptying cocks of the latter must each be large enough to fill or empty it in 3 minutes less than half the time it takes to feed the boiler with a tankful. (See note $\left(^{1}\right.$ ) on p. 304.)

No. 4.-Calibration of Measuring Tanis.

As tanks with flat sides may be flexible, cylindrical tanks should, if possible, be used for the purpose of measurement.

The measuring tanks should be carefully calibrated by pouring successive weighed quantities of water into them, and marking the height reached at each successive addition on the scale of the gauge-class or the float respectively. The water should be at the temperature which will be used during the trial. ${ }^{1}$

The distances between the marks obtained as described should be plotted full size, and a curve drawn from which intermediate divisions of the scale can be measured.

\section{No. 5.-FeEd-TANK.}

(1) For stationary trials the size of this tank is immaterial, but so long as the fixed point-gange, if fitted, can be easily seen greater accuracy will result if its horizontal section is of moderate dimensions. As the water-level is always at the same height when taking a reading, the flexibility of its sides is not so important as in the case of the measuring tanks, but they should be as rigid as is practicable.

A very convenient plan is to fit a float bearing a light rod, which noves an index ${ }^{2}$ freely up and down a scale, a contact piece being arranged so that when the index reaches the height corresponding to the datum level an electric circuit is completed and a bell rings. A switeh should be provided for switching off the current when not wanted. (Whether a point-gange or a float is used it must be protected from splashing in order to get accurate readings.) If, for any reason, it is not convenient to use a fixed point-gauge or a float in the feed-tank, a movable hook-

1 If colder water is used for calibration an error will occur in favour of the boiler, unless a correction is made for the expansion of water when leated.

2 See note on p. 301. 
gange may be used instead, as shown in Fig. 7. In this case the height of the water will vary, and must be recorded at each reading. Allowance must therefore be made for the volume of the feed-tank represented by the difference of level at two successive readings when calculating the water fed to the boiler during the corresponding interval of time. The feedtank in this case must be calibrated with water at the temperature of the feed; but, owing to the varying pressures on the sides of the feed-tank, any flexibility will be liable to cause error when using this method.

(2) In trials at sea there is sometimes a difficulty in reading the level in a feed-tank. The effect of rolling may be minimized by fixing the pointgauge at the centre of the water-surface, but the area of the latter should be kept as small as is conFig. 7.

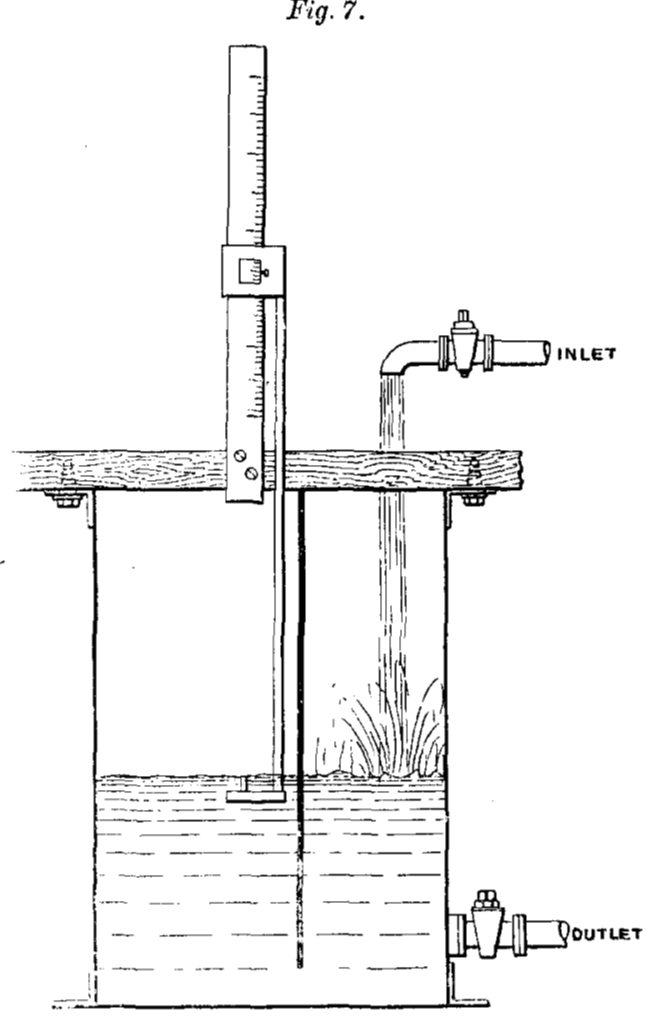
sistent with seeing the gauge. If the whole contents of the tank do not exceed a 3-minutes' supply, the level, when taking a reading, may be approximate only, without serious error resulting, as far greater errors are sure to occur in reading the boiler-level. The edge of the feed-tank should be flanged inwards and downwards to prevent loss of water by splashing over. 


\section{No. 6.-Fen-Meters.}

Feed-meters are not recommended for scientific trials, but as some makes appear to be capable of giving results within 1 per cent. of accuracy they may be usefully employed in many cases when it is desired to obtain an approximate idea of the normal performance of the boilers; they should, however, be calibrated before and after the trial with water at the temperature of the feed.

A Venturi meter, for instance, or a notch-gauge, may be used for the continuous measurement of water when the quantity is large and the flow is fairly steady, as giving fairly accurate results.

\section{No. 7.-Method of Using the Double Feed-Measuring Tanks.}

(1) Some little time before the commencement of the trial the observer in charge of the feed-measurement should fill up No. 1 measuring tank to the top level, feeding the boiler in the meantime through No. 2 measuring tank and the feed-tank. The feed should if possible be kept on at the rate intended for the trial until the principal observer is nearly ready to sound his whistle as a signal to begin the observations. ${ }^{1}$

(2) As the time for starting approaches, the level of the water in the boiler gauge-glass should be marked and recorded.

(a) If a fixed point-gauge is used in the feed-tank the waterlevel in this tank should be adjusted to a height just above the datum level. After the whistle has sounded, the outlets from both measuring tanks should be shut and the fall of the water in the feed-tank watched. The time at which the datum level is reached should be recorded as the commencement of watermeasurement. The outlet from No. 1 measuring tank and the inlet to No. 2 are then to be opened.

(b) If a float, or movable hook-gauge, is used in the feed-tank the outlet from No. 2 measuring tank should be adjusted to keep the level in the feed-tank as nearly stationary as possible. After the whistle has sounded, the position of the water-level in this tank is to be recorded, the outlet No. 2 tank closed and that from No. 1 measuring tank opened; the time of doing this being recorded as the commencement of water-measurement.

1 It is necessary to keep the feed on if there is an economizer, to prevent it from getting unduly hot. 
(3) While No. 1 tank is being emptied No. 2 should be filled. As soon as No. 1 is empty its outlet should be shut and that from No. 2 opened. The inlet to No. 1 should then be opened and No. 1 filled up while No. 2 is being emptied, and so on.

(4) The $\log$ of the feed-measurements can best be kept by ontering on it the time of commencing to empty each tank, as shown below :-

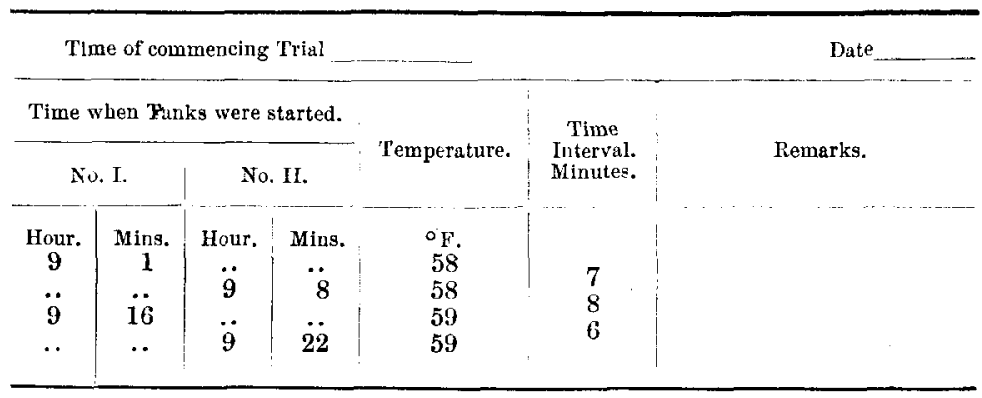

(5) (a) A minute or two before the end of the trial, the surface of the water in the feed-tank should be a little below the datum level. The height of the water in the boiler gauge-glass should then be recorded (without moving the thimble or other mark), and after the whistle has sounded, the feed-pump should be stopped, the time noted as that of ending the water-measurements, and the feed-tank allowed to fill to datum level. The outlet from the feed-measuring tank in use, say No. 2, is then to be shut, that from No. 1 opened and the pump re-started, but No. 2 tank is not to be re-filled until the quantity of water remaining in it has been recorded. The difference between this and the contents of the tank when full is to be logged as having been pumped into the boiler during the trial. If a fixed point-gange is used no account is to be taken of the water in the feed-tank, as its volume is the same as at the beginning of the trial.

(b) The same procedure is recommended when a float or moveable hook-gauge is used, the water-level in the feed-tank being brought to its original height; but, if preferred, its new height may be read off without restoring the original level and the lifference allowed for by means of a calibrated scale. 
No. 8.-Tntermemiate Readings of Feed-Water Supply.

When it is desired to take a reading during the progress of the trial the same procedure should be adopted as when ending it, except that, instead of opening the outlet from No. 1 tank when re-starting the purnp (as in Sect. 7), the outlet from No. 2 measuring tank, which has been partly emptied, is to be re-opened as soon as the contents of this tank and that of the feed-tank, if the original level is not restored, have been noted.

No. 9.--Heat contained in the Boller-Water and Boller.

Strictly speaking, any variation in the total heat of the boiler with its contents should be taken account of when calculating the heat transmitted through the heating surface; the difference at the beginning and end of a given interval of time having to be added to or subtracted from the heat measured by the steam produced during the same period of time. Such a calculation can only be made if the distribution of temperature in the boiler is accurately known. It is, however, impossible to do more than guess how much relatively cold water is present in a boiler, so that such a calculation cannot be made for lack of data. On this account it is much more important to have identical and preferably steady conditions as regards feed-supply and evaporation while taking readings ${ }^{1}$ than to alter these conditions for the purpose of regaining the same water-level with which a start was made. It is then usual to assume that those conditions which cannot be measured are also identical.

No. 10.-Scale for correcting Readings of Water Gauge.

In preparing a scale, such as suggested in the footnote on p. 298, account should be taken of the fact that a layer of water of any given depth, as measured by the scale attached to the gauge-glass on the boiler, will be of slightly different superficial area at different temperatures, owing to the expansion of the boiler; and that it will also vary in density, but that its depth will be practically unaltered. The following Table will help to allow for these.

1 See note on p. 273; also Sect. 11 (p. 311). 


\begin{tabular}{|c|c|c|c|c|c|c|}
\hline \multicolumn{2}{|c|}{ Temperature. } & \multirow{2}{*}{$\begin{array}{l}\text { Weight of } \\
\text { Water } \\
\text { Inch deep } \\
\text { per } \\
\text { 100 Square } \\
\text { Fett. } \\
3\end{array}$} & \multirow{2}{*}{$\begin{array}{c}\text { A rea nf a Sheet } \\
\text { of Steel } \\
\text { measuring at } 62^{\text {J }} \\
\text { 1 Square Foot. } \\
4\end{array}$} & \multirow{2}{*}{$\begin{array}{c}\text { Actual Weight } \\
\text { of what was } \\
100 \text { Square leet } \\
\text { of Water at } 62^{\circ} \\
\text { and is \& till } \\
1 \text { Inch deep. } \\
5\end{array}$} & \multicolumn{2}{|c|}{$\begin{array}{l}\text { Pressure. } \\
\text { J,bs. per Square } \\
\text { Incb. }\end{array}$} \\
\hline $\begin{array}{l}{ }^{\circ} \mathrm{C} . \\
1\end{array}$ & $\begin{array}{l}{ }^{\circ} \mathrm{F} . \\
2\end{array}$ & & & & $\begin{array}{c}\text { Gauge. } \\
6\end{array}$ & $\begin{array}{c}\text { Absolute. } \\
7\end{array}$ \\
\hline 162 & 324 & $\begin{array}{l}\text { Lbs. } \\
262\end{array}$ & $\begin{array}{c}\text { Square Foot. } \\
1.00634\end{array}$ & 264 & 80 & 95 \\
\hline 171 & 338 & 276 & $1 \cdot 00668$ & 278 & 100 & 115 \\
\hline 177 & 350 & 288 & $1 \cdot 00698$ & 290 & 120 & 135 \\
\hline 183 & 361 & 299 & $1 \cdot 00723$ & 301 & 140 & 155 \\
\hline 188 & 371 & 309 & $1 \cdot 00747$ & 311 & 160 & 175 \\
\hline 193 & 380 & 318 & $1 \cdot 00769$ & 320 & 180 & 195 \\
\hline 198 & 388 & 326 & $1 \cdot 00789$ & 329 & 200 & 215 \\
\hline
\end{tabular}

It will be noticed that the effect of the expansion of the boiler is to make the weight in column 5 about 2 lbs. greater than in column 3 ; an amount searcely worth considering.

Example.-If the surface of a layer of water $\frac{1}{10}$ inch deep has a mean area of $30 \times 6=180$ square feet when cold, what will the same depth at the same part of the gauge-glass scale weigh if at the temperature of $160 \mathrm{lbs}$. steam-pressure by gauge, i.e., $371^{\circ} \mathrm{F}$.?

By the Table the weight will be $311 \mathrm{lbs}$. per 100 square feet of original area if 1 inch deep. The actual weight, therefore, will be $1 \cdot 8 \times \frac{311}{10}=55 \cdot 8 \mathrm{lbs}$.

\section{No. 11.-EConOMIZERs.}

With economizers an approximate estimate of the heat contained in the water can be made by taking into account the mean inlet and outlet temperatures, but this estimate is misleading if the feed is irregular or if it is temporarily stopped. In the latter case it may even happen that steam is generated in the economizer. This further emphasizes the fact that a steady duty is one of the essential conditions of a good boiler trial.

\section{No. 12.-SUPERHEATERs.}

A superheater, if fitted, usually forms an integral part of the boiler to which it is attached. As it abstracts part of the heat from the flue gases before these give up the remainder to the boiler it is necessary in estimating the performance of a boiler to allow for the heat which is represented by the superbeat. 


\section{No. 13.-Speciric Heat of Superheated Steam.}

Experiments have for some years past been carried out with the object of ascertaining the amount of heat that is represented by various degrees of superheat, hut definite results have not yet been obtained.

As far as our present knowledge extends the value 0.48 may be adopted for the purposes of this report. Every $100^{\circ} \mathrm{F}$. superheat then represents about 4 per cent. of the total heat of the steam, and an error of 0.01 in the value of this specific heat would not affect the results of the calculations by more than 0.1 per cent. ${ }^{1}$

\section{No. 14.- Leakages.}

Leakages may become a source of very serious error in boiler trials, and for this reason all connecting-pipes should be blanked off or exposed to view, so that leakages can be detected and remedied. The quantity of water which will escape out of a hole having a sectional area of $\frac{1}{100}$ square inch, or, say, a series of slits each $1,1,00$ inch open and having a total length of 10 inches, will be about 1,500 lbs. per hour if the boiler pressure is $150 \mathrm{lbs}$. per square inch. Such a leakage has to be made good by the feedpump, and would introduce an error of from 10 to 20 per cent., according to the rate of evaporation. There is always a risk of a certain amount of leakage from the boiler-shell taking place in parts where it cannot be seen. The best safeguard is to submit the boiler to a most careful flue-inspection both before and after the tests, but the leakage may be determined approximately in the following manner.

After the trial is over, and when the level of the water-gange has become tranquil, all openings from the boiler should be blank flanged if possible, or otherwise securely closed. The pressure should then be maintuined by small additional firing and careful regulation of the draught for, say, 4 hours, and the drop in the water-level in the gauge-glass noted. The volume of hot water corresponding with this drop is then taken as the leakage.

Part of the water which is caught from leaky joints, issuing as it does at a high temperature, will be evaporated before the temperature has dropped to boiling point. The part which remains, therefore, must be multiplied by the factor given in the fourth column of the following Table in order to arrive at the actual quantity which escaped from the boiler.

1 The values given in Marks and Davis's T'ables are generally accepted. A chart giving "mean specific heat" of superheated steam over a wide range of temperatures and pressures will be found in "Principles of Thermodynamies," by G. A. Goodenough. 2nd ed. London, 1912. 
Table giving Allowange to be Made for Every Pound of Hot leakage Water from a Boiler or Steam-Pipe.

\begin{tabular}{|c|c|c|c|c|}
\hline \multirow{2}{*}{$\begin{array}{l}\text { Absolute } \\
\text { Pressures. }\end{array}$} & \multicolumn{2}{|c|}{ Temperatures.1 } & \multirow{3}{*}{$\begin{array}{c}\begin{array}{c}\text { Original } \\
\text { veight } \\
\text { of } 1 \text { lib. of } \\
\text { Collected Water. }\end{array} \\
4\end{array}$} & \multirow{3}{*}{$\begin{array}{l}\text { Equivalent Wates } \\
\text { evaporated } \\
\text { from and at } \\
212^{\circ} \mathrm{F} \text {. } \\
5\end{array}$} \\
\hline & ${ }^{\circ} \mathrm{C}$. & ${ }^{\circ} \mathrm{F}$. & & \\
\hline 1 & 2 & 3 & & \\
\hline $\begin{array}{l}1 \text { bs } \\
14 \cdot 7\end{array}$ & 100 & 212 & $\begin{array}{c}\mathrm{Lb} . \\
1 \cdot 000\end{array}$ & $\begin{array}{c}\text { L.b. } \\
0 \cdot 189\end{array}$ \\
\hline $17 \cdot 7$ & 105 & 221 & $1 \cdot 010$ & $0 \cdot 200$ \\
\hline $20 \cdot 8$ & 110 & 230 & $1 \cdot 020$ & $0 \cdot 212$ \\
\hline $24 \cdot 8$ & 115 & 239 & $1 \cdot 030$ & $0 \cdot 224$ \\
\hline $28 \cdot 8$ & 120 & 248 & $1 \cdot 040$ & $0 \cdot 237$ \\
\hline $33 \cdot 9$ & 125 & 257 & $1 \cdot 051$ & $0 \cdot 249$ \\
\hline $30 \cdot 0$ & 130 & 266 & $1 \cdot 062$ & $0 \cdot 262$ \\
\hline $45 \cdot 1$ & 13. & 275 & 1.073 & $0 \cdot 276$ \\
\hline $52 \cdot 1$ & 140 & $28 \pm$ & $1 \cdot 085$ & 0.290 \\
\hline $60 \cdot 5$ & 145 & 293 & $1 \cdot 097$ & $0 \cdot 304$ \\
\hline $69 \cdot 0$ & 150 & 302 & $1 \cdot 109$ & 0.318 \\
\hline $79 \cdot 4$ & 155 & 311 & $1 \cdot 121$ & 0.332 \\
\hline $89 \cdot 9$ & 160 & 320 & $1 \cdot 131$ & $0 \cdot 348$ \\
\hline $102 \cdot 3$ & 165 & 329 & $1 \cdot 147$ & $0 \cdot 364$ \\
\hline $111 \cdot 7$ & 170 & 338 & $1 \cdot 161$ & $0 \cdot 380$ \\
\hline $129 \cdot 7$ & 175 & 347 & $1 \cdot 175$ & 0.396 \\
\hline $14 \frac{1}{2} \cdot 8$ & 180 & 356 & $1 \cdot 189$ & $0 \cdot 413$ \\
\hline $163 \cdot 1$ & 185 & 365 & $1 \cdot 20 t$ & 0.431 \\
\hline $181 \cdot 7$ & 190 & 374 & $1 \cdot 219$ & $0 \cdot 449$ \\
\hline
\end{tabular}

Water from other Boilers.-If the steam-pipe is common to several boilers great care must be taken to exclude any water coming. from them, whether due to priming or to condensation. It is best to disconnect the boiler from the main and to fit a temporary brauch to one of the boiler-valves, and to let the steam escape through it if it cannot be used to drive an engine. The safetyvalves should not be used for this purpose as they are likely to discharge irregularly and to cause fluctuation in the steampressure.

1 As the temperature of the water inside a boiler is seldom uniformly that of the stean, this Table will in such cases somewhat exaggerate the amount lost by evaporation, unless the actual temperature of the water near the leak is known. 
No. 15.-Measuring the Motsture in Steam.

Up to a certain limit, depending on the steam velocity, the moisture can be measured by one of the forms of calorimeter in the market; these instruments are not generally reliable when the moisture exceeds about 2 per cent., as it then appears to creep along the walls of the pipes and does not all enter the calorimeter. It is therefore desirable to provide the steam-pipe with a steam-drier, and to measure the quantity of water which is discharged by an automatic trap; and also to measure the moisture of the steam after it has passed the steam-drier. Opinions differ as to whether it is best to collect the steam by a perforated tube fixed. across the diameter of the steam-pipe or by a tube arranged to collect from the centre only of the steam-pipe, but the former method is in more general favour.

\section{No. 16.-Absorption of Heat by Brickwork.}

The heat capacity of brickwork is about one half of that of water, or, say, 30 B.Th.U. per eubic foot for every $1^{\circ} \mathrm{F}$. increase of temperature, and as the furnace brickwork may attain a temperature of, say, $2,000^{\circ}$ or $3,000^{\circ} \mathrm{F}$., whereas the temperature of the boiler water rarely exceeds $350^{\circ} \mathrm{F}$., it is evident that the total quantity of heat which the heavy furnace brickwork of some modern water-tube boilers can hold may be equal to that produced by a few hours' full power firing. A trial which is begun suddenly while the brickwork is relatively cold must therefore show a lower efficiency than the real one, whereas a trial in which the firing is proceeded with at a lower rate than during the preliminary warming up will show a higher efficiency than the real one.

In order to secure the desired steady temperature a boiler must be worked under trial conditions for a certain period before the trial commences. Owing to the great mass of brickwork and the conductivity of the surrounding ground, boilers of the Lancashire or similar types require an additional period of working at ordinary rates. The following Table indicates approximately the usual periods; which may, however, be modified by local conditions. 


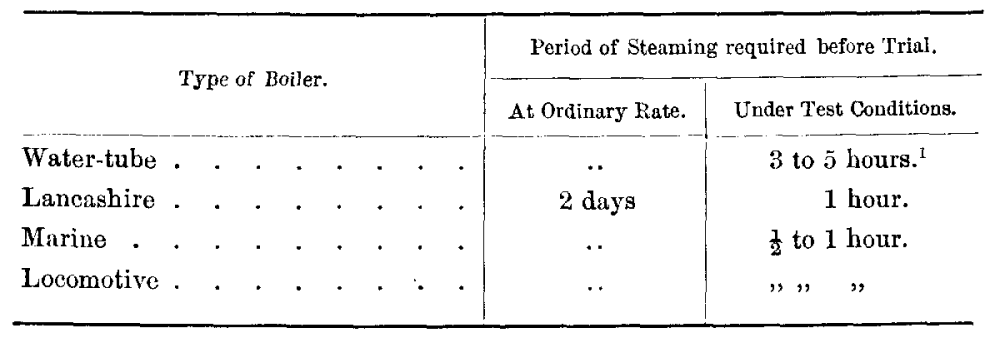

No. 17.-Radition Losses.

To determine the losses from radiation, the flues, ash-pits and firedoors should be closed and, if necessary, luted to prevent any cold air passing through the boiler or flues, and the drop in pressure should be determined at intervals for a period of, say, 3 to 6 hours, ${ }^{2}$ the corresponding temperatures being plotted on a time base. A

Fig. 8.

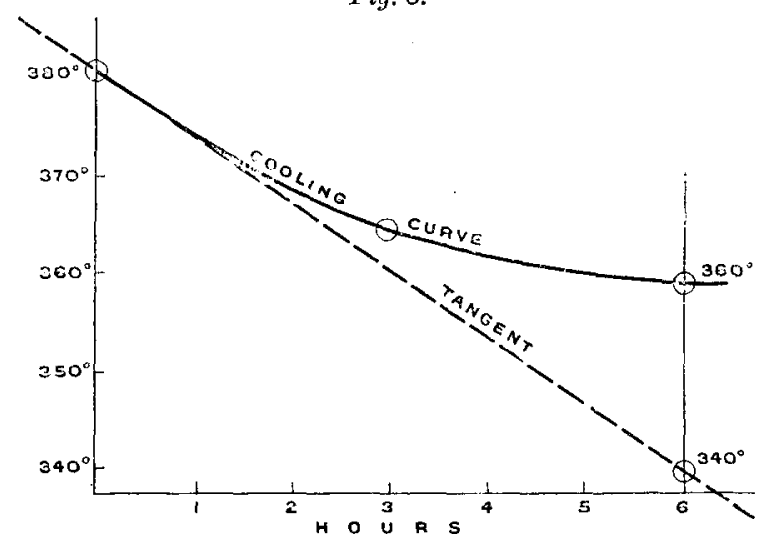

langent to the hottest end of this cooling curve will give the rate at which the temperature falls. Thus, in Fig. 8 it falls at the rate of $\frac{380-3 \pm 0}{6}=6 \cdot 6^{\circ}$ F. per hour. The heat losses in B.Th.U. per hour due to this fall of temperature are calculated on the weight and specific heat of the boiler-shell and fittings, together with those of the water and steam contained therein.

1 Water and coal consumption curves should be carefully plotted while steaming under test conditions, and the trial may commence when it is seen that the efficiency has become steady.

2 It is not necessary to continue the radiation trial for a longer period than is sufficient to determine the inclination of the tangent. 
It will be found in a well-set Lancashire boiler, working at about $180 \mathrm{lbs}$. gauge-pressure, that with the dampers closed, firedoors and flues shut, the drop in pressure will not ke more than 15 per cent. in 6 hours, the temperature falling from, say, $380^{\circ}$ to $360^{\circ}$ (Fig. 8); but this is not a measure of the rate of heat-loss at the working temperature.

With regard to the heat contained in the flues, which deliver it up slowly, there is no definite means of measurement. It may be assumed that the lining of the flue for a depth of 6 inches has acquired the temperature of the gases flowing through; the drop in temperature during the period of observation can be ascertained, but the extent to which the heat radiates outward through the building walls or is conducted away by the ground is not measurable.

\section{No. 18.-Loss of Heat from Steam-Pipes.}

An accurate measurement of the steam condensed in the steampipes is generally impossible, as steam driers are never placed near the steam boiler and also because a proportion of it, in many cases a very large proportion, is carried forward to the engine. In most cases drain-pipes are arranged only to carry away water formed while there is no current in the pipes, and are almost useless when the engine is running, as the globules of water are then moving with sufficient velocity to jump the openings into them. Even where special arrangements of separation and well-pipes exist it is certain that all the water is not extracted from the steam. ${ }^{1}$

The performance of a boiler should not be mixed up with piperadiation losses, and, in addition to measuring the condensation so far as possible, a rough check may be obtained by calculation of the heat lost by radiation from steam-pipes. It amounts to from 4 to 5 B.Th.U. per square foot of bare cast-iron surface per hour per $1^{\circ} \mathrm{F}$. difference of temperature between steam and atmosphere. In windy weather the loss may amount to from 6 to 7 B.Th.U. For covered pipes the allowance is much less. One inch thickness of covering reduces the loss to about 1 B.Th.U., and, with very high-class coverings, this loss is probably reduced to $\frac{2}{3}$ or $\frac{1}{2} \mathrm{~B}$.Th.U. per square foot.

Such water as is discharged should be caught and measured, but as it generally arrives at the outlet at a temperature above $212^{\circ} \mathrm{F}$., allowance should be made for the evaporation which takes place while the water cools to $212^{\circ}$; this may be done by

1 See Proc. Inst. Mech. E., 1905, p. 311, for the results of a test of such special well-pipes. 
means of the Table on p. 313. A better plan is to pass the discharge through a worm immersed in cold water or some similar device, but a near approach to accuracy can be obtained by using a deep vessel, so that the evaporation-surface shall be as small as possible, arranging the discharge-pipe to deliver under the water (a known weight of water sufficient to cover the end of the pipe should be put into the vessel) and using a little oil to make an oil-film, and thus diminish evaporation.

No. 19.-Fluctuations of Water-Level, etc.

The weight of water corresponding with a difference of level of each $\frac{1}{10}$ inch in the boiler gauge-glass should be determined before the trial begins in order that the corrections to the feed-measurements may be plotted as the trial proceeds. (See footnote on

Fig. 9.

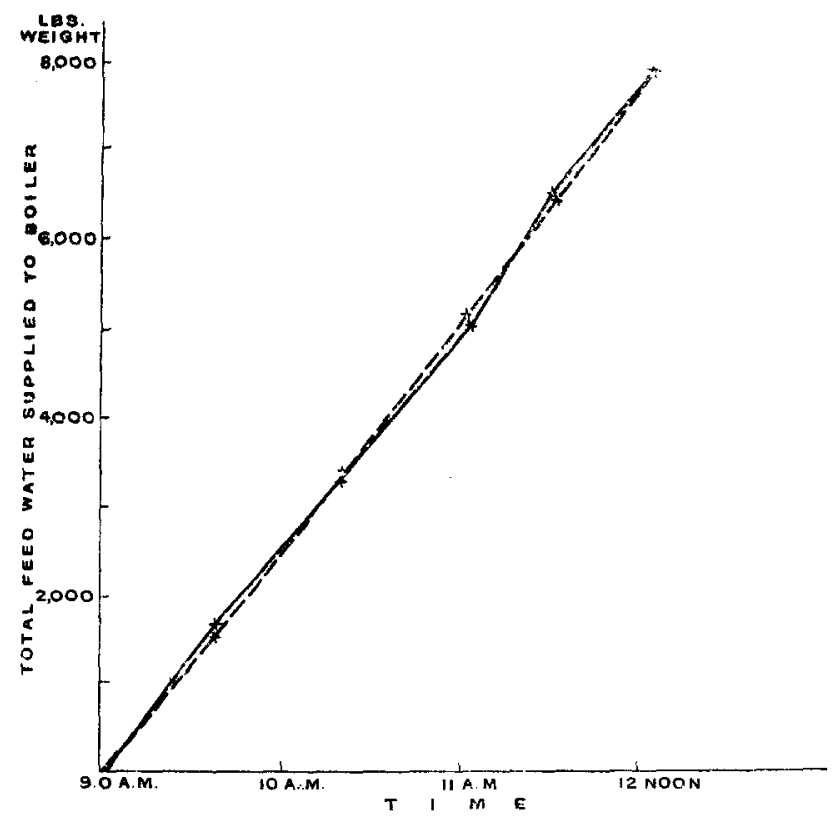

p. 298.) In Fig. 9 the full line shows the rate at which the feed was pumped into the boiler, and the dotted line the rate corrected for difference of level in the boiler, or the rate of water-evaporation. If the water-measurement is commenced, as it should be, within a minute or two after that of the coal 
trial, this difference of time may be neglected without measurable error when plotting the coal- and water-curves. If, however, it is desired to make a correction in the case of a longer interval between the beginning of coal- and water-measurement, it may be done by plotting the water-curve A B (Fig. 10) on a time base $\mathrm{B} \mathrm{C}$; producing the mean water line $\mathrm{AB}$ to cut a vertical $\mathrm{D} E$

Fig. 10.

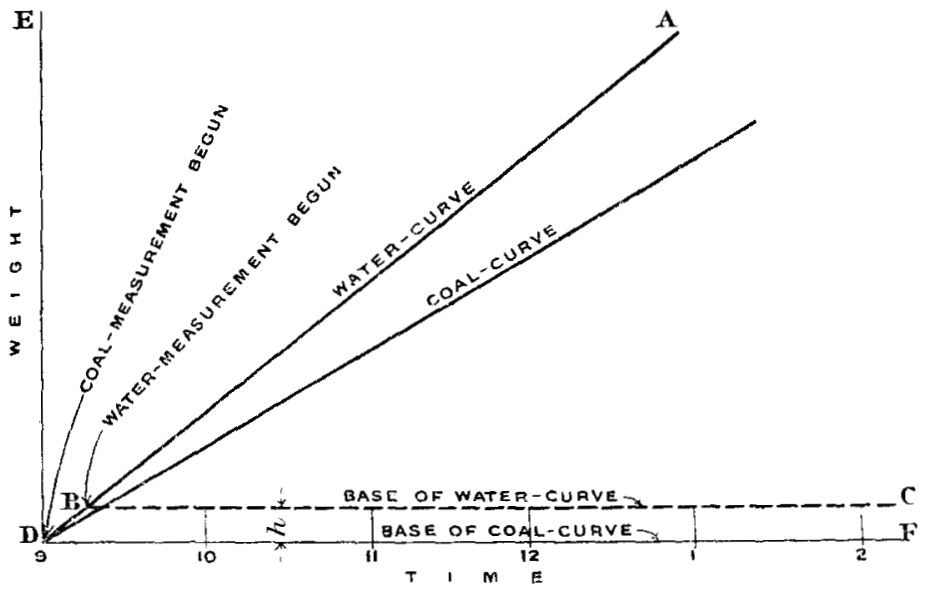

representing the time of the commencing of the coal trial at D, and drawing a horizontal line D F forming the base of the coalcurve. If preferred, the quantity $h$ may be added to the quantity of water corresponding with each reading of the water gauge-glass, and both coal and water may be plotted on the same base; $h$ will generally, however, be found to be too small to be worth considering.

\section{No. 20.--Variations in a Coal-Consumption Curve.}

The weight of each charge of fuel should be plotted, not at the time when it was thrown on to the fire, but when the first shovelful of the following charge was thrown on, the assumption being that the charge was completely burnt, not at the time when it was put on, but at the time when more coal is required to maintain the regular rate of evaporation. In a trial perfectly conducted with constant conditions, the plotted coal line should pass through the origin as shown in the diagram (Fig. 11). If it falls above the origin, this indicates that there was too little unburnt coal on 
the grate at the beginning of the trial, and the amount is given by the intercept " $(-)$ " on the vertical line, while if it falls

Fig. 11.

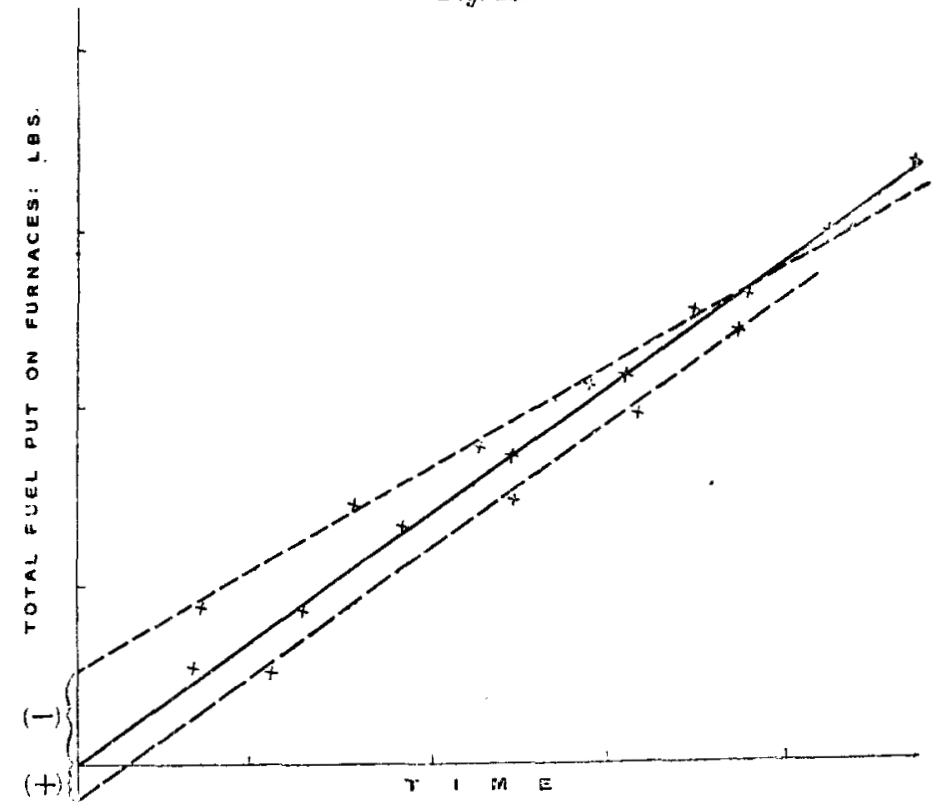

below, as shown by the lower dotted line, it shows that there was too much coal upon the grate, so that further stoking was not

Fig. 12.

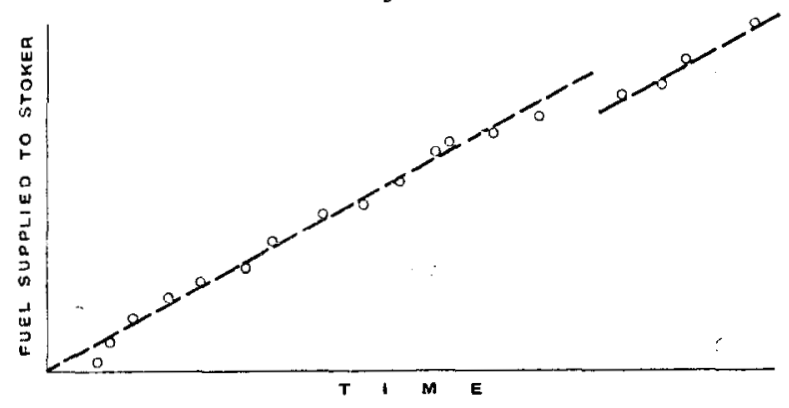

required so soon as it should have been, the excess being measured by the intercept " $(+) . "$

Fig. 12 shows a break in the coal line at the time of cleaning 
the fires. If the object of the trial is to ascertain, for scientific purposes, the rate of evaporation for a constant rate of coalconsumption, the interval between each period of cleaning should be treated as a separate trial (p. 276), and the average inclination of the lines representing the rate of coal-consumption during these intervals compared with the rate of evaporation, which will not usually show such marked variation. As these intervals are inevitable in actual service, for practical purposes the process of cleaning fires, stoppage for dinner-hour, etc., has to be recorded.

Fo. 21.- Sampling, Calorific Value and Analysis of Coal.

If the efficiency of a boiler is to be determined, it is of primary importance to have an accurate knowledge of the net calorific value of the fuel used, as the whole of the calculations are based on this. Even for comparative trials, where the determination of efficiency is not the primary object, the knowledge of the calorific value, or of its constancy, is essential. Very large errors may be introduced by assuming that the coal from the same truck, bunker, or barge is the same on two tests even when made consecutively. Coal must be treated as an essentially non-uniform substance. Apart from lumps of slate, pyrites and other obvious non-coal substances, if an apparently homogeneous coal is screened, the portion passing through the screen will always be found to have a higher ash, and hence a lower calorific value, than the larger lumps. During transit the finer portions of the coal tend to settle to the bottom, and hence in two consecutive trials from a heap, bunker, or truck there is a tendency for the coal used on the second trial to have a lower calorific value, and the difference may amount to over 10 per cent.

The determination of the gross calorific value of the fuel should be made by an experienced observer in a compressed oxygen bomb calorimeter, ${ }^{1}$ and when so made the calorific value of a sample can be determined with an error not exceeding 0.3 per cent. The sample should also be analysed, and the percentages of carbon, hydrogen, nitrogen, sulphur, ash, etc., determined, as well as the moisture it contains. This will enable the net calorific value to be obtained. The whole accuracy of the trial depends on the degree to which the sample represents the bulk of the fuel used on the trial, and it must be emphasized that the sampling demands more care than is usually taken.

Large Coal.-With large Welsh or other coal of high quality

1 For a definition of the "gross and net calorific values" see p. 338. 
the sampling may be done by taking a half shovelful from the heap at the time of weighing each lot, after breaking the coal and taking both small and large. The samples so taken should be placed in a covered box placed where it is not exposed to heat; at the end of the trial the sample should be broken up and quartered as described later, and the residual lot put into an air-tight box. The sample collected during the trial should not be less than 2 per cent. of the total coal burnt, and may with advantage be double this proportion.

For large nuts and mixed large and small coal of good quality, the same procedure as for large coal should be adopted; for inferior coal the size of the bulk sample should be increased. If the coal is very wet the procedure for washed coal should be adopted.

Washed Small Cocl.-For washed small coal (small nuts, beans, peas, etc.), while the ash distribution may be expected to be less irregular than in high quality steam coal, yet the amount of moisture may be very irregular, even in the same bunker, and there is a risk that some will be lost if the operation of sampling is unduly prolonged. A scoopful should be collected and stored as before in a tared covercd receptacle as each lot is weighed, the close covering of the stored sample being here of special importance, about $200 \mathrm{lbs}$. being collected in all. After the trial is over the sample should be then spread out on a tared metal tray and accurately weighed. If water or coal is seen to be adhering to the bin this is also weighed in along with the rest. The difference between the total weight and the sum of the weights of the dry tray and bin gives the weight of the moist coal. The tray is then left in a warm covered place at a temperature not exceeding $120^{\circ} \mathrm{F}$. for, say, 48 hours, when it should be again weighed and the loss of moisture noted. If the coal is thoroughly "air-dried," no change of weight in either direction. should be noted after leaving for another hour. This air-dried coal is now in moisture equilibrium with the atmosphere, and may be safely reduced to a smaller sample without gain or loss of moisture. If the reduction is made without this preliminary drying, muisture will be lost during the quartering, and the measured calorific value will be too high. If the air-drying on the spot is impossible, the whole sample of not less than 100 lbs. should be packed in an air-tight box.

Unwashed Small Coal.-Unwashed small coal should be sampled in the same way as washed small coal, omitting the air-drying; if it contains much moisture, however, it must bo treated as washed coal.

[THE INST. C.E. VoL. CXev.] 
Quartering.-The operation of quartering is as follows:-

Break up the coal on a metal plate so that no piece is larger than 2-inch cube; mix well and pile in a conical heap, each lot being added on the apex of the cone already formed, so that it may distribute itself by falling evenly in all directions. Flatten the cone, draw two diameters at right angles, and reject opposite quadrants. The half thus obtained is broken up further, so that the average size is not more than one-half that of the first heap. Mix, pile in a cone, and halve as before. Repeat this operation, taking care to reduce the average size of the pieces each time until about 3 per cent. of the original sample is obtained, e.g. $6 \mathrm{lbs}$. if starting with $200 \mathrm{lbs}$, and place in an air-tight bottle or tin. These operations may with advantage be replaced by the use of a mechanical crusher and sampler (if available).

It is important that all crushing and quartering be done on an iron (or metal) plate. Crushing on a cement or brick floor or on earth leads to serious contamination of the sample. If the coal has been air-dried, as directed above, and the crushing, etc., is carried out in the same atmosphere as the weighings and out of reach of direct radiation from a furnace, the coal will neither lose nor gain moisture during the operations.

The label should give the date, particulars of the coal (if known), weight of the original sample before quartering, and of the total weight of coal it is intended to represent, and the weights of the moist and air-dried coal, if air-drying has been carried out.

The samples so labelled should be sent to an expert chemist for analysis and for determination of the Gross and Net calorific values as already noted.

It should be noted that the "air-dried" coal may still contain considerable proportions of water, and cannot be treated as "dry" coal.

Coke, breeze, or other similar fuels should be treated as washed coals.

It is always preferable in working down the fuel to arrange for tto independent samples from the bulk.

No. 22.--Reliability of Coal Samples.

A number of experiments were made for the purposes of this Report by taking samples from various parts of large brilks of coal and ascertaining the deviation from the man calorific value of the bulk in each case as determined after quartoring, otc., had been carried out as described. Two independent liboratory samples 
of about 10 grammes were also taken for each coal; the ash and moisture determination on each of these were made in duplicate. It was found that the difference between the two laboratory samples never exceeded one-half the errors of the large-scale sampling.

\section{Conclusions.}

(1) For small washed coal, a sample taken with the utmost care by a trained man, and air-dried on a 150- to 200-1b. sample before the final division, will give the gross calorific value within $0 \cdot 5$ per cent.

(2) Samples taken in the ordinary way by a man not specially trained, air-dried in bulk as before, cannot be relied upon to give the gross calorific value within 2 per cent.

(3) If the preliminary air-drying on a large scale be omitted and the 5- or 10-lb. sample be taken straight from the bulk, as is usual, the gross calorific value of washed coal cannot be regarded as certainly nearer than 4 to 5 per cent.

No. 23.--Sampling of Liquid Fuel.

A sample should be taken at regular intervals, or, better, continuously, throughout the trial from the supply-pipe leading to the burners, or from the tank at the same level as the supplypipe. The contents of the can are well mixed and a 5-oz. sample is taken from the larger one. Considerable difficulty sometimes arises owing to the presence of water in certain fuel oils. This may be present in very small globules as a sort of emulsion, in which case no special precautions, except thorough stirring, are necessary. Occasionally bubbles of water of considerable size are present, and these tend to sink, ultimately forming a layer of water at the bottom of the tank. An accurate average sample of such oils cannot be taken.

No. 24.-Sampling of Gas.

The calorific value may be taken continuously by a flow calorimeter (Junker, Simmance-Abady, Boys) where such an instrument is available. In the absence of such an instrument samples should be taken as described under flue-gas sampling, and the calorific value deduced from the results of analysis.

No. 25.-Sampling the Ashes and Determination of Combustible Matter therein.

After drying and weighing, the whole of the ashes and clinker collected, as previously explained, should be thrown into a 
heap and well turned over to mix them thoroughly. The large pieces should then be broken up, and the heap quartered, and this process of breaking up and quartering should be continued upon the lines described for sampling the coal, until $3 \mathrm{lbs}$. or $4 \mathrm{lbs}$. are left. This sample should then be placed in a dry air-tight vessel and sent to an expert chemist for determination of the percentage of combustible matter.

It shonld be pointed out, however, that if a chemical analysis of the fuel has been made, it is possible to determine the quantity of combustible matter mixed with the ashes by simply deducting the weight of ash corresponding with the fuel fired, as given by the fuel analysis, from the weight of the material drawn from the furnaces and ash-pits.

In estimating the weight of the ash and clinker it must not be forgotten that some portion is always carried over the bridge by the draught. When the draught is strong, particularly when sprinkling stokers are in use, this proportion may be considerable, insomuch that the total weight of material drawn from the furnaces and ash-pits may weigh less than the total ash contained in the fuel as determined from the chemical analysis. ${ }^{\text {I }}$

\section{No. 26.-Period Between Cleaning Grates of Furnaces.}

The period between cleanings of fire-grates depends upon the rate at which the air-spaces between the bars become choked with clinker.

At high rates of combustion (say, ovor 22 lbs. of coal per square foot of grate per hour), cleaning has to be carried out at intervals varying inversely with the rate of combustion per square foot of grate, the exact period depending on the quality of the fuel.

At lower rates the interval between cleanings does not increase so rapidly as the rate of combustion diminishes. Fig. 13 represents approximately the average Admiralty practice in this respect, and may be taken as indicating the effect which may bo expected. if, after the necessary frequency of cleanings has been ascertained at one rate of firing, it is decided to make further trials at other rates of combustion.

1 This is particularly noticeable in the case of locomotives. See, for instance, F. H. Trevithick and P. J. Cowan, "Some Effects of Superheating and FeedWater Heating in Locomotive Working." Proe. Inst. Meeh. E., 1913, p. 350, Fig. 6 . 
Fig. 13.

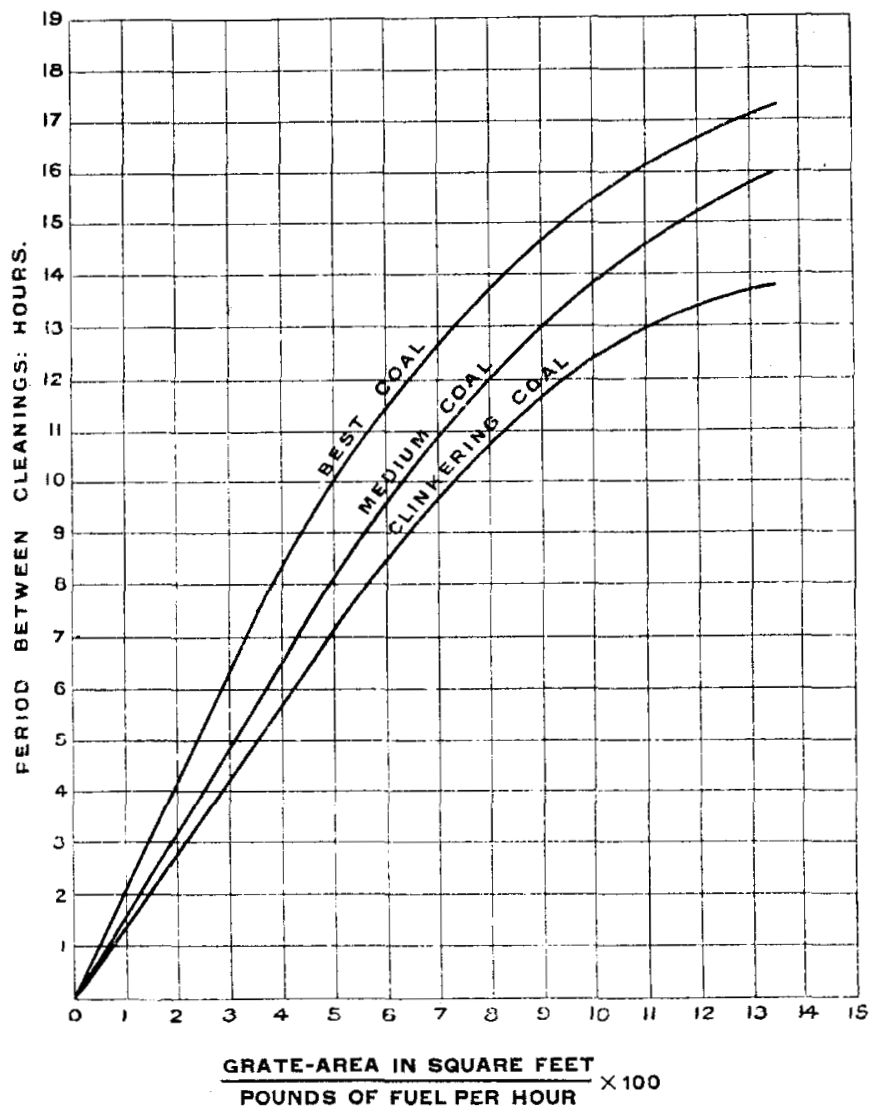

No. 27.-Measurement of Pressure or Vacuum in the Ash-pit, Chimney Draught, etc.

The usual $\mathrm{U}$-gauge is too well known to engineers to need any description, but it may be pointed out that when used with the two limbs vertical the readings are usually so small as to be difficult to observe accurately. The readings may be considerably magnified, and the proportion of the meniscus error much reduced, by inclining the gauge.

Mr. Macfarlane Gray designed ${ }^{1}$ a very convenient gauge, in

1 Minutes of Proceedings Inst. C.E., vol. exlvii, p. 235. 
which the readings are magnified by the use of two liquids of different specific gravities combined with a special form of U-tube.

Considerable inaccuracy may result from injudicious arrangement of the end of the manometer tube which is exposed to moving gases, the pressure of which it is desired to measure. If these blow across a projecting end of this tube the pressure registered will be too low, while if any eddying takes place, so that the local currents flow towards the end, the pressure registered will be too high. This may be avoided by placing a sandwich on the end of the tube, consisting of several layers of wire gauze $3 \frac{1}{2}$ inches in diameter between two thin steel plates $2 \frac{1}{2}$ inches diameter, the tube being continued to the centre of this sandwich. With such a shield it has been found that moving currents do not affect the reading of the gauge.

\section{No. 28.-Measurement of Temperature.}

(a) General Remarks.

In general the thermometers used should be chemical thermometers, made of hard glass, and it is of importance that they should be checked from time to time, since most thermometers, especially if used for measuring high temperatures, change their zero points gradually. It is not necessary to bave thermometers constantly checked at a public laboratory; it will be sufficient to test them in melting ice and in steam at atmospheric pressure. For most engineering purposes the graduation of an ordinary thermometer is sufficiently accurate, provided that any error in the zero point is added to or subtracted from the readings.

The only engineering measurements of temperature which may require exceptional accuracy are those needed to determine the rise of temperature in the water discharged from the condenser, which, under some circumstances, may be very small ; in this case the thermometers used must be very carefully compared, or, better still, a differential method should be adopted.

It is not advisable to use expensive thermometers, owing to the great risk of breakage, but to use moderately good thermometers, comparing them before and after the test with a standard instrument. It is important, however, to use sensitive thermometers when measuring varying temperatures, otherwise the lag in the movement of the mercury may cause serious errors. Spirit is not a suitable fluid as it takes too long to acquire a uniform temperature. 


\section{(b) Air- and Water-Temperatures.}

Air-Temperature.-This calls for no special remarks beyond those in the general hints given above.

Water-Temperature.-This temperature, unless the supply is taken from the mains or other source at a steady temperature, should be measured every time a tank or measuring vessel is filled, care being taken that the water is thoroughly mixed and that the thermometer is read while inserted to a proper depth. If it is not possible to read the thermometer under these conditions a small quantity of water should be drawn off or dipped out, and the temperature of this taken. Even with an ordinary thermometer it is not accurate enough to read the thermometer after it has been taken out of the water; the reading must be taken while the instrument is in the cup or tank.

In some cases, especially when the Fig. 14.

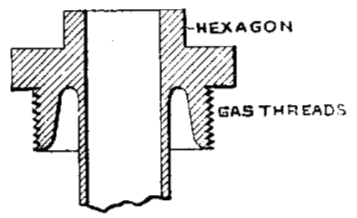
feed-water is measured through a meter, or is passed under pressure through a feed-heater, and also in the case of water returned to the boiler from jackets, reheater, etc., the temperature of the water cannot be directly measured. In this case it is necessary to drill a hole in the pipe and to screw in a cup into which the thermometer is inserted.

The cup should be made as long and with walls as thin as possible-a good form being shown in Fig. 14; it should be made of steel and filled with mercury, into which the bulb of the thermometer is dipped. ${ }^{1}$

\section{(c) Steam-Temperatures.}

These can be measured either by plunging a mercurial thermometer into a mercury cup screwed into the steam-pipe, or by an electrical method.

Mercury Cup.-If this method is used, great care must be taken to avoid the effects of conduction and radiation, for if the mercury

1 The space under the screw-threads in this Figure is usually left solid, but if the tube is short, underentting, as shown, will reduce the liability to error from the costuction of heat to or from the metal into which it is acrewed. 
cup is provided with a large solid head, the effects of the radiation from this may render the readings of the thermometer quite unreliable. The mercury cup must also be of considerable length so as to project well into the pipe, and the stem of the thermometer should be immersed far enough to cover most of the mercury column.

Hard glass thermometers, with the space behind the merculy filled with nitrogen or otber gas which does not affect tho mercury, may be used for taking the temperature of high-pressure or superheated steam, and caro must be taken to correct for change of zero.

Electrical Metluds.-Electrical thermometers, based either on the resistance or the thermo-electric couple method, can be used for taking steam temperatures; special instruments are now made for this purpose.

\section{(d) Flue-Temperatures.}

The flue-temperature should be taken as close as possible to the place where the gas samples are drawn off. It is in many cases difficult to obtain the average temperature, and it is therefore advisable to have two or more holes cut in the brickwork, and to ascertain by trial the best position for the thermometer.

Flue-temperatures, below $600^{\circ} \mathrm{F}$, can be measured with considerable accuracy by means of mercurial thermometers; but care must be taken to select thermometers made of Jena or other very hard glass, with the space above the mercury filled with nitrogen, or other gas which does not affect mercury. Unfortunately the most accurate mercurial thermometers are those of small diameter, and, if made long enough to reach the middle of a deep flue, they are extremely delicate and liable to be easily broken. Short thermometers, however, may be used by enclosing them in iron cases which themselves fit into larger cases pushed through holes in the flue-walls or roofs (Figs. 15). The hot iron round the bulb of the thermometer retains its heat long enough to prevent any change in the position of the mercury while the inner tube is withdrawn and the thermometer read, and the outer casing protects the glass from smoke and soot, which would otherwise render the markings illegible.

Thermometers for taking flue temperatures should not be too sensitive, as it is not desirable that they should be affected by every opening of the furnace doors.

The various forms of pyrometers which work by the expansion of two different metals, or by the alteration of the pressure of 
mercury in their bulbs, etc., are most of them uncertain and cannot be relied upon to record accurately for any length of time.

The most accurate and convenient method of obtaining flue temperatures is the electrical one; either the resistance of a platinum spiral is observed, or the electromotive force generated at a thermo-electric junction is measured, and from these observations

Figs. 15.
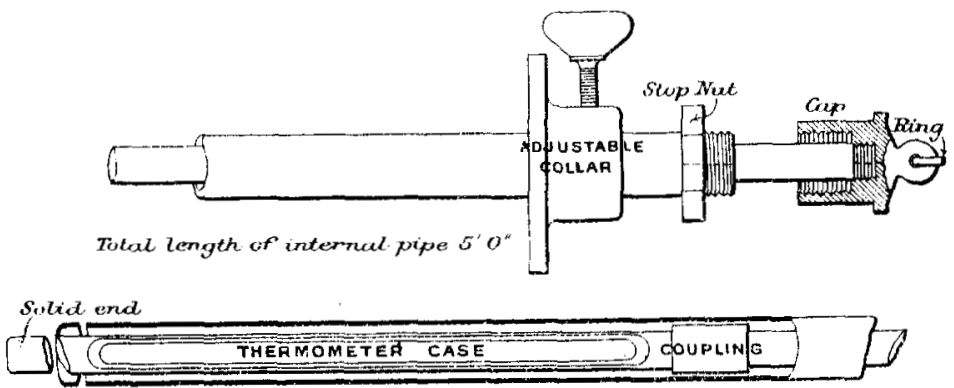

the temperature can be deduced. Instruments of both classes can be obtained, the resistance instrument being made in a form suitable for using in an ordinary boiler-flue. The description of these instruments would be out of place here, but they have been given in the Proceedings of The Institution. ${ }^{1}$

No. 29.-Collection ani Analysis of Gases.

In the case of locomotive, marine and other boilers without external flues, there is no difficulty in deciding whence the gases for analysis should be drawn, as their composition is not changed by air-leakages; but in the case of boilers set in brickwork some judgment is required in order to secure fair average samples suitable for the purpose required.

When the object is to investigate the quantity of air admitted to the furnace, the sample should be drawn, if possible, before the gases enter any of the brickwork flues, so that the sample may contain only the proportion of air which has passed through the furnaces. In Lancashire or Cornish boilers, for instance, the

1 Professor W. C. Roberts-A usten, "On the Measurement of High Temperatures." Minutes of Proceedingrs Inst. C.F., vol. ex, p. 152. 
gas should be drawn from the downtake at the end of the in-

Fig. 16.

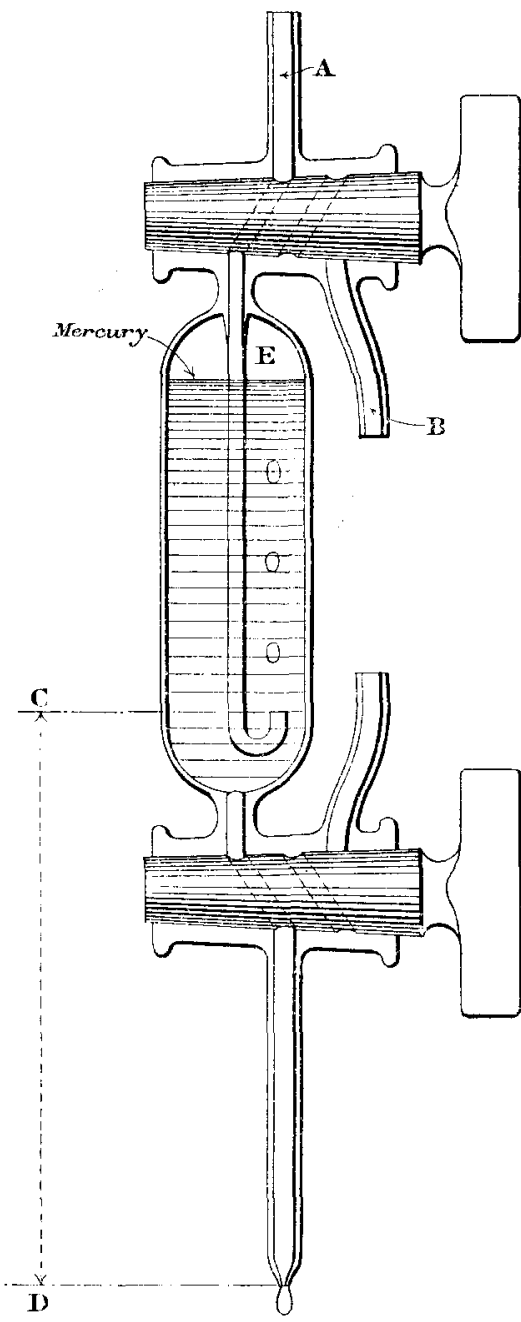

0

0 ternal flues. Where mechanical stokers are used the gas should be drawn from a point beyond the region of flame, but otherwise as near the bridge as possible.

If, however, the object is to ascertain the quantity of heat carried away from the boiler, the sample (in the case of boilers of the two classes last mentioned) should be taken at the exit from the external brickwork flues into the economizer or chimney, as the case may be, where the temperature of the gases is also measured.

It is essential that the temperature of the flue gases should be taken at the same point as that from which the sample for analysis is drawn. Great care must be taken to avoid their dilution by air leaking between the boiler and the surrounding brickwork, through cracks in the brickwork, or through illfitting damper-frames or other openings in the external flues.

Since the gases cannot be assumed to be homogeneous, an attempt must be made to obtain an average sample throughout the width of the flue; it should be remembered, moreover, that (1) The gas must be drawn into the sample tube at a uniform rate per hour. (2) The gas in the dead space between the 
flue and the sample tube must be eliminated. (3) The gas in the sample tube must not be allowed to diffuse back into the main tube or be drawn back into the main current by sudden changes of pressure. ${ }^{1}$

For a permanent apparatus the arrangement of collectingtubes illustrated by Mr. Breckenridge ${ }^{2}$ is probably the best. It averages gas both for temperature measurements and gas samples. It must, however, be built into the flue, and hence is only suitable for a permanent installation. Mr. Breckenridge has shown that a single steel tube closed at the inner end and perforated with a series of holes ${ }^{3}$ throughout its length takes a good average sample: it is readily withdrawn for cleaning, and is the most practical form for temporary trials. A very much larger quantity of gas must be drawn from the flue than is taken for analysis. The sample is drawn from a small tube joined to the main aspirating tube; the latter may be of $\frac{1}{2}$-inch bore, and the current may be conveniently produced by a steam- or water-ejector. A test should be made for gas-tightness before and after trial.

It is often necessary and advisable to carry out the analysis of the gases at once. One of the most convenient arrangements for this purpose is the Orsat apparatus, as it requires no supply of pure water and no bottles of chemicals.

A calibrated Orsat apparatus with mercury as a confining liquid gives satisfactory results for carbon dioxide, but is not suitable for determining carbonic oxide. The commercial pattern is not recommended for the determination of oxygen. Instructions for use are issued by the makers of the different instruments.

If the gases are analysed on the spot the determination of carbon dioxide alone is advisable; this will permit of tests every 15 minutes. If a fuller analysis is deemed necessary a series of continuous samples should be drawn off into small tubes over

1 Condition (3) is not satisfied by any of the ordinary forms on the market. That shown in Fig. 16 has been designed by Mr. G. Nevill Huntly to fulfil (1), (2), and (3). The gas is drawn in at $A$; the dead space is cleared by sucking at $B$; the rate at which gas is drawn in is fixed by the distance CD, and this can be increased by joining a piece of glass tube with rubber to $D$. The gas in $\mathrm{E}$ cannot be sucked back and cannot diffuse buck. The two three-way taps greatly simplify the transference of gas for analysis.

2 "A Study of Four Hundred Steaming Tests made at the Fuel-Testing Plant, St. Louis, Mo., in 1904-6." United States Geological Survey Bulletin No. 325, Washington, 1907, page 157.

3 The area of these holes must be small as compared with that of the bore of the pipe, otherwise less gas will enter the tube near its closed end than elsewhere. 
mercury and analysed either during or as soon as possible after the trial. If the percentage of carbon dioxide alone is required, the "Ados," or any other good recording instrument, may be advantageously used, previded it is checked bofore and during the trial.

Since the amount of heat carried away by the flue gases is proportional to their volume, and this volume is at any instant inversely proportional to the amount of carbon dioxide by volume, the mean percentage found from a recording instrument or from the analysis of an average gas sample is not exactly that required. The error from this cause, with a boiler fired from a mechanical stoker, will probably be under $0 \cdot 1$ per cent. of $\mathrm{CO}_{2}$; with a handfired boiler it may be as high as 0.5 per cent.; with, say, 10 per cent. of carbon dioxide in the flue gas this would mean errors of 1 per cent. and 5 per cent. respectively in the heat balance, and renders unnecessary a higher accuracy than 0.1 per cent. on the carbon dioxide; for this accuracy to be reached the gras sample must be collected over mercury. Considerable errors may occur if water is used, and the next best fluid to mercury is a mixture of equal volumes of glycerol and water, when the error would probably not exceed $0 \cdot 4$ per cont.

The apparatus used for gas analysis, therefore, must be correct to 0.1 per cont. for carbon dioxide and oxygon, 0.05 per cent. for carbon monoxide, and 0.02 for methane. These correspond roughly on an average heat balance with about $0 \cdot 25$ per cent. of the total heat availablo.

When boilers are fired by mechanical stokers, the gas samples may be drawn directly into an analysing apparatus, but when the firing is by hand continuous collection is necessary to ensure correct results.

When all the gas aspirated passes into the collecting-vessel the volume of the aspirating-tube must be very small compared with the volume of the vessel into which the gas is drawn, otherwise the sample collected will contain little besides the gas lying in the tube when the collection was begun.

\section{No. 30.-Steam used by Steam-Jers and Fans.}

Many mechanical stokers are provided with steam-jets under the bars, others require stcam for actuating the mechanism of the fans. 'The necessary steam may, under special conditions, exceed 10 per cent. of the quantity produced, and should be subtracted from the weight of feed-water (unless the efficiency of the heating surface is in question), because it is not available for useful work. 
If, however, this steam is produced in a separate boiler the fuel consumed during its production should, of course, be added to the quantity of fuel burnt in the main boiler. This, however, introduces a complication due to the efficiency of the auxiliary boiler not being the same as that of the main boiler.

If suitable arrangements can be made it is best to condense the exhaust steam of the auxiliary engines and to weigh it, whereas the steam which is blown through nozzles can with a reasonable amount of accuracy be calculated with the help of the formula :-

$$
Q=\text { lbs. of steam per minute = P. } a
$$

where $\mathrm{P}=$ the steam-pressure above that of the atmosphere (i.e., it is the gauge-pressure) plus $7 \cdot 5$ lbs.

and $a$ is the sectional area in square inches of all the nozzles.

This formula gives too high results for pressures below $50 \mathrm{lbs}$. per square inch. P should be measured near the nozzles. If the steam is superheated the woight of steam, as found above, must be multiplied by the square root of the ratio of the absolute temperatures $(t+459)$ of the saturated and superheated steam.

No. 31.-Measurement óf the Stfam Passing througit tile Evaine

The measurement of the steam passing through the engine can be effected in two ways:--

1. By deducting from the measured boiler-feed:

(a) The steam condensed in the steam-pipes.

(b) The steam used for other purposes, such as boiler feedpumps, etc.

(c) The leakage of steam from the steam-pipe joints.

2. By condensing the exhaust steam and weighing the resulting water.

This latter method is generally the more accurate, but, unfortunately, when an engine is tested in situ this method can only be adopted if the engine is fitted with a surfac econdenser. In this case it is only necessary to measure the rate of flow of water from the hot-well, provided, in the case of open engines, the leakage from the piston glands, etc., is inconsiderable. In enclosed engines the piston-rod leakage can generally be collected and measured.

In works where engines are systematically tested the surface condenser method of measuring the steam consumption of the engine is usually adopted, and the water flowing through the condenser, whether condensed at atmospheric pressure or under a vacuum, is led into a tank placed on a woighbridge. An electric contact is fitted to the steelyard, so that an electric bell rings the instant 
the balance is obtained. When a uniform flow has been established, and it is desired to begin measuring this rate of flow into the tank, the first step is slightly to overbalance the steelyard, so that in a few seconds, owing to the flow of water, the balance will be again established. The time at which the bell rings is recorded. The steelyard is now overbalanced, say 100 lbs. Obviously, as soon as another $100 \mathrm{lbs}$. of water have flowed into the tank the bell will ring again, and the time at which this occurs is recorded. From data thus obtained the rate of flow can be readily deduced. In practice several 100-1b. intervals are observed, to obtain greater accuracy and to ascertain that the rate of flow is uniform. When testing large engines the $100 \mathrm{lbs}$. nay be increased to $200 \mathrm{lbs}$, $300 \mathrm{lbs}$, or even more, so that the time intervals shall not be much less than 2 minutes. In general, observations lasting abont half an hour will give results correct within $\frac{1}{4}$ per cent. Similar sets of observations can be taken at intervals, during a trial which may last 6 hours or more, in order to test endurance and for other purposes. In this way any change in the working condition of the engine can be detected.

To approximate to the foregoing method with extempore apparatus a barrel can be placed on a portable weighbridge, and the time required for, say, 100 lbs. to flow into it observed, preferably by means of a stop-watch. The calibration can be best effected in this caso by first placing the barrel together with 100 lbs. on the weighbridge and balancing. Any error in the weighing machine is thus eliminated.

Such arrangements are only possible, however, when testing comparatively small engines, as the quantity of water to be dealt with in large engines would be unmanageable. In this latter case a large tank should be used which has been previously calibrated up to a mark by weighing water into it. The tank should be fitted with a valve to empty it. If two tanks are available the water can be allowed to flow first into one, and then into the other, and thus continuous measurement of the rate of flow can be made; this is obviously not possible with only one tank. 'The method of calibrativg the tanks in this case is identical with that described for obtaining the feed-measurement of the boiler (p. 306).

A fairly good result can also be obtained by placing a watermeter in the circuit of the pump suction. The meter should, however, be calibrated with water of the temperature of the feed, both before and after the test and when passing about the same quantity per hour as during the trial.

Attention is drawn in regard to the reheaters to the remarks in the second paragraph on page 297. 


\section{APPENDIX II.}

\section{Notes on Filding in the Forms with the Records of Trials, AND THE Nature of the Intorma- TION WHICH SHOULD BE GIVEN. ${ }^{1}$}

IN order to assist those who may use the forms it was considered by the Committee to be desirable to explain briefly how they should be filled in, and what kind of information should be given upon them. They have therefore prepared the following notes :---

\section{BOILER.}

Reference Number. Line 1.-In describing a boiler, it should be treated as a machine for transmitting heat rather than as a structure for maintaining pressure. If it is of a well-known type, a mention of the type, of the dimensions of the shell, furnaces and tubes, and the conrse taken by the gases will generally suffice. If, on the other hand, the shape or arrangement is unusual, all the peculiarities should be carefully and minutely described. Descriptions of riveted joints, stays, safety-valves, and other particulars affecting the strength and safety of the boiler are not generally required. A drawing of the boiler and its setting and flues is a useful addition to the report of the trial.

The following example will serve as an illustration:-Lancashire type, ordinary form, length of shell $30 \mathrm{feet}$, diameter of shell 8 feet 6 inches; two internal flues each 3 feet $5 \frac{1}{2}$ inches in diameter, except at the front end of the first ring, where the diameter is reduced to 3 feet $2 \frac{1}{2}$ inches, and at the back end of the last ring but one, and at the last ring, where the diameter is 3 feet. Each flue has three Galloway tubes; the fire-grates are 5 feet 4 inches in length, with 12 inches of dead-plate in the front; the boiler is supplemented by a Green economizer. The

1 The Boiler Trial, and Complete Steam-Plant Trial Forms, are to be obtained from the Institution printers (see p. 265), accompanied by copies of the diagrams. These diagrams are not reprinted in this Report. They appear in the Report dated April, 1902. 
brickwork about the boiler and economizer was in very good condition. The boiler and flues were thoroughly cleaned out four days before the trial.

Line 2.-If the method is that suggested on pp. 275 to 279 , it will be sufficient to say so. If, however, some other method has been adopted, it should be described accurately and in detail.

Line 3.-It should be stated whether the boiler was fired by hand or mechanically. If by hand, the size, weight, and frequency of the charges should be given approximately, and also some notes as to the degree of skill and intelligence displayed by the firemen. If mechanical "stokers" are used, the name of the "stoker" should be stated, and also whether it was of the sprinkling or coking type, unless the information has already been given in line 1. It is desirable, if possible, to give particulars of the power needed to work the stoker and how supplied. The general thickness and condition of the fires should be described, and the average thickness throughout the trial given, and anything in the methods of firing which wonld be likely to affect the rate of evaporation should be stated, and also how often and when the fires were cleaned.

Line 4.-If any system of forced or induced draught is used it should be carefully explained, and the positions and any peculiarities of the draught gauges described; data as to the power necded or steam used should be supplied if possible.

Lines 5-11.-The data given on these lines should be obtained with accuracy from actual measurements made at the time, or from the working drawings used in the construction of the boilers. In determining the amount of heating surface, all surfaces which are directly exposed to the gases leaving the fire-grate should be reckoned as heating surfaces. Thus in a Lancashire boiler the parts of the internal flues below the fire-grates are not to be considered as heating surface, but the bottoms of the internal flues beyond the bridges are to be so counted, although they may be covered with flue dust, and so protected from contact with, or radiation from, the flames. A blank space has been left at the foot of this form, and any general information as to the conditions of the weather during the test, as to anything abnormal which occurred, or anything else which might help to explain the results obtained, should be stated here. In particular, information should be given as to the amount of smoke shown during the test. Diagrams of different intensities of smoke (Plate 1$)^{1}$ were sub-

1 Not reprinted. See the Committee's previous lieport, dated $A$ pril, 1902. 
mitted to the Committee by the late Mr. Bryan Donkin, and a form for plotting smoke observations by reference to these diagrams is shown in Fig. 17.

Line 12.-The total period of coal-measurement in hours and minutes should be given (see p. 270).

Line 13.-If the fuel used was coal the name of the colliery should be given, and the quality, such as nuts, slack, etc., should also be stated. If any patent fuel or oil was employed, sufficient particulars should be supplied to enable it to be identified.

Line 14.-This line should give the total weight of fuel (see p. 279) placed upon the fres per hour, and the condition in which it was used; the figures will be obtained by dividing the total weight of fuel used by the hours of duration of the trial (line 12).

Line 15.-Information should be given in the remarks column as to whether a special analysis (Sect. $21, A_{p-}$ nendix $I$, p. 320) was made of the coal actually used during the trial, or

[THE INST. C.E. VOL. CXCV.]

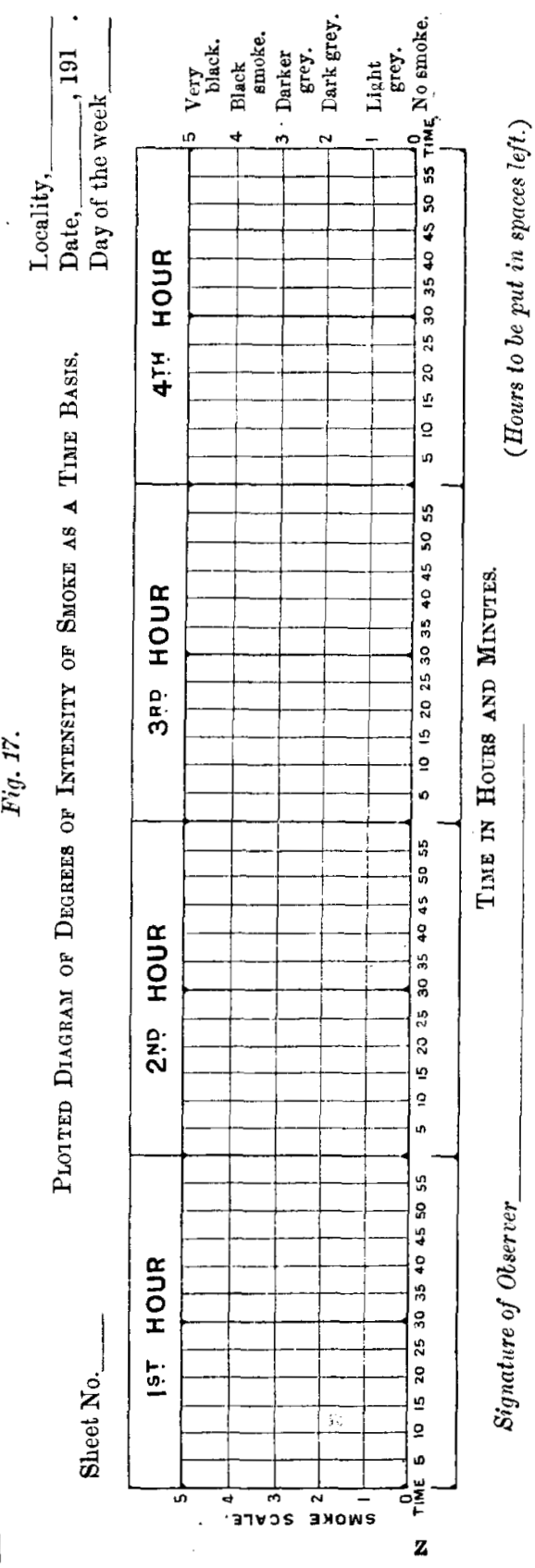

Downloaded by [ Swinburne University] on [26/09/16]. Copyright (C ICE Publishing, all rights reserved. 
whether the analysis was that of coal of a similar quality from the same colliery made at some previous date.

Line 16. -The moisture in the fuel as fired should be determined from the sample sent for chemical analysis, and from the data obtained when air-drying the samples, as pointed out on p. 321 of Appendix I.

Line 17. - Full information should be given as to the kind of calorimeter which was used for determining the calorific value of the fuel, and whether the determination was made by a chemist or some other expert (Sect. 21, p. 320).

(1) The Gross Calorific Value of the sample of fuel as fired should be determined in a compressed oxygen bomb-calorimeter, all the products of combustion being taken as cooled down to $60^{\circ} \mathrm{F}$.

(2) The Net Calorific Value used for calculating the boiler efficiency will be the Gross value, less the latent heat (reckoned at 1,055 B.Th.U. per lb.) of the water condensed from the products of combustion by cooling to $60^{\circ} \mathrm{F}$, and can be found from the following formula-

Net calorific value per pound of coal $=$ gross calorific value $-1,055$ (lbs. of moisture $+9 \times$ lbs. of hydrogen).

The Committee do not consider it desirable to give any formula for calculating the heating value of a fuel from the chemical analysis. Practically all the formulas which are given in textbooks and by authorities are of the following form:-Heating value of the fuel per pound $=$

$$
(\mathrm{C} \times \mathrm{a} \text { constant })+\left(\mathrm{H}-\frac{\mathrm{O}}{8}\right) \times \mathrm{a} \text { constant }+(\mathrm{S} \times \mathrm{a} \text { constant })
$$

where $\mathrm{C}, \mathrm{O}, \mathrm{H}$, and $\mathrm{S}$ represent the percentages of carbon, oxygen, hydrogen and sulphur respectively present in the fuel, as determined by the chemical analysis, and the constants are the heating values per pound of pure carbon, hydrogen and sulphur. It is desirable to point out, however, that the percentage of oxygen in a fuel analysis is practically a fictitious figure, for it is always an undetermined quantity obtained by difference and written as (" $O$, etc.") in the analysis; it thus contains all the errors of the analysis. A formula of the foregoing type assumes that the amount of oxygen present and the condition of its combination are known accurately; but neither of these conditions is known with any degree of certainty. If the results obtained by calculation, using 
formulas of the foregoing type, are compared with those obtained by actual combustion of the fuel in a calorimeter, it will be found that a formula which assumes that the whole of the carbon and the hydrogen exist as such and entirely uncombined gives results which are too high; but, on the other hand, a formula which employs the factor $\left(H-\frac{O}{8}\right)$ gives results which are too low. In view, therefore, of the uncertainty of present knowledge as to the conditions of combination which obtain in any fuel, it seemed to the Committee inadvisable to adopt any formula which pretends to any degree of accuracy, and it appeared better frankly to own that any formula which can be used is an approximate one only. It should be used merely as a check, or in the few cases in which it is impossible to obtain a calorimetric determination of the calorific value of the fuel. The most recent determinations of the calorific values of carbon and hydrogen are the following:-

Carbon when converted to $\mathrm{CO}_{2}$ - . . - 14,544 B.Th.U. per lb.

Hydrogen . . . . . . . . . 52,200 " "

the products of combustion in the latter case being assumed to be discharged at $60^{\circ} \mathrm{F}$., that is to say, the figures give the Net Calorific Value. These figures can be used in calculations based on any of the ordinary formulas.

Line 18.-The figure for this line is obtained by dividing the total amount of ash and clinker (Sect. 25, App. I, p. 323) formed during the trial by the number of hours during which the trial lasted (line 12).

Line 19. - The Calorific Value of the ash can be obtained, as stated on p. 324 in Appendix I, by forwarding samples ${ }^{1}$ to a chemist, or by calculation, based on the previous chemical analysis of the coal, of the amount of ash and clinker which ought to be formed from the amount of fuel which has been burnt. In many cases, however, e.g., when forced draught is used, it will be found that the actual amount of clinker and ash collected is less in total weight than the amount which ought to be present as shown by the chemical analysis, much of it having been blown up the chimney.

Line 20.--This is obtained by multiplying line 19 by 14,544 , the Calorific Value of 1 lb. of casbon.

Line 21.-In the column "Remarks," particulars should be given

1 The sampling should be carried out as systematioally as if dealing with coal (Sect. 25, p. 323). 
as to where the gas for analysis was taken from, and whether the aspiration was continuous or intermittent (Sect. 29, App. I, p. 329); in the blank lines at the bottom of the form a brief description of the apparatus employed for collecting the gas may be given with advantage.

Line 22.-The kind of thermometer or pyrometer employed should be stated in the column for remarks (see Sect. 28 (d), App. I, p. 328), and the position in which it was placed should also be described.

Line 23.--The mean specific heat of the products of combustion can be calculated as soon as an analysis has been made of the dry furnace gases; the method of making the calculation is explained in detail in connection with the explanations given later for determining the heat losses corresponding with lines 39 and 40 of the forms (p. 342).

Lines 24-29 and 32.-An explanation should be given as to how the various pressures, draughts (Sect. No. 27, App. I, p. 325) and temperatures (Sect. No. 28, App. I, p. 326) were measured, and it should be stated how frequently the observations were taken.

Line 30.-Wherever possible the amount of steam employed in producing the draught (whether an actual steam-jet is used or whether the steam is used in working an engine for driving fans) should be given, and it should be determined by an independent test. 'The steam which is blown through nozzles can, however, with a reasonable degree of accuracy, be calculated by the formula on p. 333 (Sect. 30).

Line 31.- Some brief explanation should be given as to the method of determining the weight of the feed-water, that is, whether it was measured by a system of tanks or whether by use of a meter or by any other method (see Sects. 2 and 3, App. I, pp. 301 and 302).

Line 32.-See line 24.

Line 32a.-Seo No. 14, 1. 312.

Line 32b.-This is $\left(\begin{array}{c}\text { Line 32a } \\ \text { Line 31 }\end{array}\right) \times 100$.

Line 33.-In the column "Remarks," information should be given as to whetleer the gauge has been tested for accuracy, and the same remark applies to other gauges wherever such observa. tions occur on the forms.

Line 34.-This is obtained by adding the atmospheric pressure (line 25) to the gauge pressure (line 33).

Line 35.-Full information should be given as to the method 
of determining the weight of the moisture present in the steam, and how it was trapped or collected and weighed. ${ }^{1}$

Line 35a.-The "dryness fraction" is equal to $(1-$ line 35$)$,

Line 36.-The temperature of saturation corresponding to the absolute steam pressure (line 34 ) can be obtained from any reliable steam-tables or from a $\theta \phi$ chart.

Line 36a.--Rate of Loss of Heat from the Boiler by Radialion.Let $s$ be the specific heat of steel (about 0.122 at temperatures usual in boilers) and $S$ that of water at the same temperature (say $1 \cdot 03) ; v=$ pounds weight of metal and $\mathrm{W}$ the pounds of water in the boiler. Loss of heat in B.Th.U. per hour $=(s w+\mathrm{SW}) \times$ rate of cooling in degrees Fahrenheit per hour; (obtained from the tangent in Fig. 8, page 315).

Blank lines are left at the bottom of this form for additional information upon any points in respect of which further details can be given with advantage.

Line 37.-This is merely a repetition of line 17.

Line 38.-The heat transferred to the water should be calculated by one or other of the following formulas:-

(a) When the steam is not superheated-

$$
\text { B.Th.U. }=\mathrm{W}\left\{\left(\mathrm{H}_{1}-h_{0}\right)-w\left(\mathrm{H}_{1}-h_{1}\right)\right\}
$$

(b) When the steam is superheated-2 2

$$
\text { B.Th.U. }=\mathrm{W}\left\{\left(\mathrm{H}_{1}-h_{0}\right)+0 \cdot 48\left(t_{s}-t_{1}\right)\right\}
$$

In these formulas $W=$ weight of steam and water leaving the boiler per pound of fuel as fired

$$
=\left(\begin{array}{l}
\operatorname{Line} 31 \\
\operatorname{Line} 14
\end{array}\right) \text {. }
$$

$w=$ weight of moisture per pound of steam leaving the boiler (line 35).

$t_{0}, t_{1}$, and $t_{s}$ are the temperatures of the feed-water, of the saturated steam at the boiler pressure, and of the steam leaving the superheater respectively (lines $32,36,72$ ).

$\mathrm{H}_{1}$ is the total heat above $32^{\circ} \mathrm{F}$. of a pound of saturated steam at the temperature $t_{1}$.

$h_{0}$ and $h_{1}$ are the B.Th.U. above $32^{\circ} \mathrm{F}$. in a pound of water at the corresponding temperatures $t_{0}$ and $t_{1}$.

The quantities $h_{0}, h_{1}$, and $H_{1}$ can be obtained from any reliable

1 See Paper by Dr. W. C. Unwin, Proc. Inst. Mech. E., 1895, p. 31.

2 For specific heat of superheated steam ste footnote on p. 312 . 
steam-table or $\theta \phi$ chart $^{1}$ (Plate 2), ${ }^{2}$ care being taken that they are all measured from the same temperature, usually $32^{\circ} \mathrm{F}$.

The following approximate formulas may be used for calculating the heat transferred to the water when no steam-tables are at hand:-

(a) When the steam is not superheated-

$$
\text { B.Th.U. }=\mathrm{W}\left\{1,114+0 \cdot 305\left(t_{1}-t_{0}\right)\right\}-w\left(1,114-0 \cdot 7 t_{1}\right)
$$

(b) When the steam is superheated ${ }^{3}$

$$
\text { B.Th.U. }=\mathrm{W}\left\{1,114+0.305\left(t_{1}-t_{0}\right)+0.48\left(t_{\mathrm{s}}-t_{1}\right)\right\}
$$

The following example illustrates the use of this formula. In a boiler trial the absolute steam pressure (line 34) was $179 \cdot 6$ lbs. per square inch; the corresponding temperature of saturation (line 36 ) was $373^{\circ} \mathrm{F}$.; the temperature of the feed to the boiler (line 32 ) was $106^{\circ}$; the total fuel fired per hour was 942 lbs.; the total feed-water entering the boiler was 8,616 lbs. per hour (line 31), and the total moisture present in the steam was 0.0298 per lb. (line 35); the steam used was therefore not superheated.

$$
\begin{aligned}
\mathrm{W} \text { in this case } & =\begin{array}{l}
8,616 \\
942
\end{array}=9 \cdot 147 \mathrm{lbs} . \\
w & =0.0298 .
\end{aligned}
$$

From the steam tables $\mathrm{H}_{1}=1,196$ B.Th.U.

and

$$
\begin{array}{ll}
h_{1}=345 \text { B.Th.U. } \\
& h_{0}=106^{\circ}-32^{\circ}=74 \text { B.Th.U. }
\end{array}
$$

Hence the heat transferred in this case, per pound of fuel as fired,

$$
\begin{aligned}
& =9 \cdot 147\{(1,196-74)-0 \cdot 0298(1,196-345)\} \\
& =10,238 \text { B.Th.U. }
\end{aligned}
$$

Lines 39 and 40.-In order to determine the number of heat-units carried away from the boiler by the products of combustion and the excess air, the following data are required: A chemical analysis of the dry flue-gases, the temperature of the external air, the temperature at which the gases leave the boiler, and an analysis of the fuel. The analysis of the dry gases is always made volumetrically, and the first step is to convert this into an analysis

${ }^{1} h_{0}$ is not given on the $\theta \phi$ chart for feed temperatures below $100^{\circ} \mathrm{F}$. It may be taken as $\left(t_{0}-32^{\circ}\right)$ for these temperatures.

2 Not reprinted. See the Committee's previous Report, dated April, 1902.

3 For specific heat of superheated steam see footnote on p. 312. 
by weight. I An example will most readily show how this can be done.

\begin{tabular}{|c|c|c|c|c|c|}
\hline \multicolumn{2}{|l|}{ Gas. } & $\begin{array}{l}\text { Analysis by } \\
\text { Volume. }\end{array}$ & $\begin{array}{l}\text { Density. } 2 \\
\text { Pounds per } \\
\text { Cuble Foot. }\end{array}$ & $\begin{array}{l}\text { Product. } \\
(1) \times(2)\end{array}$ & $\begin{array}{l}\text { Proportion by } \\
\text { Weight. }\end{array}$ \\
\hline Carbon dioxide. & . . & $0^{(1)}$ & $\begin{array}{l}(2) \\
0 \cdot 1235\end{array}$ & $0 \cdot \stackrel{(3)}{01013}$ & $0 \cdot \stackrel{(4)}{1219}$ \\
\hline Carbon monoxide & . . & 0.000 & 0.0781 & .. & .. \\
\hline Oxygen . & . & $0 \cdot 112$ & 0.0893 & 0.0100 & $0 \cdot 1204$ \\
\hline Nitrogen & . . & 0.806 & $0 \cdot 0781$ & 0.06295 & $0 \cdot 7577$ \\
\hline & & & & $0 \cdot 8308$ & $\mathbf{1} \cdot 0000$ \\
\hline
\end{tabular}

By multiplying each of the volume proportions by the corresponding densities in the second column, adding the results so obtained, and then dividing each product by the sum, the proportion by weight of each gas present is determined as shown in the last column.

It may be assumed that the whole of the carbon present in these gases came from the fuel which was burnt, and as in $\mathrm{CO}_{2}$ the proportion of carbon by weight is $\frac{3}{1 \mathrm{~T}}$ and in $\mathrm{CO}$ it is $\frac{3}{7}$, the actual weight of carbon present in a pound of dry flue-gases is readily calculated by the following formula:-

Weight of carbon in $1 \mathrm{lb}$. of dry flue-gases = $\frac{3}{11}$ (proportion by weight of $\left.\mathrm{CO}_{2}\right)+\frac{3}{7}$ (proportion by weight of $\mathrm{CO}$ ).

Employing it in the above example, the weight of carbon in 1 lb. of dry gas is

$$
\left(0.121 \times \frac{3}{1}\right)+\left(0.000 \times \frac{3}{7}\right)=0.033 \mathrm{lb} .
$$

The analysis of the fuel gives the carbon in $1 \mathrm{lb}$. of it, and on the assumption that all the carbon in the fuel appears in the fluegas it is now possible to calculate at once how many pounds of dry flue-gases leave the boiler flues per pound of fuel burnt.

The weight of dry the-gases per pound of carbon burnt will be (weight of $\mathrm{C}$ present in $1 \mathrm{lb}$. of dry flue-gases $)=$ say, $x$ lbs.; and the weight of dry flue-gases per pound of fuel burnt will equal ( $x \times$ weight of $\mathrm{C}$ in $1 \mathrm{lb}$. of fuel).

1 This conversion is not necessary if Mr. Huntly's shortened method is adopted (see p. 347).

2 The density is measured at the standard pressure of 29.92 inches of mercury ( $=14 \cdot 7 \mathrm{lbs}$. per square inch), the temperature being $32^{\circ} \mathbf{F}$. 
In the trial from which the figures used in this example are taken the analysis of the fuel gave the following results:-

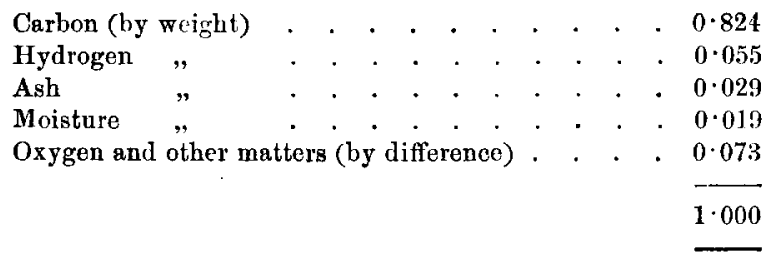

Hence the weight of dry flue-gases per pound of carbon burnt was $\frac{1}{0 \cdot 033}=30 \cdot 30 \mathrm{lbs} .{ }^{1}$ and the weight of dry flue-gases per pound of fuel burnt was $30 \cdot 30 \times 0.824=24 \cdot 97 \mathrm{lbs}$. In addition to the dry flue-gases, there is a certain weight of steam present in the products of combustion due to the combustion of the hydrogen of the fuel, and this weight will be 8.94 times the weight of the hydrogen originally present in the fuel ; therefore in the example the weight of steam in the flue-gases is equal to $0.055 \times 8.94=$ $0.49 \mathrm{lb} .+0 \cdot 02=0.51 \mathrm{lb}$.

Therefore, the total weight of the flue-gases per pound of fuel was $24 \cdot 97+0.49+0.02=25.48$ lbs.

The combustible matter in a pound of fuel burnt on the grate in this example was $0.97 \mathrm{lb}$. Hence the weight of air drawn into the flues per pound of fuel as fired was $25 \cdot 48-0 \cdot 97=$ $24 \cdot 71$ lbs., and this is the figure to enter in line 51 .

A considerable proportion of this is excess air over and above that which was needed for the complete combustion of the fuel; the weight of air needed for the perfect combustion of any fuel. can be readily determined by the following formula:

Weight of air theoretically needed per pound of fuel (line $52):-$

$=(11 \cdot 5 \times$ carbon per pound $)+(34 \cdot 22 \times$ hydrogen per pound $)$.

In the above example the weight of air theoretically needed $=(0.824 \times 11.5)+(0.055 \times 34.22)=11.36 \mathrm{lbs}$. per pound of

1 The weight of dry gases per pound of carbon burnt also-

$$
=\frac{11 \mathrm{CO}_{2}+8 \mathrm{O}+7(\mathrm{CO}+\mathrm{N})}{3\left(\mathrm{CO}_{2}+\mathrm{CO}\right)}
$$

where $\mathrm{CO}_{2}, \mathrm{O}, \mathrm{CO}$, and $\mathrm{N}$ are the proportions by volume of each of those gases in the dry flue-gases. 
fuel. Hence the excess air used per pound of fuel burnt in this trial was $24 \cdot 71-11 \cdot 36=13 \cdot 35$ lbs.

Lines 39 and 40 of the form may now be readily calculated. The total weight of the flue-gases per pound of fuel has been determined, and the weight of the excess air ; in the example these were respectively $25 \cdot 48$ and $13 \cdot 35 \mathrm{lbs}$, and their difference (in the example $12 \cdot 13$ ) will be the weight of the products of combustion (line 54). The specific heat of air being $0 \cdot 243$, line 40 is at once calculated by multiplying the weight of excess air by its specific heat, and by the difference of temperature between the flue-gases and the air, the latter two temperatures being given in lines 22 and 24 ; or heat carried away in excess air = weight of excess air per pound of fuel $\times 0.243 \times\left(t_{g}-t_{a}\right)$.

In the example the temperatures were respectively $452^{\circ}$ and $62^{\circ}$; therefore, the heat carried away in the excess air $=(13.35 \times 0.243)$ $\times(452-62)=1,265$ B.Th.U.

To calculate the heat carried away by the products of combustion their mean specific heat must be determined, and this will also give the data to fill up line 23 of the form.

The proportion by weight of each of the constituents $\mathrm{CO}_{2}, \mathrm{CO}$, $\mathrm{N}$, and $\mathrm{H}_{2} \mathrm{O}$ in the products of combustion produced per pound of dried fuel burnt must first be determined. The weight of $\mathrm{CO}_{2}$ generated per pound of fuel burnt in this example is obtained by multiplying the weight of carbon in $1 \mathrm{lb}$. of fuel by the fraction $\frac{11}{3}$; hence the weight of $\mathrm{CO}_{2}=0.824 \times \frac{11}{3}=3.021 \mathrm{lbs}$. The weight of $\mathrm{CO}$ in the example is nil, since none is shown in the analysis of the gases. If $\mathrm{CO}$ had been present in the gases, it would have been first necessary to find the proportion by weight of the carbon in $1 \mathrm{lb}$. of fuel burnt into $\mathrm{CO}_{2}$ and $\mathrm{CO}$ respectively, thus :-

Proportion by weight of C.burnt to $\mathrm{CO}_{2}$ $=\frac{\frac{3}{\mathrm{I}^{2}} \text { (weight of } \mathrm{CO}_{2} \text { in } 1 \mathrm{lb} \text {. gas) }}{\frac{3}{1 \mathrm{r}} \text { (weight of } \mathrm{CO}_{2} \text { in } 1 \mathrm{lb} \text {. gas) }+\frac{3}{7} \text { (weight of } \mathrm{CO} \text { in } 1 \mathrm{lb} \text {.gas) }}$.

Then the weight of $\mathrm{CO}_{2}$ formed per pound of fuel burnt would have been equal to $\frac{11}{3} \times$ weight of $\mathrm{C}$ in $1 \mathrm{lb}$. fuel $\times$ proportion by weight of $\mathrm{C}$ burnt to $\mathrm{CO}_{2}$, and similarly the weight of $\mathrm{CO}$ would be determined by using $\frac{7}{3}$ as the multiplying fraction.

The weight of $\mathrm{H}_{2} \mathrm{O}$ formed per pound of fuel has been already determined; in the example it is $0.51 \mathrm{lb}$. (see p. 322).

The weight of nitrogen will be equal to the total weight of the products of combustion, less the weight of $\mathrm{CO}_{2}, \mathrm{CO}$ and $\mathrm{H}_{2} \mathrm{O}$; or, in the example, weight of $\mathrm{N}=12 \cdot 13-(3 \cdot 02+0 \cdot 51)=8 \cdot 60 \mathrm{lbs}$. 
The proportions by weight of each of the constituents are now readily determined. They are:-

$$
\begin{aligned}
\mathrm{CO}_{2} & =\frac{3 \cdot 021}{12 \cdot 13}=0 \cdot 249 . \\
\mathrm{CO} & =0 \cdot 0=0 \cdot 000 . \\
\mathrm{H}_{2} \mathrm{O} & =\frac{0 \cdot 51}{12 \cdot 13}=0 \cdot 042 . \\
\mathrm{N} & =\frac{8 \cdot 60}{12 \cdot 13}=\frac{0 \cdot 709 .}{1 \cdot 000 .}
\end{aligned}
$$

The mean specific heat of the products of combustion (line 23) will be found by multiplying each of these weights by the

\begin{tabular}{|c|c|c|c|c|c|c|c|}
\hline & & $\begin{array}{l}\text { Over the } \\
\text { Range. }\end{array}$ & & & & & $\begin{array}{l}\text { Range of } \\
\text { Temperature. }\end{array}$ \\
\hline Air. & $0 \cdot 243$ & ${ }^{\circ} \mathrm{F} . \quad{ }^{\circ} \mathrm{F}$. & \multicolumn{3}{|c|}{ Carbon dioxide. } & 0.216 & ${ }_{60} \mathrm{~F}$ to 300 \\
\hline Oxygen . . . & $0 \cdot 222$ & \multirow{2}{*}{60 to 400} & ", & ", & & $0 \cdot 222$ & 60,400 \\
\hline Nitrogen . . & $0 \cdot 249$ & & ", & & .• & $0 \cdot 227$ & 60,500 \\
\hline \multirow[t]{2}{*}{ Carbon monoxide } & $0 \cdot 243$ & & ", & ", & . & $0 \cdot 232$ & 60,600 \\
\hline & & & Steam & & & $0 \cdot 480$ & 60,600 \\
\hline
\end{tabular}
corresponding specific heats of the respective gases and adding the results. The following are the mean specific heats of these gases:-

In the example, therefore, the mean specific heat of the products of combustion (line 23) is

$$
0.249 \times 0.225+0.042 \times 0.480+(0.709 \times 0.249)=0.253 .
$$

The heat carried away per pound of fuel in the products of combustion (line 39) can now be calculated; it is equal to the weight of the products of combustion per pound of fuel $\times$ difference of flue-gas and air temperatures $x$ specific heat just found. In the example, the heat is

$$
12 \cdot 13 \times\left(452^{\circ}-62^{\circ}\right) \times 0 \cdot 253=1,195 \text { B.Th.U. }
$$


Mr. G. N. Huntly, B.Sc., has devised the following closely approximate formula for the heat carried away by $d r y$ flue-gases per pound of coal :-

If $a$ is the percentage of carbon (by weight) in fuel (corrected for unburnt carbon in clinker and ash);

If $\mathrm{C}, \quad, \quad, \mathrm{CO}_{2}$ (by volume) in flue-gas (corrected for other gaseous carbon compounds).

Then heat carried away by dry gases per pound of fuel

$$
=\frac{\text { Constant } \times a \times(\mathrm{T}-t)}{\mathrm{C}} \text { B.Th.U. }
$$

$\mathrm{T}$ and $t$ are the temperatures of gas and atmosphere.

The "constant" for flue-gas at about $500^{\circ}$ F. may be taken as 0.605 , and the error will not exceed 1 per cent. on the heat balance, which is well within the limits of experimental error. It shonld be noted that this formula is not empirical, but is constructed on a rational basis.

In the example above:-

$$
\begin{aligned}
a & =84 \text { per cent.; } \\
\mathrm{T} & =452^{\circ} \mathrm{F} . ; \\
t & =62^{\circ} \mathrm{F} . ; \\
\mathrm{C} & =8.2 \text { per cent. by volume. }
\end{aligned}
$$

Hence heat carried away per pound of fuel by dry gases

$$
=0.605 \times \frac{84}{8 \cdot 2} \times 390=2,418 \text { B.Th.U. }
$$

By the fuller method given above it

$$
=1,265+1,195=2,460 \text { B.Th.U., }
$$

or about 2 per cent. more. If this heat is 23 per cent. of the heat in $1 \mathrm{lb}$. of fuel the error is only $2 \times 0.23=0.46$ per cent. on the heat balance.

Line 41.-Heat lost by incomplete combustion.

This is equal to the weight of carbon burnt into $\mathrm{CO}$ per pound of fuel burnt, multiplied by the difference between the calorific value of carbon when burnt to $\mathrm{CO}_{2}$ and when burnt to $\mathrm{CO}$.

Assuming, for a numerical example, that the proportion of carbon burnt into $\mathrm{CO}$ was $12 \cdot 4$ per cent., and that the weight of $\mathrm{C}$ in $1 \mathrm{lb}$. of fuel was $0.7716 \mathrm{lh}$., then the heat lost

$$
=0.7716 \times 0.124 \times(14,544-4343)=976 \text { B.Th.U. per lb. }
$$


Line 42. - Heat lost by unburnt carbon in the ash per pound of fuel as fired.

This is equal to line $20 \times$ line $18 \div$ line 14 .

Line 42a.-Heat contained in the red-hot ashes and clinker.

Allowance for heat contained in the red-hot ashes and clinker can be made by assuming that when drawn they have a temperature of $2,000^{\circ} \mathrm{F}$. in excess of that of the atmosphere and that their specific heat is 0.3 ; then the B.Th.U. lost by this means can be found by multiplying their weight by 600 . Separate samples should be taken of the clinker and ashes for determining the unburnt carbon.

Line 43.-Loss per hour, by radiation, per pound of fuel.

'This is obtained by dividing line $36 a$ by line 14 .

Line $44=$ line 37 - (the sum of lines 38 to 43 both inclusive).

Line 45.-This is obtained by multiplying the weight of fuel burnt per hour (line $14-\operatorname{line} 14 \times \operatorname{line} 16$ ) by the heat transferred to the water per pound of fuel (line 38), and dividing the product by the area in square feet of the heating surface as given on line 8.

$$
\begin{aligned}
& \text { Line } 46=\begin{array}{l}
\text { line } 14 \\
\text { line } 6
\end{array} \\
& \text { Line } 47=\frac{\operatorname{line} 31-\operatorname{line} 31 \times \text { line } 35}{\text { line } 14} .
\end{aligned}
$$

Line 48 is line 47 multiplied by the evaporation factor, and the evaporation factor is equal to the total heat required to evaporate a pound of steam under boiler conditions, divided by 966 ; i.e., it is equal to $\mathrm{H}_{1}-h_{0}$.

For values of $\mathrm{H}_{1}$ and $h_{0}$ see Notes on line 38 (p. 341).

$$
\text { Line } 49=\frac{(\operatorname{line} 31-\text { line } 31 \times \operatorname{line} 35) \times \text { evaporation factor }}{\text { line } 8} \text {. }
$$

$$
\text { Line } 50=\left\{\begin{array}{l}
\text { Weight of feed in lbs. per hour (line } 31) \times \text { volume } \\
\text { of } 1 \text { lb. of hoiler steam in cubic feet (from steam } \\
\text { tables, or } \theta \phi \text { chart). } \\
\text { Area of water surface at working level in square feet } \\
\text { (line 11) } \times 3,600 .
\end{array} \mid\right.
$$

Lines 51-52.-These are obtained in the calculation for lines 39 and 40 (p. 342).

$$
\text { Line } 53=\frac{\text { line } 51}{\text { line } 52} .
$$




\section{ECONOMIZER AND SUPERHEATER.}

Line 57.-In giving a description of the economizer and the arrangement of the flues, the name of the economizer, if it is of a well-known type, should be stated, and as full particulars as possible should be supplied as to the arrangements for scraping the tubes, and the position of the economizer relative to the boiler and to the chimney, and any other details which would be of service in following the working. An outline sketch will frequently be found of service in simplifying the necessary written description. Particulars should be given as to the number, size, and length of pipes, etc.

Line 58. - The figure for this line should give the total effective heating-surface of the economizer.

Line 59.- The name of the superheater, if it is of a wellknown type, should be stated, and in that case generally a brief description of the method of working the superheater will be sufficient. It is, however, desirable to record the area inside the superheating tubes by which the volume of the steam passing per second must be divided in order to determine its velocity; also the area between the outside of the tubes forming a passage for the flow of gases should be stated in order that their velocity may be ascertained. If the superheater is of some unusual type, a full account of its construction and arrangements should be given, and in particular the method of regulating the amount of superheat. This form is only intended for use where the superheater is part of the boiler proper; if it is a superheater separately fired, then all its records should be entered upon an ordinary boiler sheet, and not upon this form at all.

Line 60.-The total amount of effective heating-surface should be stated in this line, and it is advisable to give some of the measurements for determining this heating-surface, as, for example, if it is a superheater with pipes, the diameter, length and thickness of the pipes should be stated.

Line 61.- This quantity is the total amount of measured feed during the test (see pp. 300-309, Appendix I) divided by the number of hours during which the test lasted; if there are no leaks in the economizer or through the feed-pump gland, or no loss through the economizer safety-valve, it should be the same figure as that on line 31 of the Boiler Sheets.

Lines 62-65.-All these temperatures (Sect. 28, App. I, pp. 326 to 329$)$ should be measured close to the points of entry into, 
or escape from, the economizer, at regular intervals throughout the run, and the mean of these observations after correction, if any is required for thermometer errors, should be entered in these lines. The kind of thermometer used should be stated in the remarks column.

Line 66.-The instructions already given in reference to line 21 apply to this line.

Line 67.-The mean specific heat of the flue-gases should be calculated as follows :-

The calculation requires (a) the analysis of the fuel; (b) a volume analysis of the flue-gases as they leave the economizer.

The method can be best explained by an actual example. During a test of an economizer, samples of the gases were collected, and an analysis of the fuel burnt in the boiler was made at the conclusion of the trial, with the following results :-

$$
\begin{aligned}
& \text { Anatysis of Finel. }
\end{aligned}
$$

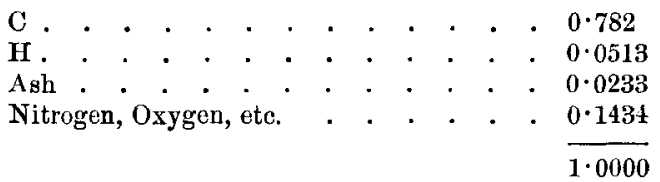

Mean Composttion of Dry Gases ay Volume.

$$
\begin{aligned}
& \mathrm{CO}_{2} \text {. . . . . . . . . . . . . } 941
\end{aligned}
$$

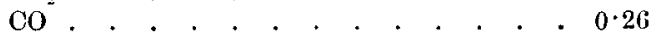

$$
\begin{aligned}
& \text { o . . . . . . . . . . . . . } 10.98 \\
& \mathrm{~N} . . \quad . \quad . \quad . \quad . \quad . \quad . \quad . \quad . \quad .79 \cdot 35 \\
& 100 \cdot 00
\end{aligned}
$$

The first step will be the conversion of analysis by volume into analysis by weight. The method of doing this has been previously explained in the notes referring to lines 39 and 40 .

analysis of Dry Gasez by Weight.

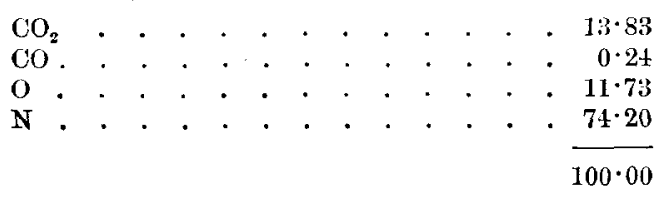

In $100 \mathrm{lbs}$. of flue-gases there are therefore $\left({ }_{1 \mathrm{~T}}^{3} \times 13 \cdot 83\right)+$ $\left(\frac{3}{7} \times 0.24\right)$ lbs. of carbon, all of which may be assumed to have come out of the fuel ; that is, there are in $100 \mathrm{lbs}$. of dry flue-gases $3.875 \mathrm{lbs}$. of carbon. But if $3.875 \mathrm{lbs}$. of carbon correspond with 
100 lbs. of dry flue-gases, it is very easy to determine how many pounds of dry flue-gases correspond to the combustion of $1 \mathrm{lb}$. of fuel, which only contains, from its analysis, $0.782 \mathrm{lb}$. of carbon.

The weight of dry tlue-gases per pound of fuel will be $\frac{100 \times 0 \cdot 782}{3 \cdot 875}=20 \cdot 18$ lbs., but in addition the flue-gases contain a small quantity of water, produced by the combustion of the hydrogen in the fuel, and its weight will be nine times the weight of the hydrogen in a pound of fuel, or in the example $=0.0513 \times 9=0.46 \mathrm{lb} .+0.02 \mathrm{lb}$. (moisture) $=0.48 \mathrm{lb}$.

The actual weight of each constituent in the gases due to $1 \mathrm{lb}$. of fuel may now be determined:-

$$
\begin{aligned}
& \begin{array}{c}
\text { Constituent. } \\
\mathrm{CO}_{2}=20.18 \times \quad \begin{array}{c}
\text { Weight in lbs. per lb. of } \\
\text { dried fuel burnt. }
\end{array}
\end{array} \begin{array}{c}
\begin{array}{c}
\text { Weight in lbs. of each } \\
\text { gas in } 1 \mathrm{lb} \text { of dry gas. }
\end{array} \\
\mathrm{CO} \quad 0.1383=0.1351
\end{array} \\
& \mathrm{CO}=, \quad \times 0.0024=0.048=0.0023 \\
& \mathrm{O}=" \times 0.1173=2.367=0.1146 \\
& \mathrm{~N}=" \times 0.7420=14.974=0.7248 \\
& \mathrm{H}_{2} \mathrm{O}=0.480=0.0232 \\
& \frac{0.480}{20 \cdot 660}=\frac{0.0232}{1 \cdot 0000}
\end{aligned}
$$

The mean specific heat (see Table on p. 346, ) of the flue-gases as they leave the economizer is equal to:-

(weight of $\left.\mathrm{CO}_{2} \times 0.216\right)+($ weight of $\mathrm{CO} \times 0.243)+$ (weight of $\mathrm{O} \times 0.222$ ) + (weight of $\mathrm{N} \times 0.249)+$ (weight of $\left.\mathrm{H}_{2} \mathrm{O} \times 0.480\right)^{1}$

or in the example selected it is equal to-

$$
\begin{gathered}
(0.1351 \times 0.216)+(0.0023 \times 0.243)+(0.1146 \times 0.222) \\
+(0.7248 \times 0.249)+(0.0232 \times 0.480)=0.247 .
\end{gathered}
$$

Line 68.-The figure for this line should be the same as that of line 31 , unless any corrections are necessary for leakage from the boiler (Sect. 14, App. I, p. 312).

Line 69.-Unless a special pressure-gauge is fitted to the steampipe as it enters the superheater, this pressure must be taken as equal to the boiler pressure (line 296).

Line 70.-A short statement should be given in the remarks column as to the method adopted for determining the percentage of moisture present in the steam as it enters the super-

1 This 0.480 is the approximate specific heat of superheated steam, taken from the 'Table on p. 346 , and not the $0.48 \mathrm{lb}$. of moisture given in line 9 supra. 'Their equality is a coincidence. 
heater. If it is considered desirable, as for example, if some special and little known method has been adopted, a full account should be given on a separate sheet attached to the report. Line 70 is generally a little less than line 35 owing to condensation in the steam-pipe, etc.

Lines 71-74.-The explanations given for lines 62-65 apply equally to these four lines (Sect. 28 (c) and (d), App. I, p. 327). It is especially desirable that full particulars should be given as to how frequently these temperatures were taken and the kind of thermometer used.

Line 75.-See notes on line 21 (Sect. 29, App. I, p. 329.)

Line 76.-See notes on line 67.

Line 77.-This line is the sum of lines 39 and 40 , if the waste gases pass straight to the economizer from the boiler flues; if, however, they first pass through a superheater, the figure for this line will be the same as in line 83 .

Line 78.-This line is obtained by multiplying the weight of the feed per pound of fuel by the rise of temperature of the feed in passing through the economizer-

$$
=\frac{(\operatorname{line} 61)}{(\operatorname{lin} \theta 14-\operatorname{line} 14 \times \operatorname{lin} \theta 16)} \times(\operatorname{lin} \theta 63-62) .
$$

Line 79.-The calculations necessary for filling in this line are precisely similar to those given for lines 39 and 40 . The weight of the chimney gases per pound of fuel burnt must be determined, and then the heat carried off in them is equal to : weight of chimney gases per pound of fuel $\times$ mean specific heat (line 67) $\times$ excess of temperature on leaving economizer above that of atmosphere (line 65 - line 24). Using the data already assumed in the example worked out for line 67, the following calculations may serve as an illustration :-

Taking the data from the example already given for line 67-

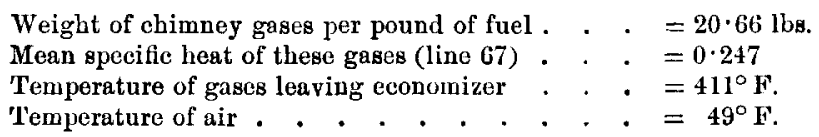

Hence the heat carried off by the chimney gases per pound of fuel $=20 \cdot 66 \times 0.241 \times(411-49)=1802$ B.Th.U.

Line 80 = line $77-($ line $78+$ line 79$)$.

Line 81. - This line is the sum of lines 39 and 40 , if the waste gases pass straight from the boiler-flue to the superheater. 
Line 82. - This line should be calculated as follows :-

$w=$ weight of moist steam entering the superheater per pound

$$
\text { of fuel }=\frac{\text { line } 68}{(\operatorname{line} 14)-(\operatorname{line} 14 \times \operatorname{line} 16)}
$$

$x=$ moisture in $1 \mathrm{lb}$. of steam (line 70).

$t_{1}=$ temperature of moist steam as it enters superheater (line 71).

$t_{s}=$ temperature of superheated steam as it leaves superheater (line 72).

Then heat transferred to steam ${ }^{1}$ per pound of fuel as fired $=\left\{x \times v \times\left(1,114-0.71 t_{1}\right)\right\}+0.48 v\left(t_{s}-t_{1}\right)$ B.Th.U., or $\quad=v\left\{\left(x \times\left[1,114-0.71 t_{1}\right]\right)+0.48\left(t_{\dot{s}}-t_{1}\right)\right\}$ B.Th.U.

Line 83.-The calculations to obtain the figures for this line are similar in all respects to those already given for line 79.

The heat carried off in the chimney gases $=$ weight of gases per pound of fuel $\times$ line $76 \times$ (line $74-$ line 21 ).

Line $84=$ line $81-($ line $82+$ line 83$)$.

Line $85=\frac{\text { weight of fuel burnt per hour } \times \text { line } 78}{\text { line } 58}$;

or

$$
=\frac{(\text { line } 14-(\text { line } 14 \times \text { line } 16)) \text { line } 78}{\text { line } 58} .
$$

Line 86.-This line is obtained in the same way as line 85, using line 82 in place of line 78 , and line 60 in place of line 58 , i.e., heat transmitted per square foot of surface of superheater per hour-

$$
=\frac{(\text { line } 14-(\text { line } 14 \times \text { line } 16)) \text { line } 82}{\text { line } 60} .
$$

Line 87.-This line is the ratio of the whole amount of heat passed into the feed per pound of dried fuel to the whole amount of heat available from the combustion of a pound of dried fuel

$$
=\frac{\text { line } 88+\text { line } 78+\text { line } 82}{\text { line } 17}
$$

1 For apecific heat of superheated steam, see footnote, p. 312.

[THE INST. C.E. VOL. CXCV.] 


\section{ENGINE.}

Line 88.-If the engine is of a well-known make, it will be sufficient to say so, and then to give a fow leading dimensions. The following example will illustrate this.

Inverted vertical marine, triple expansion, surface condensing. The cylinders were placed in the order-intermediate, high, low; and the cranks rotate in the sequence-high, intermediate, low. The high-pressure cylinder alone was jacketed, the steam for this jacket coming direct from the boiler, the drain from the jacket in ordinary work passing straight to the hot-well. Two feedpumps, one circulating-pump, one air-pump, and two bilge-pumps were driven by levers from the crosshead of the low-pressure cylinder.

Line 89.-The following example will illustrate the information which should be given.

The H.-P. and L.-P. cylinders were fitted witl ordinary doubleported slide-valves; the I.-P. cylinder had a trick slide-valve. None of these valves were balanced, and they were driven by the ordinary Stephenson link-motion.

It is desirable to state here whether the valves were specially tested for leakage before the trial. ${ }^{1}$

Line 90.-A full statement of the kind of governor in use, and whether it merely operated a throttle-valve or varied the cut-off of the steam, should be given in this line.

Line 91.-State whether the feed to the boiler, or the discharge from the air-pump hot-well, was measured, also whether a system of tanks or a tumbling-bay or a meter was used (Sect. 31, App. I, p. 333).

Lines 92-99.-All these dimensions should be given with the greatest possible accuracy; the diameters of the cylinders should be obtained if possible at the time of the trial, gauges being made for each cylinder. Where no other means of determining clearance volumes and surfaces is available, they should be calculated by measurements off the drawings from which the engines were

1 Absence of leakage when stationary is no guarantee of tightness when valves are in motion. (See Minutes of Proceedings Inst. C.E., vol. cxxxi, pp. 174 and 214, also Proc. Inst. Mech. E., 1905, 1. 290.) 
made, but cylinder clearance volumes, whenever it can be done, should be determined accurately by filling the spaces with wate1 at a known temperature.

Line 100.-The total length of the trial in hours and decimals should be given.

Line 101.-It should be stated whether a mercury barometer or an aneroid barometer was used for determining the pressure. For reducing from the barometer reading to pounds per square inch the following rule may be adopted :-

$14 \cdot 7 \mathrm{lbs}$. per square inch $=29 \cdot 92$ inches of mercury ; or,

1 inch of mercury $=0.492 \mathrm{lb}$. pressure per square inch.

Line 102.-This is the total weight of steam used in the cylinders divided by the number of hours during which the trial lasted, the weight of steam being determined by one of the methods explained in Section 31 of Appendix I, p. 333.

Line 103.-Is equal to the total weight of water collected from the jacket drains divided by the duration of the trial in hours.

In collecting the water from the jacket drains attention is drawn to Section 18 of Appendix I, p. 316, as to the precautions necessary for preventing loss owing to the possibility of a considerable quantity of the discharge escaping in the form of steam.

If the jackets drain directly back to the boiler, a special determination should be made, on some other occasion than the actual trial, of the condensation in the jackets, when working under exactly the same conditions as in the trial itself. This can be done by temporarily disconnecting the drain from the boiler and collecting the drainage, but it must be remembered that the results are only approximate.

Line 104. - The pressure-gauge should be read at regular intervals throughout the whole run, and the mean reading should be corrected for any errors in the gauge; and in the column for remarks it should be stated whether or not the gauge has been recently tested for errors.

The absolute pressure is obtained by adding the barometrical pressure to the mean gange-pressure reading.

Line 105.-This should be determined from a set of steam-tables. or a $\theta \phi$ chart, or by direct measurement (Sect. 28 (c), App. I, p. 327).

Line 106.-In the column for remarks a brief statement should be given as to how the moisture in the steam was determined; and if some special or unusual means was adopted, a full account of it. 
should be given on the blank lines at the bottom of the form, or on a separate sheet attached to the report.

Line 107.-This should be the same as line 103 if there is no leakage from the jackets; and the remarks already made with reference to line 103 apply to this line.

Line 108.-This temperature should be measured, if possible, by a thermometer placed as close as possible to the exit of the jacket drains from the engine; if no other means is available the pressure may be measured by means of a gauge attached to the jacket drain at the exit, and then the temperature corresponding to the mean of these pressure readings should be obtained from steam-tables or a $\theta \phi$ chart.

Line 109. - This pressure should be determined by means of a gauge fixed on the exhaust-pipe at the point where it leaves the engine, and regular readings should be taken and their mean corrected for any gange errors.

Line 110.-This should be determined from steam-tables, or from the $\theta \phi$ chart for steam ; a copy of this chart, prepared by Captain H. Riall Sankey, is given in Plate $2,{ }^{1}$ and is also attached to the engine trial and complete steam-plant trial forms.

Line 111.-'This temperature may be obtained by an ordinary mercury thermometer placed in the exhaust-pipe, close to the engine; but special precaution will have to be adopted to prevent fracture of the thermometer bulb (Sect. 28 (c), App. I, p. 327).

Line 112.-It should be stated in the remarks column whether the mean pressures were obtained by the use of a planimeter, or by dividing up the diagrams by ordinates; also how often sets of diagrams were taken.

Line 113.-The figure for this line will be obtained by adding to the mean effective pressure in the L.-P. cylinder, the mean effective pressure in the H.-P. cylinder multiplied by the fraction

$$
\text { H.-P. cylinder effective area }
$$

and also the mean effective pressure in the I.-P. cylinder multiplied by the fraction-

$$
\begin{aligned}
& \text { effective I.-P. cylinder area } \\
& \text { effective L.-P. cylinder area }
\end{aligned}
$$

If the piston speeds in the various cylinders are different, a further obvious correction must be made.

1 This diagram is not reprinted. See the Committee's previous Report, dated April, 1902. 
Line 114.-In calculating the mean area of the cylinder, if there is only a piston-rod and no tail-rod, the mean area is $\left(0.785 \mathrm{D}^{2}\right.$ $-\frac{1}{2} 0.785 d^{2}$ ), where $\mathrm{D}$ is the diameter of the cylinder and $d$ the diameter of the piston-rod (see line 92); if there is a tailrod as well as a piston-rod the mean area will be-

$$
0 \cdot 785 \mathrm{D}^{2}-\frac{1}{2}\left(0 \cdot 785\left(d_{1}{ }^{2}+d_{2}{ }^{2}\right)\right)
$$

where $d_{1}$ is the diameter of the piston-rod and $d_{2}$ the diameter of the tail-rod.

Line 115.--The total revolutions as recorded by the counter for the whole run divided by the whole number of minutes during which the trial lasted.

Line 116. - The average piston speed in feet per minute is equal to twice the average number of revolutions per minute multiplied by the stroke of the L.-P. piston in feet, or

$$
=\frac{\text { line } 115 \times \text { L.P. } . \text { stroke in inches (line 92) }}{6} \text {. }
$$

Line 11\%.- This line is the sum of the horse-powers given on line 112.

Line 118. -If it is possible to measure the brake horse-power, it should be given in this line, and in the remarks column a statement should be made as to how the power was measured-that is, whether by a friction brake, or by absorbing the power electrically, or any other means.

$$
\text { Line } 119=\frac{\text { line } 118}{\text { line } 117} \times 100 .
$$

The method of filling up lines 120 to 130 of this form will best. be illustrated by taking an actual example.

Line 120.--The gross heat-supply entering the engine per minute will be equal to the total heat above $32^{\circ} \mathrm{F}$. contained in $1 \mathrm{lb}$. of steam at the pressure given on line 104 multiplied by the weight of steam entering the engine per minute, or

$$
=\mathrm{H}_{1}\left(\begin{array}{c}
\text { line } 102+\text { line } 103 \\
60
\end{array}\right) \text {. }
$$

Example.1-Steam pressure (line 104), 201 lbs. absolute; the corresponding total heat of a pound of steam above $32^{\circ} \mathrm{F}$. for

1 The data for this example are taken from the Report dated April, 1902 (p. 102). 
this pressure is 1,198 B.Th.U. ; weight of steam entering cylinders per hour (line 102), 1,054.8 lbs, ; steam passing through jackets (line 103), 158.4 lbs.; hence gross heat-supply entering engine per minute-

$$
\begin{aligned}
& =\left(\frac{1,054 \cdot 8+158 \cdot 4}{60}\right) \times 1,198 \\
& =24,223 \text { B.Th.U. }
\end{aligned}
$$

Line 121.-One I.HP. is equal to $42 \cdot 41$ B.Th.U. per minute ${ }^{1}$; hence the figure for this line is obtained by multiplying the I.HP. (line 117) by $42 \cdot 41$.

In the example selected the engine was developing 73.87 I.HP, hence the figure for line 121 would be-

$$
42 \cdot 11 \times 73 \cdot 87=3,133 \text { B.Th.U. }
$$

Line 122.-This line will be equal to the weight of water leaving the jacket per minute multiplied by the difference between the temperature at which it leaves the engine and $32^{\circ}=\frac{\text { line } 103}{60}$ $\times\left(t_{3}-32\right)$, where $t_{3}$ is the temperature at which the water leaves the cylinder jackets. In the example selected the weight of jacket-steam per hour (line 103) was $158.4 \mathrm{lbs}$., and the temperature at which it left (line 108) was $382^{\circ} \mathrm{F}$; hence the heat passing away in the jacket drains per minute (line 122)-

$$
\begin{aligned}
& =\frac{158 \cdot 4}{60} \times(382-32) \\
& =92+\text { B.Th. } \mathrm{T} .
\end{aligned}
$$

Line 123.-The heat leaving the engine in the exhaust steam cannot be directly calculated unless observations are made as to the quantity of condensing-water used in the condenser, and the rise of temperature of the water as it passes through the condenser. If these observations are made and the temperature of the hot-well is also measured, the figure for line $123 \mathrm{can}$ be readily calculated.

The heat leaving the engine in the exhaust steam per minute = (the weight of condensing water per minute) $\times$ (the rise of temperature of the condensing water) + (the weight of condensed steam leaving the engine per minute) $\times$ (the hot-well temperature (line 110) $-32^{\circ}$ ).

$$
\frac{33,000}{778}=42+1
$$


For example, in the above trial the weight of condensing water per hour (line 145) was 24,180 lbs., the temperature of the cooling water as it entered the condenser (line 146 ) was $52 \cdot 3^{\circ} \mathrm{F}$., and the temperature of the cooling water as it left the condenser (line $14 \bar{i}$ ) was $9 . \cdot 9^{\circ} \mathrm{F}$; , hence the heat carried away in the condensing water was-

$$
=\frac{24,180}{60} \times(94 \cdot 9-52 \cdot 3)=17,168 \text { B.Th.U. per ninute. }
$$

The heat carried away by the condensed steam-

$$
=\frac{1,054 \cdot 8}{60} \times(132 \cdot 5-32)=1,767 \text { B.Th.U. per minute. }
$$

Hence the total heat passing away from the engine per minute in the exhaust steam was : $-17,168+1,767=18,935$ B.Th.U.

Line 124.-This line is equal to line 120 minus the sum of lines 121,122 , and 123 ; or, in the example, $24,223-22,992$ $=1,231$ B.Th.U.

Line 125.-In accordance with par. 3 of the recommendations of the Committee on Thermal Efficiency of Steam-Engines, the available heat supplied to an engine is calculated as "the total heat of the steam entering the engine less the 'water heat' of the same weight of water at the temperature of the engine exhaust, both quantities being reckoned from $32^{\circ} \mathrm{F}$."

In the above example the weight of steam supplied to the engine per minute per I.HP. $=\frac{\operatorname{lin} \theta 102+\operatorname{lin} \theta 103}{\operatorname{lin} \theta 117 \times 60}=\frac{1,054 \cdot 8+158 \cdot 4}{73 \cdot 87 \times 60}=$ line $130 \div 60=0 \cdot 274 \mathrm{lbs}$.

$\mathrm{H}_{1}=$ the total heat (above $32^{\circ}$ ) of $1 \mathrm{lb}$. of steam (see notes on line 120) as it enters the engine $=1,198$ B.Th.U. at $201 \mathrm{lbs}$. per square inch absolute pressure.

$h_{e}=$ the water heat (above $32^{\circ}$ ) of $1 \mathrm{lb}$. of water (see line 111) at the exhaust temperature $=103$ B.Th.U. (read off $\theta \phi$ diagram, or $=135^{\circ}-32^{\circ}$ ).

Hence the heat supplied in this case per I.HP. per minute $=0 \cdot 274(1,198-103)=300$ B.Th.U. (line 125).

Line 126. - This is obtained by dividing the heat equivalent to $1 \mathrm{HP}$. per minute $(=+2 \cdot 41 \times 100)$ by line 125 ; this in the example $=\frac{42 \cdot 41 \times 100}{300}=14.14$ per cent.

Line 127.-The method of calculating the heat required per I.HP. per minute by the Institution standard of comparison was

1 Minutes of Proceediugs Inst. C.E., vol. exxxiv, p. 278. 
fully explained in the Report ${ }^{1}$ of the Committee on Thermal Efficiency, and a portion of that Report is reprinted here for convenience of reference.

\section{Extract from Report. ${ }^{2}$}

"The B.Th.U. per HP. for the standard engine of comparison can be calculated as follows:-

The formula ${ }^{3}$ for the thermal efficiency of the Rankine cycle for saturated steam is

$$
\frac{\left(\mathrm{T}_{a}-\mathrm{T}_{e}\right)\left(1+\frac{\mathrm{L}_{a}}{\mathrm{~T}_{a}}\right)-\mathrm{T}_{e} \text { hyp } \log \frac{\mathrm{T}_{a}}{\mathrm{~T}_{e}},}{\mathrm{~L}_{a}+\mathrm{T}_{a}-\mathrm{T}_{e}}
$$

in which formula the increase in the specific heat of water at higher temperatures affects the numerator and denominator nearly equally.

The B.Th.U. per minute per HP. for the standard engine of comparison is 42.4 divided by the thermal efficiency of the Rankine cycle thus :-

For saturated steam, the B.Th.U. per minute per HP. for the standard engine of comparison is :-

$$
\frac{42 \cdot 4\left(\mathrm{~L}_{t}+\mathrm{T}_{t}-\mathrm{T}_{e}\right)}{\left(\mathrm{T}_{a}-\mathrm{T}_{e}\right)\left(1+\frac{\mathrm{L}_{a}}{\mathrm{~T}_{t}}\right)-\mathrm{T}_{e} \text { hyp } \log \frac{\mathrm{T}_{t \prime}}{\mathrm{T}_{c}}}
$$

and similarly for superheated steam it is :-

$$
\begin{aligned}
& 42 \cdot 4\left\{\mathrm{~L}_{16}+\mathrm{T}_{\text {w }}-\mathrm{T}_{\mathrm{e}}+0 \cdot 48\left(\mathrm{~T}_{\mathrm{cts}}-\mathrm{T}_{\mathrm{n}}\right)\right\} \\
& \left(\overline{\mathrm{T}_{c}}-\mathrm{T}_{e}\right)\left(1+\frac{\mathrm{T}_{a}}{\mathrm{~T}_{u}}\right)+0 \cdot 48\left(\mathrm{~T}_{w s}-\mathrm{T}_{c}\right)-\mathrm{T}_{e}\left(\operatorname{byp} \log \frac{\mathrm{T}_{a}}{\mathrm{~T}_{e}}+0 \cdot 48 \operatorname{lgp} \log \frac{\mathrm{T}_{w s}}{\mathrm{~T}_{u}}\right)
\end{aligned}
$$

It will be noticed that the usually accepted figure of 0.48 for the specific heat of superheated steam at constant pressure has been taken, although this figure is open to much doubt. ${ }^{4}$

These formulas being somewhat complex, the curves shown in

1 Minutes of Proceedings Inst. C.E, vol. exxxiv, p. 278.

Ihill.. p. 244 .

$3 T_{1 /}$ denotes absolute temperature of steam at boiler sido of engine stop-val re.

$T_{\alpha *}, \quad$ absolute temperature of steam on boiler side of stop-valve.

T. , absolute temperature of steam at exit from encrine.

$\mathbf{L}_{\star}, \quad$ latent heat of $1 \mathrm{lb}$. of steam at $\mathbf{T}_{n}$.

4 See footnote p. 312 . 
Figs. 18 and 19 (pp. 362 and 363 ) have been prepared, ${ }^{1}$ from which the B.Th.U. per minute per HP. in the case of saturated steam can be read off directly. ${ }^{2}$

In the case of superheated steam, the figure is obtained by applying a correction to that got for saturated steam. At the bottom of each Figure is a set of curves marked 'coefficient for superheat correction.' Against the temperature of saturation corresponding to the stop-valve pressure, and on the curve corresponding to the temperature of the superheated steam $\left(T_{a n}\right)$, is found a coefficient. This coefficient multiplied by the exhaust temperature, and by the B.Th.U. already found, gives the deduction to be made from these B.Th.U." 3

Using the same example as before the absolute steam pressure $=201 \mathrm{lbs}$. per square inch, the corresponding temperature being $382^{\circ} \mathrm{F}$., and the latent heat per pound $8+8 \mathrm{~B} . \mathrm{Th} . \mathrm{U}$. The exhaust pressure is $135 \mathrm{lbs}$. absolute and its temperature $135^{\circ} \mathrm{F}$.

In this case

$$
\begin{aligned}
& \mathrm{T}_{a}=382+461=843 \\
& \mathrm{~T}_{e}=135+461=596 . \\
& \mathrm{L}_{\mathfrak{d}}=848 \text { B.Th.U. }
\end{aligned}
$$

Hence B.Th.U. per minute per HP.

$$
=\frac{42 \cdot 4(848+843-596)}{(843-596)\left(1+\frac{848}{843}\right)-596 \text { hyp } \log \frac{843}{596}}=160 \cdot 6 \text { B.Th.U. }
$$

Line 128. This is line $127 \times 100=\frac{160 \cdot 6 \times 100}{300}=53.5$ per cent. in the example.

Line 129.-This will be equal to $\begin{gathered}\text { line } 125 \times 100 \\ \text { line } 119\end{gathered}$ example $=\frac{300 \times 100}{79 \cdot 6}=377$ if the mechanical efficiency $=79 \cdot 6$ per cent.

Line 130.-This is the sum of lines 102 and 103 divided by line $117 ;$ or, in the example $=\frac{1,054 \cdot 8+158 \cdot 4}{73 \cdot 87}=16 \cdot 4 \mathrm{lbs}$.

1 "From Fig. 19, which has been added by request of the Council, the calories per minute per kilnwatt man be read off."

" "Thus, for ' $\mathrm{I}^{\prime}=350^{\circ}$ and ' $\mathrm{T}_{c}^{\prime}=21 \%$, the figure is $265 \mathrm{~B} . \mathrm{T}^{\prime} \mathrm{l} . \mathrm{U}$. per HP. per minute."

${ }^{3}$ "Thus, let $\mathbf{T}_{a s}=500^{\circ} \mathbf{F}, p_{* \prime}=135 \mathrm{lbs}$. (so that $\mathbf{T}_{a}=350^{\circ}$ ) and ' $\mathrm{T}_{e}=212^{2}$. A gainst $350^{\circ}$, and on the curve for $500^{\circ}$, we read the coefficient $0 \cdot 00015$. This gives the correction thus: $0 \cdot 0015 \times 212 \times 265=8 \cdot 5$, and $26.5-8 \cdot 5=256 \cdot 5$, the number of B.Th. U. required.". 
Line 131.-This line in the case of saturated steam $=$ line 130 $\times\left(\begin{array}{c}\mathrm{H}_{1}-h_{0} \\ 1,100\end{array}\right)$. In the case of superheated steam this line $=$

Fig. 1 s.

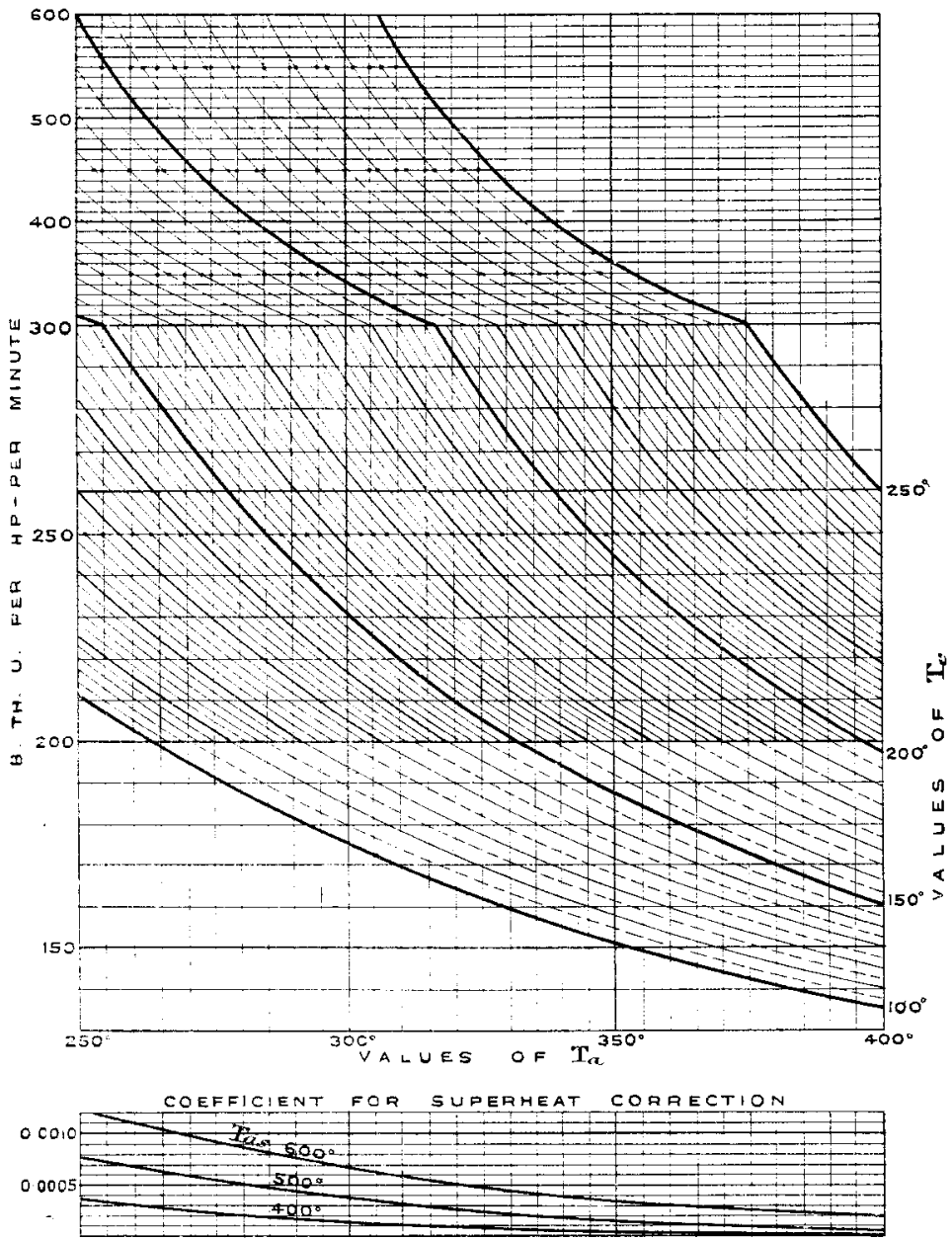

line $130 \times \frac{\left(\mathrm{H}_{1}-h_{0}\right)+0 \cdot 48\left(t_{s}-t_{1}\right)}{1,100}$. For values of $\mathrm{H}_{1}, h_{0}, t_{s}, t_{1}$ see under line 38, p. 323.

Line 130 does not give a true criterion of the economy of a 
steam-engine, because the thermal units required to evaporate each pound of steam will vary with the boiler pressure, whether

Fig. 19.
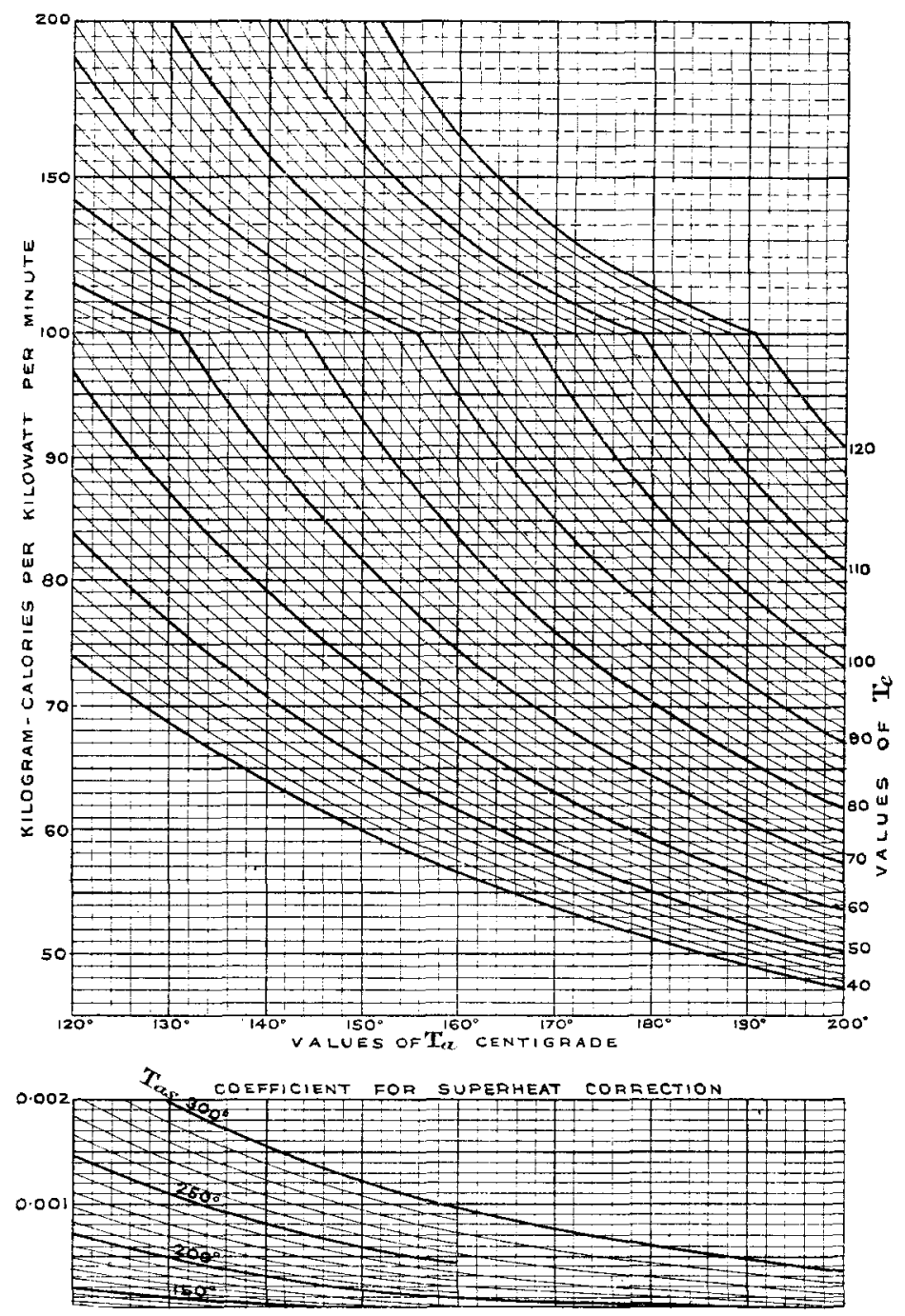

the steam is saturated or superheated, and also with the back pressure. The figure 1,100 has been chosen because it approxi- 
mately lies between the heat in a pound of steam in a non-condensing engine, and that in an engine using superheated steam, and is the amount required per pound in the case of a condensing engine with an admission pressure of $160 \mathrm{lbs}$. absolute and a back pressure of $2 \mathrm{lbs}$. absolute, these being usual pressures for a modern condensing engine.

\section{ENGINE ACCESSORIES.}

Line 132.- It should be stated whether a jet-, evaporative- or surface-condenser is used, and a short but full account should be given of the form of the condenser and its general arrangements.

Lines 133-136.- These dimensions should be given by actual measurements from the condenser or from the working drawings. The condenser tubes to be measured on the vater side.

Line 13\%.-The following is the kind of description which should be given :-

The air-pump was a vertical single-acting pump 17 inches in diameter, with a stroke of 26 inches, and was driven by a lever from the cross-head of the low-pressure cylinder, the valves being formed of flexible india-rubber $\frac{1}{2}$ inch thick, and provided with brass guards. The suction pipe was 3 inches in diameter.

Line 138.-A description similar to that given on line 137 will suffice in this case.

If the circulating pump is a centrifugal pump driven by an independent engine, the diameter of the pump disk and width of vanes near the periphery should be given, and also the dimensions of and power required by the independent engine, and in this case records of a test of this independent engine should be filled up in an ordinary engine sheet.

Line 139.-The following is the kind of description which sbould be given :-

There were two feed-pumps, each $4 \frac{1}{2}$ inches in diameter and 8 inches in stroke; they were driven off the air-pump rockinglever. The suction- and delivery-pipes were 3 inches in diameter.

Line 140. - The general dimensions of the feed-heater and the sizes of the various pipes and connections to the feed-pump and boiler should be given.

Line 141.-The extent of the heating-surface should be determined by actual measurements if possible.

Line 142.- Under this line a general description of the arrangements of the pipes and of the particular covering adopted, its 
thickness, and any other details should be given, and it should be stated whether it slopes towards the engine; state also the number of flanges and whether the flanges are covered, and tho plan adopted for draining the pipes and collecting the drainag. for weighing purposes.

Lines 143-144.- These dimensions should be given from the drawings or from actual measurements nade from the pipes.

Line 145.-This will be obtained by dividing the whole quantity of cooling water used throughout the trial by the number of hours during which the trial lasted. In the column for remarks it should be stated whether the measurement of the condensation water was made by a weir, or by the use of a meter, or by a system of double tanks (see App. I, Sect. 3, Fig. 4, p. 303, and Sects. 6 and $7, \mathrm{pp} .304,305$ ), or by some other method.

Lines 146-147.- The temperatures should be read at regular intervals and the means given in these two lines; after correction, if necessary, for any thermometer errors (see Sect. 28 (b), App. I, p. 327$)$.

Line 148.- This should be the same figure as line 102, if there are no losses of steam while passing through the engine, such as leakage past the glands of piston-rods and valve-rods; if such leakage occurs it should be determined, if possible, and deducted from the amount given in line 102 , the result being then entered in this line.

Lines 149-150.-The same remark applies to these two lines as to lines 146 and 147 (see Sect. 28 (c), App. I, p. 327).

Line 151.- It should be stated in the column for remarks whether the vacuum was measured by an ordinary vacuum-gauge or by means of a mercury column, ${ }^{1}$ and if a gauge was used whether it has been recently tested for accuracy.

Line 152.- The volume should be calculated from the dimensions of the air-pump given in line 137.

Line 153. - Indicator diagrams should be taken at regular intervals from the frump, and the horse-power should be worked out in the ordinary way.

Lines 154-155. - Similar remarks apply to these two lines as to the two previous lines.

Lines 156-159. - All these temperatures should, as stated in other

1 If a mercury column is used, great care must be taken to avoid condensed steam collecting on the surface of the mercury. If it cannot be avoided the mercury will be 0.074 inch too low for each inch of water column resting upon it, and the readings should be corrected accordingly. 
cases, be read at regular intervals, and the means should be given after correction for thermometer errors (see Sect. 28 (c), App. I, p. 327).

Line 160.-The quantity of steam used by the feed-pump when it is driven by a separate engine should be determined by an independent test, which may or may not be on the same day as the other test. If it is on the same day, special arrangements should be made for condensing the steam in a separate condenser, and collecting the resulting water during the whole period of the test (see Sect. 3, App. I, p. 302).

Lines 161-162.- The gauges should be read at regular intervals and the means corrected for any gauge errors.

Lines 163-164.-These temperatures, if the steam is not superheated, may be obtained directly from steam-tables or a $\theta \phi$ chart for the pressures given in lines 161 and 162 ; but if the steam is superheated the temperatures must be directly measured by thermometers and the mean temperatures given in these two lines (see Sect. 28 (c), App. I, p. 327).

Lines 165-166.-Information should be given in the remarks column as to how the moisture was determined, that is, what type of Separator and Calorimeter was used, and, if it is considered desirable, a separate report may be attached to the form giving full particulars of these observations.

Line 167.-The figure for this line is obtained by dividing the whole amount of water drained off from the steam-pipes during the trial by the number of hours during which the trial lasted, and a brief statement should be given in the remarks column as to how the water was collected (see Sect. 18, App. I, p. 316).

\section{ECONOMY OF THE COMPLETE PLANT.}

Line 168.-The figure for this line is obtained by multiplying together the number of pounds of fuel used per minute in the boiler (line 14) and superheater, if separately fired, by the net heating value of a pound of fuel determined (line 17) as explained on p. 338.

Line 169.-This is equal to the I.HP. $\times 42 \cdot 41$.

Line $\mathbf{1 7 0}=$ B.HP. $\times 42 \cdot 41$.

Line $171=\frac{\text { Line } 169}{\text { Line } 168} \times 100$. 
Line $172=\frac{\text { Line } 170}{\text { Line } 168} \times 100$.

Line 173 is equal to the total weight of fuel fired per hour divided by the I.HP.

A number of blank lines are left at the bottom of this form in which any other observations or explanations of the method of carrying out the trial may be inserted. In all cases it should be remembered that in order to compare one trial with another the relative conditions of the two trials must be accurately known, and therefore the fullest possible information should be given in all cases not only of the results of the observations, but of the way in which they were carried out.

NoTE.--In the original report reduced facsimiles of the Committee's forms, sets $A, B$, and $C$, were given, filled in with data taken from trials, in order to illustrate the method of using them. The Committee have considered, it unnecessary, after several years' experience of the use of the forms has been gained, to reprint these examples of trials. They may be referred to in the Minutes of Proceedings Inst. C.E., vol. el, pp. 296-314. 